DEVELOPMENT, VALIDATION AND IMPLEMENTATION OF A WEARABLE ULTRASONIC BLADDER SENSOR FOR PEDIATRIC APPLICATIONS
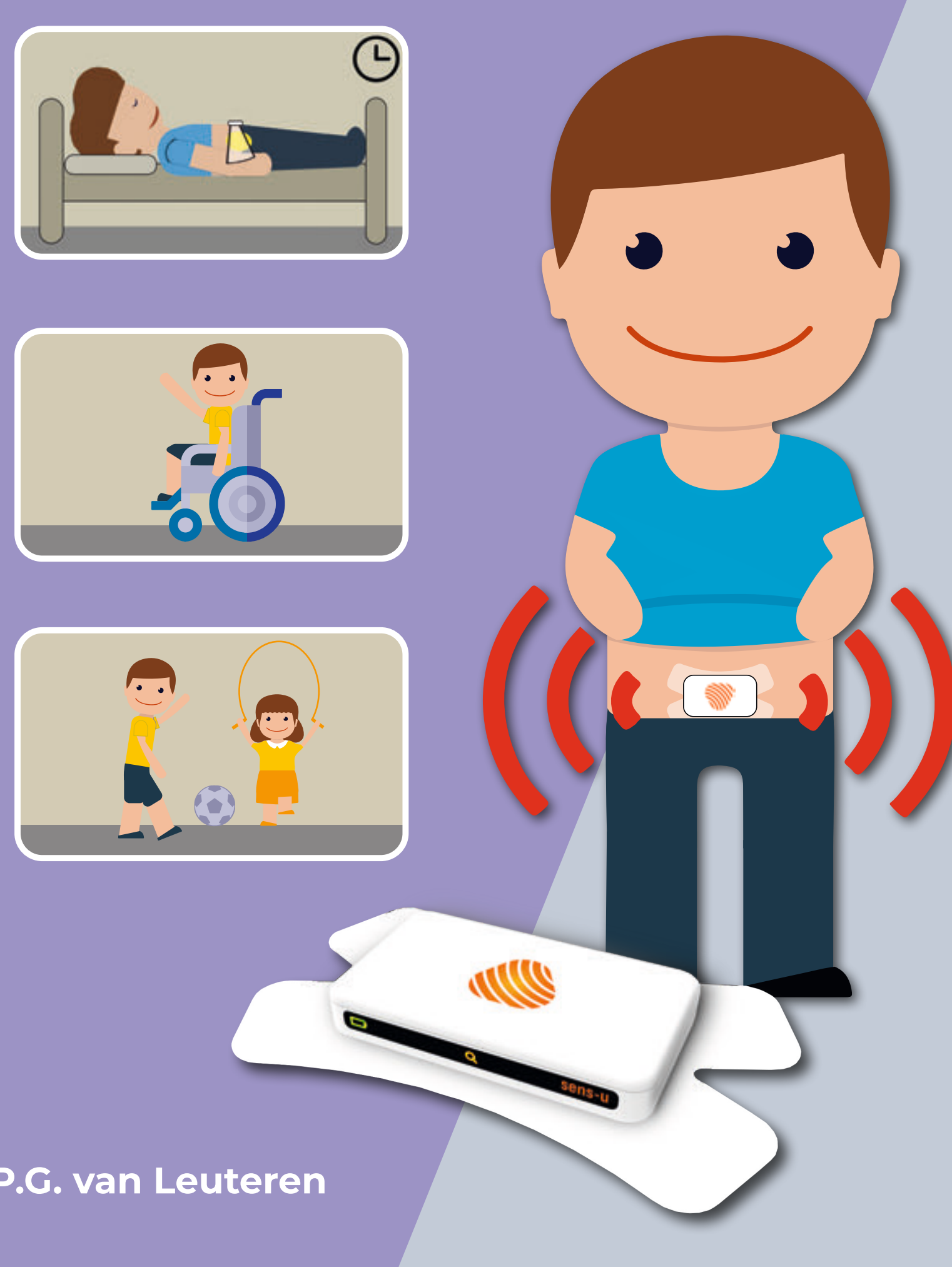

P.G. van Leuteren 



\section{DEVELOPMENT, VALIDATION AND IMPLEMENTATION OF A WEARABLE ULTRASONIC BLADDER SENSOR FOR PEDIATRIC APPLICATIONS}





\section{DEVELOPMENT, VALIDATION AND IMPLEMENTATION OF A WEARABLE ULTRASONIC BLADDER SENSOR FOR PEDIATRIC APPLICATIONS}

\section{PROEFSCHRIFT}

ter verkrijging van

de graad van doctor aan de Universiteit Twente, op gezag van de rector magnificus,

Prof. dr. ir. A. Veldkamp, volgens besluit van het College voor Promoties in het openbaar te verdedigen

op donderdag 10 december 2020 om 12:45 uur

door

\section{Paulus Gerardus van Leuteren}

geboren op 6 juni 1990

te Hengelo, Nederland 
Dit proefschrift is goedgekeurd door:

de promotor:

prof. dr. ir. B. ten Haken

de co-promotor:

prof. dr. P. Dik

\section{Colofon}

Lay-out and design: $\quad$ Stijn Eikenaar | www.persoonlijkproefschrift.nl

Printing:

Ridderprint | www.ridderprint.nl

ISBN:

978-90-365-5072-7

DOI:

(C) 2020 Paulus Gerardus van Leuteren, The Netherlands. All rights reserved. No parts of this thesis may be reproduced, stored in a retrieval system or transmitted in any form or by any means without permission of the author. Alle rechten voorbehouden. Niets uit deze uitgave mag worden vermenigvuldigd, in enige vorm of op enige wijze, zonder voorafgaande schriftelijke toestemming van de auteur. 


\section{PROMOTIE COMMISSIE:}

$\begin{array}{lll}\begin{array}{ll}\text { Voorzitter/secretaris } \\ \text { Promotor }\end{array} & \text { prof. dr. J.L. Herek } & \text { Universiteit Twente } \\ \text { po-promotor } & \text { prof. dr. ir. B. ten Haken } & \text { Universiteit Twente } \\ & & \begin{array}{l}\text { Sechenov Universiteit } \\ \text { Wilhelmina Kinderziekenhuis } \\ \text { UMC Utrecht }\end{array} \\ \text { Leden } & \text { prof. dr. ir. R.M. Verdaasdonk } & \text { Universiteit Twente } \\ & \text { prof. dr. ir. C.L. De Korte } & \text { Universiteit Twente } \\ & \text { prof. dr. G. De Win } & \text { Universitair Ziekenhuis } \\ & & \text { Antwerpen } \\ & \text { prof. dr. W.F.J. Feitz } & \text { Radboud Universiteit } \\ & \text { dr. J.G.L. Cobussen-Boekhorst } & \text { Radboud Universiteit }\end{array}$


The author gratefully acknowledges financial support of this thesis by: Novioscan BV. (Nijmegen, the Netherlands, www.novioscan.com), Pontes Medical (Utrecht, The Netherlands, www.pontesmedical.com), the Dutch Technology Foundation STW (OND1359525), the European Union, University of Twente (Enschede, the Netherlands), and the European Funds for Regional Development, and this work is partly funded in the ULIMPIA project funded by PENTA under grant number PENTA-2017-Call2-16101ULIMPIA, www.ulimpia-project.eu. 


\section{CONTENTS}

Chapter 1 General Introduction and Outline of the Thesis 8

$\begin{array}{lll}\text { PART I Development \& Clinical Validation Phase } & 24\end{array}$

Chapter 2 URIKA: design and Safety Evaluation of a Wearable Ultrasonic 26 Bladder Monitor

Chapter 3 URIKA: continuous ultrasound monitoring for the detection of a 40 full bladder in children with dysfunctional voiding - a feasibility study

Chapter 4 SENS-U: validation of a wearable ultrasonic bladder monitor in $\quad 54$ children during urodynamic studies

PART II Clinical Implementation \& Valorization Phase 66

Chapter 5 SENS-U: clinical evaluation of a full-bladder notification - a pilot 68 study

Chapter 6 SENS-U: continuous home monitoring of natural nocturnal bladder filling in children with nocturnal enuresis - an observational study

Chapter 7 SENS-U: a Series of Cases Reports

Chapter 8 General Discussion and Future Perspectives

Chapter 9 Summary

Chapter 10 Nederlandse samenvatting

Chapter 11 List of abbreviations

Co-authors and affiliations

Dankwoord

Curriculum Vitae

List of publications 

General Introduction and Outline of the Thesis

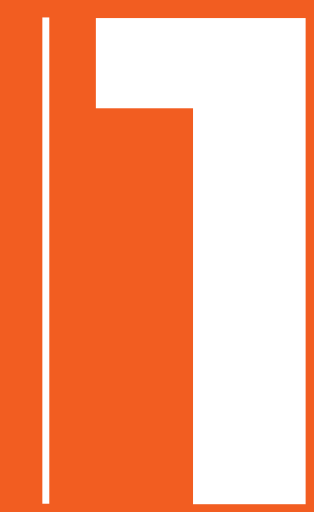




\section{INTRODUCTION}

Urinary incontinence, the involuntary leakage of urine, remains a common problem in children of all ages [1]. The International Children's Continence Society (ICCS) defines urinary incontinence as one of the symptoms of Lower Urinary Tract dysfunction which is related to the storage phase of the urinary bladder (for children $>5$ years of age) [3].

The Lower Urinary Tract (LUT) consists of the urinary bladder (or bladder) and urethra (and in adult males also the prostate). The bladder is a hollow, muscular and distensible organ that functions as a temporal reservoir of urine. The bladder is a retroperitoneal organ, positioned at the base of the pelvis, located behind the pubic bone and supported by the pelvic floor muscles. During the storage phase, urine produced by the kidneys is transported by the ureters into the bladder. When the child's bladder volume almost reaches its maximum capacity, the child will experience the urge to empty the bladder through the urethra, initiating the voiding phase.

For control of the voiding phase, two muscles sphincters are present: the internal and external sphincter. The internal sphincter, the bladder neck, is controlled by the sympathetic and parasympathetic nerves. The external sphincter is located in the pelvic floor and is innervated by a somatic nerve (the pudendal nerve), which allows the voluntarily control of the flow of urine. In males, the external sphincter is located just below the apex of the prostate and in females approximately halfway the urethra.

Sympathetic nerves (hypogastric nerve from the thoracolumbar level) innervate detrusor relaxation (-) and constriction (+) of internal sphincter muscles. These sympathetic nerves serve to hold urine autonomically. Parasympathetic nerves (pelvic nerve originating from the sacral motor unit ( $\mathrm{S} 2-3)$ and hence from pelvic ganglia) innervate detrusor contraction (+) and relaxation (-) of the internal sphincter. These parasympathetic nerves are active when voiding is needed.

The external sphincter is the last control mechanism, innervated by the pudendal nerve, contracting the pelvic floor if voiding is not appropriate at that time. This somatic innervation can be done as a reflex or voluntary and intentionally. This nerve system is summarized in this Figure 1.1.

Urinary incontinence can be continuous or intermittent [3]. This thesis focusses mainly on intermittent incontinence; the leakage of urine in discrete amounts. Intermittent incontinence that occurs while awake is termed daytime incontinence. When intermittent incontinence occurs exclusively during sleeping periods, it is termed enuresis [3] (Figure 1.2). 


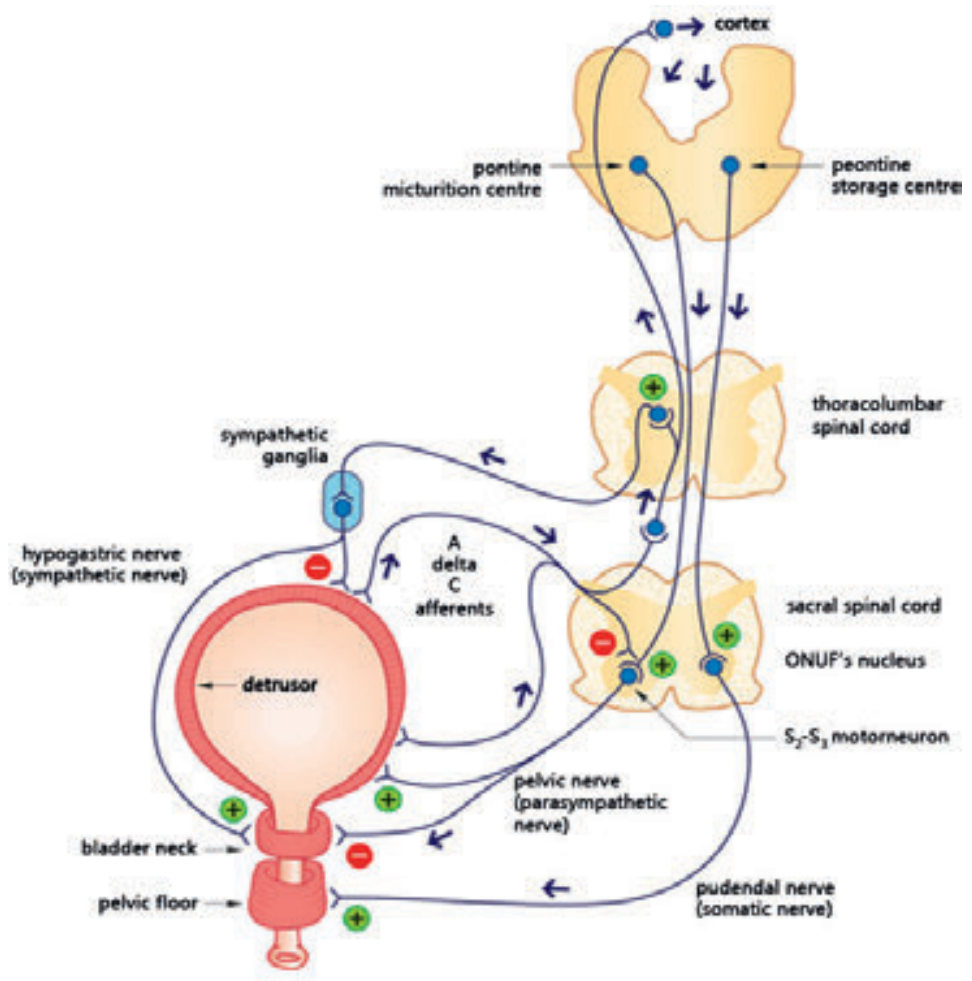

Figure 1.1: Sympathetic and parasympathetic innervation of the urinary system. The figure illustrates the complexity of the control loops that play a role in the control of the bladder. The sympathetic (Th12-L2) and parasympathetic circuits (S2-3) are under the influence of the brain stem (especially the punch) and the cerebral cortex. With permission taken over from (originally in Dutch) [2].

Generally, urinary incontinence appears in children without an underlying anatomical or neurological lesion in the LUT [4], [5]. Approximately 6-9\% of school-age children (6-10 years) suffer from functional daytime incontinence, slowly diminishing to an average of $2 \%$ at the age of 12 [6]. For enuresis, the prevalence varies from $5-10 \%$ for 5 -year-olds, gradually decreasing with age to $1 \%$ among 15 years and older [3], [4]. In other words, in an average classroom of 30 children, approximately 2 or 3 children experience involuntary loss of urine during either day or night.

\section{Subtypes of LUT dysfunction}

In accordance with the ICCS guidelines, there are several subtypes of LUT dysfunction. The main subtypes of pediatric daytime incontinence are: overactive bladder (OAB), dysfunctional voiding (DV), underactive bladder (UAB) and voiding postponement (VP) [3], [4]. Enuresis is defined into monosymptomatic nocturnal enuresis and nonmonosymptomatic nocturnal enuresis [3] (Figure 1.2). 


\section{Daytime}

Overactive bladder indicates symptoms of urinary urgency, the sudden and unexpected experience of an immediate and compelling need to void [3], usually accompanied by an increased voiding frequency and nocturia (the complaint that the child has to wake at night to void), with or without urinary incontinence, in the absence of urinary tract infection (UTI) or other obvious pathology.

Children with dysfunctional voiding, more often in girls than boys, habitually contract the urethral sphincter or pelvic floor during voiding and present a staccato voiding pattern with or without an interrupted flow pattern [5][6], increasing the risks of a post void residual and a potential UTI. These children often experience difficulties in perceiving the filling status of the bladder, which may lead to overflow incontinence as result of postponing micturition or due to bladder overactivity when the bladder becomes overdistended [4].

An underactive bladder refers to children who need to raise intra-abdominal pressure to initiate, maintain or complete voiding [3]. These children also suffer from overflow incontinence, because they do not feel the urge to void when their bladder is almost full. As a result, observed symptoms are a low voiding frequency, an interrupted uroflow pattern, a post void residual and therefor a risk of UTI's.

Voiding Postponement is defined as a habitual postponement of micturition using holding maneuvers (i.e. standing on tiptoes, forcefully crossing the legs, squatting), for example because the child does not want to stop playing or finish a videogame. VP is often indicated by a low micturition frequency, a feeling of urgency and possibly incontinence from a full bladder [3], [4].

\section{Nighttime}

Monosymptomatic nocturnal enuresis (MNE) refers to children without any other LUT symptoms (nocturia excluded) and without bladder dysfunction. Children who suffer from enuresis and any daytime LUT symptoms are indicated as having non-monosymptomatic nocturnal enuresis (NMNE) [3] (Figure 1.2). Next, enuresis is divided into primary and secondary enuresis: children with secondary enuresis have had a previous dry period of $>6$ months, in contrast to children with primary enuresis.

The general consensus is that enuresis is a heterogeneous problem which is either caused by (1) nocturnal polyuria (enuretic voided volume (EVV) $>130 \%$ of expected bladder capacity (EBC)); (2) a low or reduced nocturnal bladder capacity (EVV $<65 \%$ of EBC); (3) or by nocturnal detrusor overactivity, combined with an increased arousal threshold during sleep [4]. EBC is defined as "30 x (age in yrs +1) $\mathrm{ml}$ " and applies to children aged 4-12 years, with a maximum volume of $390 \mathrm{ml}$ at the age of 12 . 


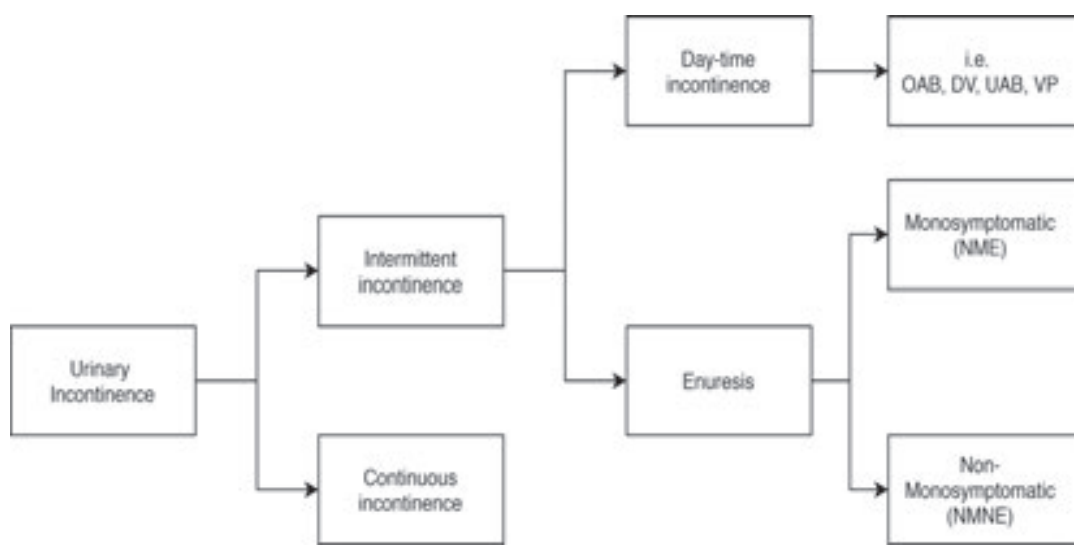

Figure 1.2: Subtypes of LUT dysfunction [3]

\section{Diagnostics}

Urinary incontinence has a major impact on the wellbeing of the child and its family; socially, emotionally, and behaviorally [7]. As result of being incontinent, many children have a low self-esteem and self-confidence, and experience social difficulties at school potentially resulting in poorer academic performance [4], [5]. Children rated 'wetting their pants in class' repeatedly in the top 5 of most stressful life events between 'losing my mother or father' or 'going blind' [3], [4].

In addition, urinary incontinence in childhood has been found to be related to an increase risk of daytime incontinence and personal, psychological and social problems in adolescence and adulthood [4], [5]. These aspects emphasize the importance of treating urinary incontinence effectively and efficiently.

The treatment of LUT dysfunction starts with the determination of the proper diagnosis (see Subtypes of LUT dysfunction). Diagnostics tools consist of an extensive patient history including a voiding diary, physical examination, uroflowmetries (combined with electromyography [EMG]), ultrasound assessment and in some cases invasive urodynamic studies (Figure 1.3). To evaluate for LUT dysfunction in accordance with ICCS guidelines, a voiding diary should be documented consisting of a 7-night recording of incontinence episodes and nighttime urine volume measurements to evaluate enuresis, and a 2-day daytime frequency and volume chart (not necessarily recorded on two consecutive days) [3].

The next step is a physical examination to exclude congenital malformations and potential neurological defects [4], followed by an uroflowmetry which examines the flow during urination into an uroflowmeter. This examination provides information 
on e.g. the voided volume, flow rate, voiding time and flow pattern. The shape of the flow curve serves as diagnostic guide, e.g. indicating an overactive bladder (towershaped curve), dysfunctional voiding (staccato or interrupted curve) or a bladder outlet obstruction (plateau-shaped curve). Uroflowmetry can be combined with EMG on the perineal muscles to assess the (dys)synergy between the bladder and the pelvic floor muscles [3].

In addition to signal-based methods, also imaging modalities are used for diagnostic purposes, including transabdominal - and pelvic ultrasound and invasive (video) urodynamics combined with fluoroscopy. Transabdominal ultrasound can be applied to examine the bladder, estimating the bladder volume (i.e. post void residual) and assessing bladder wall thickness and the diameter of the rectum. Pelvic ultrasound allows the physician to visualize the pelvic floor muscles in real-time (e.g. while increasing abdominal pressure during coughing or Valsalva maneuver) and examine the urethra length [3], [4].

Invasive (video) urodynamics (either combined with fluoroscopy) examines the filling and voiding phases of the bladder. By inserting a transurethral catheter, the bladder is filled with saline and the bladder pressure is measured. A transrectal catheter is placed to determine the abdominal pressures. Next, the bladder is emptied through the same transurethral catheter during micturition [8]. Invasive (video) urodynamics is indicated if non-invasive investigations raise the suspicion of i.e. (non)neuropathic detrusorsphincter dysfunction, obstruction (i.e. posterior urethral valves), or vesicoureteral reflux. In children, invasive (video) urodynamics should only be considered if the outcome is likely to affect treatment or when current treatment does not result in the expected improvement [4], [9].

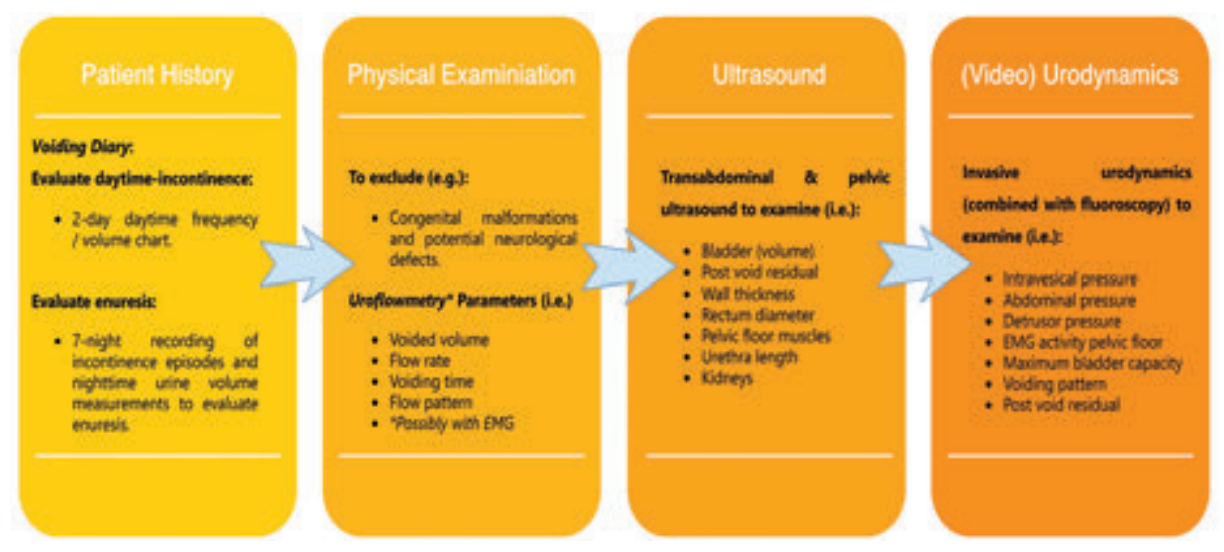

Figure 1.3: Diagnostic work-flow for children with urinary incontinence 


\section{Treatment}

In line with ICCS guidelines, urotherapy is the recommended first-line approach for children with all subtypes of urinary incontinence. Urotherapy is defined by the ICCS as a conservative-based, non-surgical, non-pharmacological therapy and treatment of LUT dysfunction, which can be divided into standard therapy and specific urotherapy (i.e. interventions) [3], [4]. The aim of urotherapy is to correct the filling and voiding function of the bladder and sphincters [4], and to teach children how to respond adequately to their bladder filling and bladder signals.

However, it is not advised to subject children younger than 6 years to intensive urotherapy, because, at this age, they do not have an adequate level of discipline and body-awareness or are capable to reflect on their own actions [4]. For this group of children, parents should be informed how to support their child in appropriate ways [4].

Standard therapy includes information and demystification, instructions (i.e. fluid intake), lifestyle advice, registration of symptoms and voiding habit (i.e. voiding diaries) and support and encouragement for children and their parents, e.g. by regular follow-up with the healthcare professional for an initial maximum duration of three months [3], [4]. Based on the ICCS criteria, treatment results are indicated as: no response $(<50 \%$ reduction of symptoms), partial response (50-99\% reduction of symptoms), or complete response (100\% improvement) [3], [4].

If initial standard therapy does not result in the desired improvement, the advised next step is specific urotherapy which may include specific interventions such as pelvic floor training (e.g. biofeedback), cognitive behavioral therapy, psychotherapy, and neuromodulation [3], [4]. Examples of biofeedback tools are timed voiding (e.g. alarm watches; to avoid postponing micturition), real-time uroflowmetry and EMGassessment of the pelvic floor. However, if treatment results do not improve after specific urotherapy, also a pharmacological (i.e. oxybutynin) or surgical therapy can be considered for daytime incontinence.

Regarding the effectiveness of urotherapy, Van Gool et al. (2014) reported that the cure rate of cognitive treatment (i.e. explanation, demystification, and re-education) for children with dysfunctional voiding was equal to $52 \%$, assessed 12 months after finishing treatment [10]. Combined with specific interventions (pelvic floor training) the cure rate was equal to $49 \%$. The overall reported cure rates ranges from $40-90 \%$ [2], which can be explained by the fact that it remains unclear which specific elements of urotherapy are crucial for its overall effectiveness [2]. Despite promising results, many children still do not respond to the available treatment options and are no longer aware that urinary incontinence occurs, resulting in wet pants [11]. 


\section{Enuresis}

Regarding the treatment for children with enuresis (above the age of 6 years), there are several similarities for the treatment of daytime incontinence. Treatment also starts with general lifestyle advice, pharmacological therapy and biofeedback (alarm therapy), or combined. In general, pharmacological therapy (i.e. desmopressin, anticholinergics) is often successful for these children, but the side-effects and the relapse after discontinuing the medication is relatively high [12]. Alarm therapy is based on the concept of negative reinforcement, in which the child reacts to an alarm alerting urinary leakage by contracting the pelvic floor muscles to avoid setting of the alarm in the future. The effectiveness of alarm therapy, being able to stay dry for 14 consecutive nights, ranges from $65-75 \%$ within a period of 5-12 weeks. The 6-month relapse rate equals $15-30 \%$ [13]. Nevertheless, during this period, the child and parents need to be highly motivated and still have the disadvantages of being awakened by wet sheets during treatment.

\section{History of Bladder Monitoring Techniques}

To increase the effectiveness of current treatment options for children with daytime incontinence and/or enuresis, it could be beneficial to continuously monitor the filling status of the bladder, in a non-invasive, wearable and child-friendly manor. Through real-time assessment of the bladder, the child could potentially be notified before the bladder reaches its maximum capacity, enabling the child to go to the toilet in time and prevent urinary incontinence, during day or night.

In the previous decades, several technological advances within this scope have been reported, e.g. in the fields of bioelectrical impedance analysis (BIA) [14], [15] and transabdominal ultrasound assessments [14], [16]-[22] (Figure 1.4). BIA is a simple, quick, non-invasive method which uses surface electrodes to measure the drop in voltage, as result of the body's resistance to the provided minor, electrical current. Generally, the measured body's resistance is used to assess the body's composition, related to hydration, nutrition and the quantities of fat and fat-free mass [14]. BIA has also been used to determine the bladder volume over time, by positioning surface electrodes to the lower abdomen and measuring the changes in the electrical impedance. However, this application had several practical limitations which influenced the accuracy and reproducibility of the bladder volume assessment. For example, the subject has to lie still, supine, with the arms and legs spread, which is not suitable for the continuous, real-time application in active children. Secondly, room temperature and (in)accurate electrode placement also have a significant impact on the measurement outcomes [14].

The second technique applies transabdominal ultrasound for the assessment of the bladder volume (Figure 1.4). Ultrasound imaging or sonography is a relatively cheap, non-invasive, mobile technique which has been used for more than 50 years. Ultrasound 
devices use sound waves with operating frequencies of more than $20 \mathrm{kHz}$, which is above the upper limit of the audible human hearing. Ultrasound is created by applying an electrical current through piezoelectric crystals, which will vibrate at a particular frequency. In general, medical applications generate ultrasound waves at frequencies between 1-20 MHz. When conducting transabdominal ultrasound of the bladder, the ultrasound waves will enter the lower abdomen, using an ultrasound transducer, and interact with bladder walls, generating clear ultrasound reflections (due to a difference in acoustic impedance between urine and the surrounding soft intestinal tissue). The reflections are received by the same piezoelectric crystals, which generate an electrical amplitude signal (A-mode). The time delay $(\Delta t)$ between generated acoustic waves and the recorded reflections of the bladder walls, combined with the body's speed of sound (c $\sim 1540 \mathrm{~m} / \mathrm{s}$ ), can be used to determine the dimensions $(\mathrm{d})$ of the bladder $(\mathrm{d}=\Delta \mathrm{t} / 2 \cdot \mathrm{c}$ ) and estimate the bladder filling status.

In 1979, Rise at al. described one of the first simplified, pocket-size ultrasonic bladdervolume sensors, consisting of electronic body pack, a single-element 2.25 MHz transducer and an earphone to notify the user when the bladder was almost full. The user applied the transducer directly on the skin and the bladder was indicated as "full", when the bladder dome rose above the pubic bone, generating and receiving the A-mode reflection of the posterior wall of the bladder [17], [18] (Figure 1.4). In 1998, Petrican and Sawan, reported on a second, similar example of A-mode based, miniaturized ultrasonic bladder sensor [14]. This device was intended for children with enuresis and consisted of an elastic belt around the waist, containing also a single-element transducer. The presented prototype was based on a time-window principle. If the time to receive the echo from the posterior wall exceeded an pre-set time-threshold, an alarm was activated and the child could potentially be awakened before an enuretic event [14] (Figure 1.4).

In addition to the described techniques, which indicate whether the bladder is full or empty, several attempts have been made to develop an ultrasound-based device which measures an actual bladder volume (ml). In 1999, Pretlow described the "ideal treatment regimen" for children with enuresis, indicating that the treatment should prevent the bedwetting, and contribute to a higher cure rate through associative conditioning between a full bladder and the notification, enabled by positive reinforcement [23]. Pretlow tested this hypothesis by using a miniaturized, portable, battery-powered ultrasound bladder volume monitor, mounted within an elastic garment [23]. This device recorded the bladder volume every $15 \mathrm{~m}$ during the night and provided a notification at $80 \%$ of average nighttime volume (Figure 1.4).

More recently, Kristiansen et al. (2014) presented a new ultrasonic bladder monitor, which estimates the actual bladder volume. This device was intended for children with enuresis and was based on a circle-configuration of seven transducers. Each transducer individually records reflections from 15 different directions and construct a three-dimensional reconstruction of the bladder, estimating the bladder volume $(\mathrm{ml})$

(Figure 1.4). 


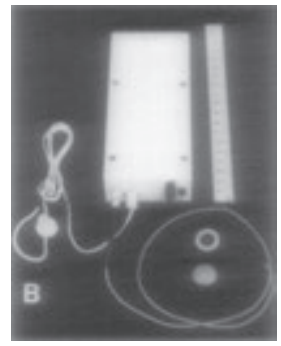

Rise et al. (1979)[17]

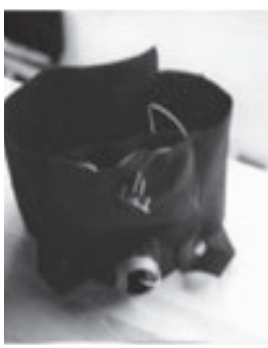

Petrican \& Sawan

(1998) [14]

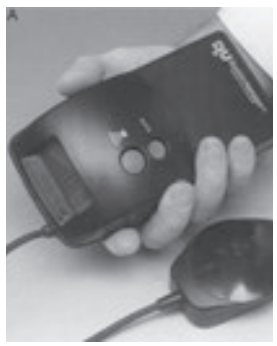

Pretlow (1999) [23], Kristiansen et al. (2014) [24]

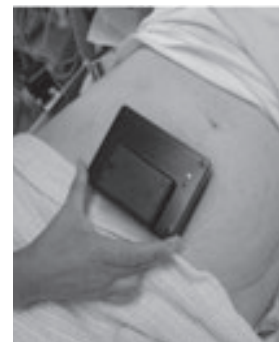

[25]

Figure 1.4: Several examples of Bladder Monitoring Techniques

Despite often promising results in vitro and in vivo, none of the previous discussed devices has been implemented in the treatment of children with urinary incontinence. Often the configuration of these devices had multiple, practical limitations, which influenced the accuracy of the measurements. For instance, the sizes of these devices was often too bulky for a pediatric application. Also, proper, stable fixation of the ultrasound transducer remained difficult (e.g. by elastic garments or sticky gel pad), allowing the interference with air which has a significant impact on the ultrasound transmission. Next, using cabled connections to collect data, to process data or to provide a notification, is unpractical when working with either active children or sleeping children [23], [24]. Finally, none of the devices were clinically evaluated during natural bladder filling (day or night) or used in children during longer times.

\section{WEARABLE ULTRASOUND}

At the end of 2013, the department of Pediatric Urology of the Wilhelmina Children's Hospital UMC Utrecht (Utrecht, the Netherlands), started a new line of research initiated by pediatric urologist Prof. Dr. Pieter Dik. He hypothesized that the child's awareness of a full bladder could increase when introducing a new sensing technique which could detect a full bladder, provide a notification, and prevent urinary incontinence (e.g. voiding postponement), with the primary objective to increase the current training effectiveness.

Despite the discussed practical limitations, ultrasound still remained a promising, non-invasive, feasible technique for the continuous assessment of the bladder filling status, when considering the previous, documented in vitro and in vivo results [14], [16]-[22]. This was also recently confirmed by the president of the ICCS, Mr. Tryggve Nevéus, who stated that continuous ultrasound could be beneficial e.g. for children with enuresis to document urine loss or the number of enuretic events during the night [26], [27]. He concluded that "the only way to overcome the problems of detecting multiple or incomplete enuretic episodes without disturbing the patient would be continuous overnight assessment of bladder volume using body-worn ultrasonographic probes" [26]. 
In collaboration with the Department of Medical Technology and Clinical Physics of the University Medical Centre Utrecht (UMC Utrecht, Utrecht, the Netherlands), a first ultrasonic, lab-based prototype was developed within 3 months. This technical department is ISO 13485 certified for the development and manufacturing of medical devices, which allows the development of custom-made devices for in-house clinical investigations within a quality management system.

This first lab-based, table-size ultrasonic prototype consisted of a single-element ultrasound transducer (range: 4-5 MHz) which was connected (coaxial cable) to the electronic hardware, containing a high-voltage, pulse generator to generate the acoustic wave. The returning reflections were measured by a digital oscilloscope and allowed data extraction during in vitro and in vivo experiments. Based on this first prototype, it was concluded that it was possible to measure the dimensions of the bladder and to detect an increase in bladder dimensions over time, which could serve as a potential indicator for the bladder filling status.

Based on this first feasibility experiment, an official Pontes Medical Project (Utrecht, the Netherlands) was initiated. Pontes Medical brought technical, clinical and business competences together in order to develop a first clinical prototype, the URIKA Bladder Monitor, suitable to be worn by children. In this project, UMC Utrecht collaborated with Novioscan (Nijmegen, the Netherlands), who provided their technical, business and commercial expertise.

In approximately one year, the URIKA Bladder Monitor was developed in accordance to regulatory guidelines and it was ready to be used (exclusively) for in-house clinical investigations at the department of Pediatric Urology. At the end of 2015, this study demonstrated proof-of-concept and resulted in a detailed list of device requirements, which initiated the development of a new, non-invasive, medically certified, wearable ultrasonic bladder sensor: the SENS-U Bladder Sensor, brought to the market in 2018 by Novioscan.

\section{AIMS AND OUTLINE OF THE THESIS}

This thesis focusses on the design, the development, the verification, the clinical validation and the implementation of a new, non-invasive, wearable, wireless ultrasonic bladder sensor for children suffering from urinary incontinence. Similar to the medical product life cycle, which can be divided based on the regulatory status ("before CEmarking" and "CE marked"), this thesis is divided into two phases.

The first phase focusses on the design, the verification, and clinical validation of the initial clinical prototype, the URIKA Bladder Monitor, and the new redesigned, commercialized device: the SENS-U Bladder Sensor. The described (pre) clinical 
results are directly derived from these particular stages before product availability (CE-marking). The main objective of the first phase is to determine the safety and performance of these new ultrasound devices, under normal conditions of use.

In Chapter 2, the design of the first clinical research-prototype: the URIKA Bladder Monitor (UBM) is presented and it reports on the applied ultrasound method to estimate the bladder filling status. Next, Chapter $\mathbf{2}$ describes the conducted pre-clinical safety evaluation in accordance to regulatory requirements (IEC 60601-2-37), in order to demonstrate that the UBM could be used safely for future clinical investigations, as part of the preparation for ethics approval. Chapter 3 reports on the first observational, clinical feasibility study conducted with the UBM, in order to demonstrate that this device was able to measure the anterior-posterior (A-P) bladder dimensions over time, in a study population of school-age children with urinary incontinence. Based on the results of this feasibility study, the process of redesigning the UBM model was initiated, in order to increase the full-bladder detection rate and improve the transducer's stability of this first prototype.

Chapter 4 presents the redesigning of the UBM, the SENS-U Bladder Sensor (SENS-U). The performance of this product-prototype was clinically validated over a broad range of bladder volumes in children during (video) urodynamic evaluation, in order to determine the full-bladder detection rate and the measurable bladder volume range. Based on the results of this first phase, the SENS-U became officially, medically certified as a CE-marked, class Ila medical device (March 2018).

As a CE-marked device, the SENS-U was introduced to the European Healthcare Market, enabling (pediatric) urologists, pediatricians and nurses to work with this new device on a broader scale.

This product milestone initiated the second part of the thesis: the clinical implementation and valorization phase. The clinical results reported are directly derived from using this CE-marked device for children with urinary incontinence during daily life activities. The main objectives of the second phase are (1) to evaluate the performance of the SENS-U during regular daily life activities, (2) to verify the accuracy for nighttime registration of the bladder filling and (3) to establish and verify the clinical benefits of the device.

Therefore, Chapter 5 presents the results of the conducted pilot study in order to evaluate the performance of the SENS-U in a group of children during regular physical activity and natural bladder filling. It was hypothesized that the SENS-U would be equally accurate during activities of daily living as during static, standardized (video) urodynamics. In addition, the children's level of response to the provided full-bladder notification was assessed. 
Chapter 6 reports on the results of the first night-time, home-based evaluation of the SENS-U in children with monosymptomatic nocturnal enuresis. It was hypothesized that the device would be equally accurate for both daytime - and nighttime registrations.

Chapter 7 provides a first series of (inter)national cases reports to illustrate the clinical impact of using the SENS-U in the treatment of children with different types of (refractory) urinary incontinence.

Finally, Chapter $\mathbf{8}$ presents the general discussion and future perspectives, ending with Chapter $\mathbf{9}$, the summary of this thesis (Chapter 10 provides the summary in Dutch). 


\section{REFERENCES}

1. A. J. Schaeffer and D. A. Diamond, "Pediatric urinary incontinence: Classification, evaluation, and management," African J. Urol., vol. 20, no. 1, pp. 1-13, Mar. 2014. https://doi. org/10.1016/j.afju.2013.10.001

2. M. Hadders-Algra, K. Maathuis, R. F. Pangalila, J. G. Becher, and J. de Moor, Kinderrevalidatie. Koninklijke Van Gorcum BV, Assen, 2015.

3. P. F. Austin et al., "The standardization of terminology of lower urinary tract function in children and adolescents: Update report from the standardization committee of the International Children's Continence Society," Neurourol. Urodyn., vol. 35, no. 4, pp. 471481, 2016. https://doi.org/10.1002/nau.22751

4. A. J. Nieuwhof-Leppink, R. P. J. Schroeder, E. M. van de Putte, T. P. V. M. de Jong, and R. Schappin, "Daytime urinary incontinence in children and adolescents," Lancet Child Adolesc. Heal., vol. 3, no. 7, pp. 492-501,2019.https://doi.org/10.1016/S2352-4642(19)30113-0

5. B. S. Buckley, C. D. Sanders, J. S. Kwong, K. A. Kilpatrick, and C. A. Anderson, "Conservative treatment for functional daytime urinary incontinence in children," Cochrane Database Syst. Rev., vol. 2016, no. 9, 2016. https://doi.org/10.1002/14651858.CD012367

6. NVU, "Richtlijn Urine incontinentie bij kinderen," Richtlijn "Incontinentie bij Kinderen," pp. 1-144, 2008.

7. B. A. Thibodeau, P. Metcalfe, P. Koop, and K. Moore, "Urinary incontinence and quality of life in children.," J. Pediatr. Urol., vol. 9, no. 1, pp. 78-83, Feb. 2013. https://doi.org/10.1016/j. jpurol.2011.12.005

8. P. G. van Leuteren, A. J. Klijn, T. P. V. M. De Jong, and P. Dik, "SENS-U: Validation of a wearable ultrasonic bladder monitor in children during urodynamic studies," J. Pediatr. Urol., vol. 14, no. 6, pp. 569.e1-569.e6, 2018. https://doi.org/10.1016/j.jpurol.2018.07.018

9. S. B. Bauer, R. J. M. Nijman, B. A. Drzewiecki, U. Sillen, and P. Hoebeke, "International Children's Continence Society Standardization Report on Urodynamic Studies of the Lower Urinary Tract in Children," Neurourol. Urodyn., vol. 34, no. 3, pp. 224-230, 2015. https:// doi.org/10.1002/nau.22783

10. J. D. Van Gool et al., "Multi-center randomized controlled trial of cognitive treatment, placebo, oxybutynin, bladder training, and pelvic floor training in children with functional urinary incontinence," Neurourol. Urodyn., vol. 33, no. 5, pp. 482-487, 2014. https://doi. org/10.1002/nau.22446

11. E. Van Laecke et al., "The Daytime Alarm: A Useful Device for the Treatment of Children With Daytime Incontinence," J. Urol., vol. 176, no. 1, pp. 325-327, 2006. https://doi.org/10.1016/ S0022-5347(06)00303-X

12. T. Neveus et al., "Evaluation of and treatment for monosymptomatic enuresis: a standardization document from the International Children's Continence Society.," J. Urol., vol. 183, no. 2, pp. 441-447, 2010. https://doi.org/10.1016/j.juro.2009.10.043

13. P. C. Friman and K. M. Jones, "Behavioral treatment for nocturnal enuresis.," J. Early Intensive Behav. Interv., vol. 2, no. 4, pp. 259-267, 2005. https://dx.doi.org/10.1037/ h0100319

14. P. Petrican and M. A. Sawan, "Design of a miniaturized ultrasonic bladder volume monitor and subsequent preliminary evaluation on 41 enuretic patients.," IEEE Trans. Rehabil. Eng., vol. 6, no. 1, pp. 66-74, 1998. https://doi.org/10.1109/86.662622 
15. Y. S. L. and H. K. S. Shin, J. Moon, S. Kye, K. Lee, "Continuous bladder volume monitoring system for wearable applications," in 39th Annual International Conference of the IEEE Engineering in Medicine and Biology Society (EMBC), 2017, pp. 4435-4438. https://doi. org/10.1109/EMBC.2017.8037840

16. A. Beauchamp-Parent and M. Sawan, "New reconfigurable ultrasonic enuresis monitoring system," Eng. Med. Biol. Soc., vol. 20, no. 2, pp. 789-792, 1998. https://doi.org/10.1109/ IEMBS.1998.745549

17. W. E. Bradley, M. T. Rise, and D. L. Frohrib, "Clinical Bladder Use of Biocompatible Volume Ultrasonic Sensor," Urology, vol. 14, no. 3, pp. 300-302, 1979. https://doi.org/10.1016/00904295(79)90510-7

18. M. T. Rise, W. E. Bradley, and D. A. Frohrib, "An Ultrasonic Bladder-Volume Sensor," Trans. Biomed. Eng., vol. BME-26, no. 12, pp. 709-711, 1979. https://doi.org/10.1109/ TBME.1979.326464

19. N. K. Kristiansen, J. C. Djurhuus, and H. Nygaard, "Design and evaluation of an ultrasoundbased bladder volume monitor," Med. Biol. Eng. Comput., vol. 42, pp. 762-769, 2004. https://doi.org/10.1007/bf02345209

20. P. Palanchon, D. van Loon, C. H. Bangma, and N. Bom, "Bladder volume measurements with a limited number of fixed ultrasound beams.," Ultrasound Med. Biol., vol. 30, no. 3, pp. 289-94, Mar. 2004. https://doi.org/10.1016/j.ultrasmedbio.2003.11.009

21. H. Niu et al., "Design of an Ultrasound Bladder Volume Measurement and Alarm System," 2011 5th Int. Conf. Bioinforma. Biomed. Eng., vol. M, no. 1, pp. 1-4, May 2011. https://doi. org/10.1109/icbbe.2011.5781498

22. H. Kodama, H. Yoshimura, and Y. Nagata, "An ultrasonic urine sensor," Gerontechnology, vol. 8, no. 1, pp. 35-37, 2009. https://doi.org/10.4017/gt.2009.08.01.008.00

23. R. A. Pretlow, "Treatment of nocturnal enuresis with an ultrasound bladder volume controlled alarm device," in Journal of Urology, 1999, vol. 162, no. 3 II, pp. 1224-1228. https://doi.org/10.1097/00005392-199909000-00103

24. S. Mattsson, D. Persson, G. Glad Mattsson, and S. Lindström, "Night-time diuresis pattern in children with and without primary monosymptomatic nocturnal enuresis," J. Pediatr. Urol., vol. 15, no. 3, pp. 229.e1-229.e8, 2019. https://doi.org/10.1016/j.jpurol.2019.02.002

25. N. K. Kristiansen, H. Nygaard, and J. C. Djurhuus, "Clinical evaluation of a novel ultrasoundbased bladder volume monitor.," Scand. J. Urol. Nephrol., vol. 39, no. 4, pp. 321-8, Jan. 2005. https://doi.org/10.1080/00365590510031165

26. T. Nevéus, "The amount of urine voided in bed by children with enuresis," J. Pediatr. Urol., vol. 15, no. 1, pp. 31.e1-31.e5, 2019. https://doi.org/10.1016/j.jpurol.2018.08.006

27. W. M. J. Kwinten, P. G. van Leuteren, M. van Duren - van lersel, P. Dik, and P. E. Jira, "SENS-U: continuous home monitoring of natural nocturnal bladder filling in children with nocturnal enuresis - a feasibility study," J. Pediatr. Urol., vol. 16, no. 2, pp. 196.e1-196.e6, 2020. https://doi.org/10.1016/j.jpurol.2020.01.012 



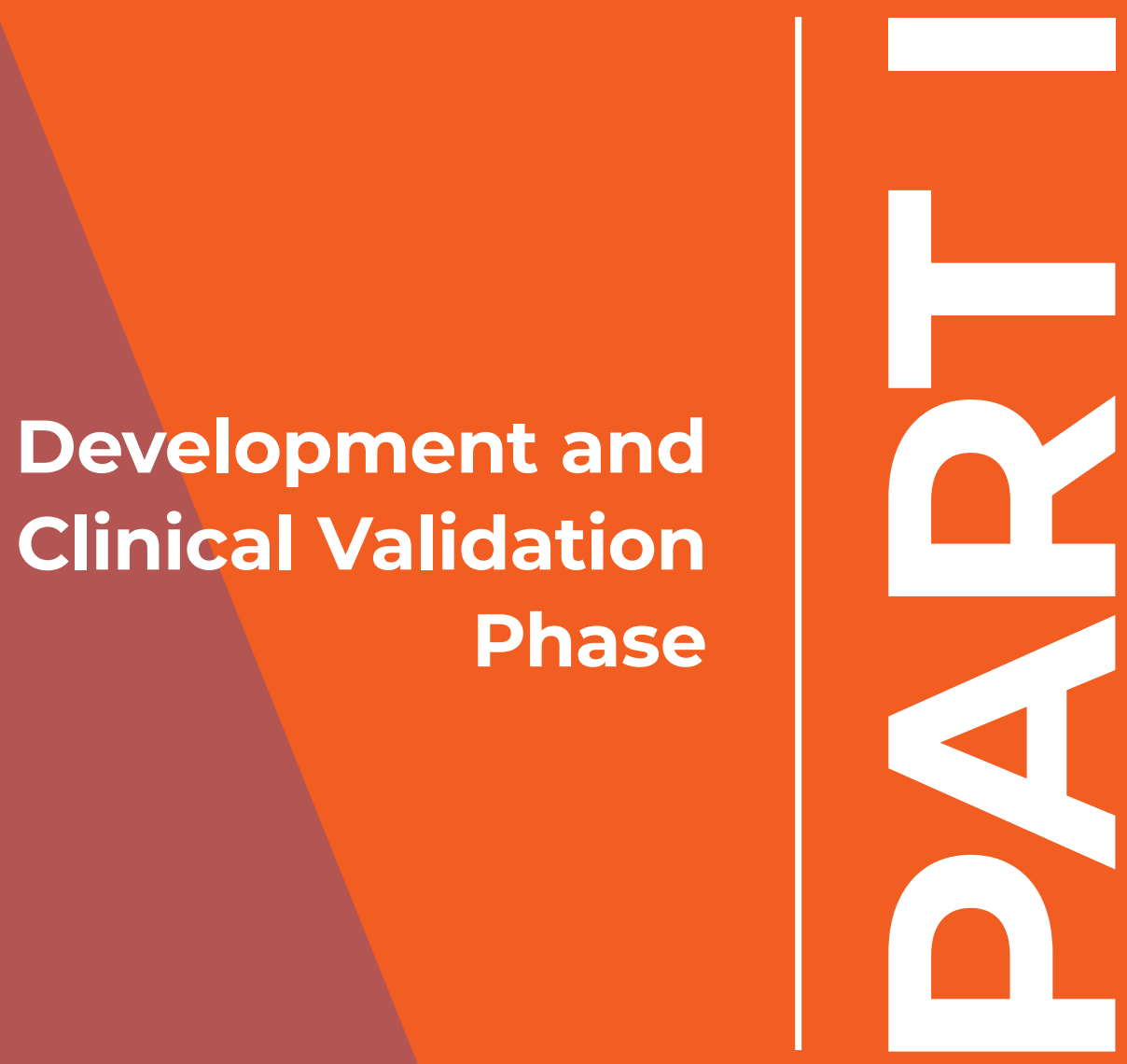




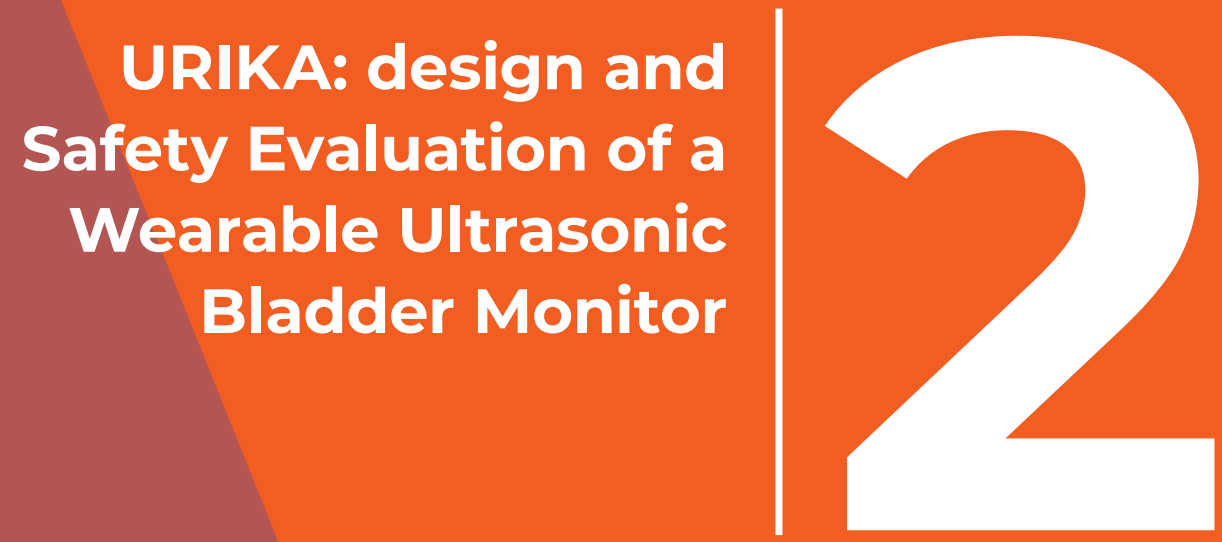


\section{SUMMARY}

Pediatric urinary incontinence remains a common problem in daily clinical practice. To support these children, it may be beneficial to continuously monitor the fullness of the bladder for both diagnostics - and treatment purposes. A new, wearable and wireless ultrasonic device, the URIKA Bladder Monitor, was designed. Related to the international safety and performances requirements, this device was pre-clinically evaluated estimating e.g. the thermal - and mechanical indices. Experiments demonstrated that this device is not expected to exceed the allowable acoustic exposure levels and exposures indices. It was concluded that this new device is safe to use for in-house clinical investigations. 


\section{INTRODUCTION}

Pediatric urinary incontinence (UI) remains a common problem in daily clinical practice and is defined as the involuntary leakage of urine, either continuously or intermittent [1]. The estimated prevalence of UI at school-age (6-10 years) varies between $6-9 \%$ in girls and $7 \%$ in boys, and decreases with age [1], [2]. To support these children, it may be beneficial to continuously monitor the fullness of the bladder in a non-invasive way, for both diagnostics - and treatment purposes. By real-time monitoring of the bladder filling, the child could be notified a short time before micturition, allowing the child to act by going to the toilet in time and remaining dry. Over the last couple of decades, several technological attempts have been made in order to develop a method to assess the bladder fullness, including e.g. bio-impedance (measuring changes in resistance due to bladder filling) and ultrasound measurements [3]-[8]. Regarding bio-impedance analysis, this method had several limitations which influenced reproducibility and practical implementation, such as (in)correct electrode placement, room temperature and the fact that the subject had to remain in a static position (supine or seated) [6]. However, Rise et al. (1979) presented a simplified wearable ultrasonic device (based on a single-element $2.25 \mathrm{MHz}$ transducer) which provided a notification, as soon as the bladder dome was detected when it rose above the symphysis pubis [4], [7]. A second example was a miniaturized ultrasonic bladder sensor mounted in a belt for children with nocturnal enuresis [6]. By monitoring the reflection of the posterior bladder wall and comparing the time to receive it to a threshold value, the child could be notified before wetting the bed. Despite these promising previous efforts, none of these wearable devices made its way to the daily clinical practice for children with UI.

In this paper, we present the first design of a prototype for a wearable, wireless ultrasonic bladder monitor: the URIKA Bladder Monitor. Secondly, the prototype was pre-clinically evaluated in order to demonstrate that it can be used safely for future, inhouse clinical investigations (exclusively), as part of the preparation for ethics approval. No ethics approval was required at this stage, as the pre-clinical safety evaluation did not entail animal or human research. The aim of this new line of research is to eventually develop a medically certified device specially designed for children which can notify him/her before the bladder is (to) full, preventing daytime incontinence or an enuretic event during the night.

\section{MATERIALS AND METHODS}

The URIKA Bladder Monitor (UBM) is a custom-made medical ultrasound device, specifically (and exclusively) designed and manufactured for in-house clinical investigations. In collaboration with Department of Medical Technology and Clinical Physics of the University Medical Centre Utrecht (Utrecht, the Netherlands), which is 
ISO 13485 certified for the development and manufacturing of medical devices, a technical file was compiled in accordance to regulatory guidelines. This technical file included all details of the UBM i.e. (technical) design, risk analysis and manufacturing processes.

The UBM is based on A-mode ultrasound technology which detects the anterior and posterior bladder wall and uses the intermediate dimension as an indicator for bladder fullness [9]. A next future step would be to include the notification functionality, comparing the estimated dimension to a pre-set personalized threshold. The UBM is presented in Figure $\mathbf{2 . 1}$ and consists of two main parts: an electronic body pack and an ultrasound transducer assembly (Figure 2.1), worn around the waist with an elastic belt. The UBM can be divided into the following subsections: 1) ultrasound transducer assembly, 2) the controller, 3) the emitter, 4) the receiver, 5) the power supply and 6) the user interface.

\section{Transducer Assembly}

The transducer assembly $(90 \times 72 \times 21 \mathrm{~mm})$ (Figure 2.1) is positioned at the lower abdomen, just above the pubic bone and below the umbilicus with a yellow, disposable, latex-free elastic band (product number: PMS-M2208A, Philips Healthcare). Buttonholes (and white plastic buttons) in the elastic belt allows adjustments for each individual child's waist circumference. Furthermore, these buttons holes are used to connect the top button of transducer assembly itself to the belt (Figure 2.1). The transducer assembly is a custom-made, 3D-printed thermoplastic enclosure which is based on a blend of polycarbonate and acrylonitrile butadiene styrene (ABS).
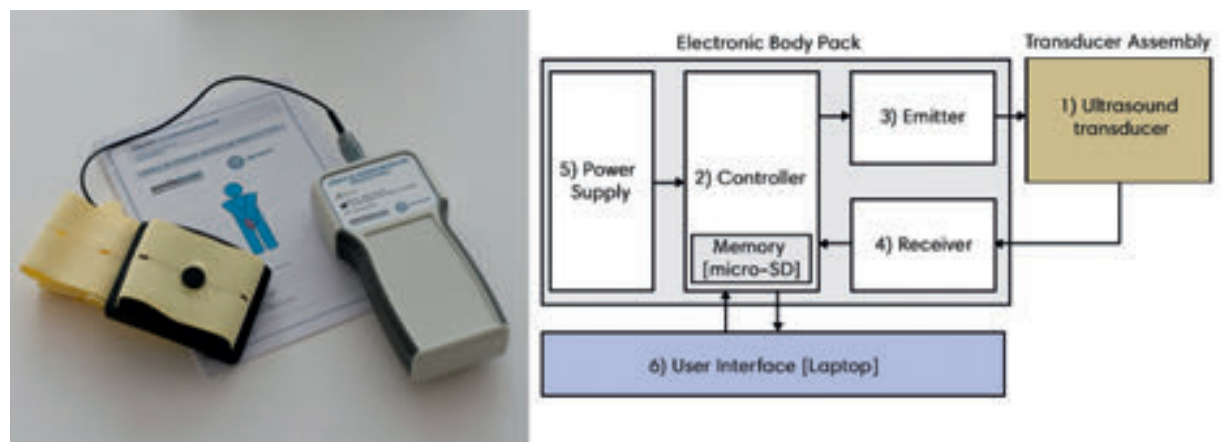

Figure 2.1: The overall architecture of the URIKA Bladder Monitor

The transducer assembly contains a single element, unfocused transducer with an acoustic working frequency of $3.81 \mathrm{MHz}$ and an active diameter of $19 \mathrm{~mm}$ (Probe number: 14AD-01, HQSonics BV, Waalre, The Netherlands). The combination of this acoustic working frequency and active diameter, results in a near field length of approximately $23 \mathrm{~cm}$ which is deep enough to detect the posterior wall of the urinary bladder in children. 
The transducer assembly is the only part that will come in contact with the skin. To ensure biocompatibility and use it for clinical investigations, the transducer assembly is coated with an epoxy layer (LOCTITE ${ }^{\circledR}$ M-21HP, Henkel KGaA, Düsseldorf, Germany). A liquid coupling gel (article No. 2010, Sonogel ${ }^{\circledR}$, Sonogel Vertriebs GmbH, Bad Camberg, Germany) is used to minimize the interference with the presence of air, which stays in place throughout the day without drying out [9].

\section{Electronic Body Pack}

The transducer assembly is connected with a short coaxial cable to an electronic body pack (EBP). The EBP consists of the following parts: a (handheld) enclosure, a printed circuit board (PCB) and the power supply (2 AA-batteries). The enclosure is based on an ABS, T-shaped casing $(165 \times 80 \times 28 \mathrm{~mm})$ with an internal battery compartment (Product number: 1553TTGYBAT, Hammond Manufacturing Co. Ltd., Ontario, Canada), containing two AA batteries [9].

The internal PCB consists of the controller, the emitter, the receiver, the memory and the user interface (Figure 2.1). The controller is a complex programmable logic device (CPLD), which controls the remaining main parts of the UBM. The CPLD autonomously records measurement data by activating the emitter, controlling the receiver and by storing the data in a memory. The emitter is based on an analogue circuit containing a high voltage DC/DC converter, a pulse forming network and a capacitor [9]. In order to excite the ultrasonic transducer with a short, high-voltage pulse, the controller activates the high voltage DC/DC converter (which generates $100 \mathrm{~V}$ ) which charges the capacitor (10 nF). This capacitor is discharged by a pulse forming network, generating pulse (duration $=0.13 \mu \mathrm{s}$ ) into the ultrasound transducer, resulting in a high-frequency acoustic sound wave [9]. To minimize the ultrasound exposure to the user and to minimize the energy consumption of the batteries, the controller deactivates the high voltage DC/DC converter and the pulse forming network in-between measurements (every $2 \mathrm{~min}$ ).

The returning ultrasound reflections of the anterior - and posterior bladder walls are recorded by a radio frequency receiver. To compensate for signal attenuation, due to tissue interaction, a variable gain amplifier in included in the receiving circuit. The recorded, digitalized reflections are stored in the CPLD's internal memory [9]. By using either a Bluetooth ${ }^{\circledR}$ Low Energy (BLE) USB dongle or the internal micro-SD card of the UBM, the recorded A-mode data can be uploaded to a software program for offline evaluation. Measurements can also be performed on demand (using the BLE USB dongle) for which the repetition time can be set by the user, using the software program on the research laptop. Lastly, the calculations of the dimensions between the anterior - and posterior bladder wall reflections are conducted off-line by an MATLAB-based algorithm installed on the research laptop [9]. 


\section{Pre-Clinical Safety Evaluation}

To evaluate if the UBM prototype is acoustically safe to use for future clinical investigations, first the possible biological side-effects of ultrasound exposure are discussed. To our knowledge, no biological effects have been stated in literature after short-time exposure to diagnostic ultrasound instruments [10], [11]. However, ultrasound waves have the ability to cause biological effects, depending on the ultrasound wave and tissue properties. In general, there are two main effects in human tissue: thermal effects and mechanical effects [11]-[13]. When acoustic waves interact with matter, energy is absorbed and converted into heat. Temperature elevation depends on the amount of energy absorbed, the intensity of the wave, the time of exposure, the beam width and the specific absorption properties of the tissue [11]. When temperature rises, cellular structures and biochemical processes can be affected, which results in damage to cells. The second category of biological responses are mechanical effects, which includes ultrasonic cavitation, radiation forces and micro-streaming [11]. Cavitation is defined as the formation or growth of gas bubbles in a liquid medium [11], [14], [15]. Ultrasonic waves interact with gas bubbles causing them to grow or collapse. When a bubble collapses, it releases all its energy which results in a local rise in temperature and mechanical stress on surrounding tissues [15].

\section{Thermal \& Mechanical Indices}

The International Electrotechnical Commission (IEC) has defined the requirements for basic safety and essential performance for ultrasonic medical (diagnostic and monitoring) equipment, in the IEC 60601-2-37 standard [13]. To estimate the potential risks of thermal or mechanical effects, the standard has defined two exposures indices for non-scanning transducers (such as UBM): the soft-tissue thermal index (TIS) and the mechanical index (MI) [13].

The TIS is used to estimate the potential risk of thermal effects [13], [16]. If the ultrasound equipment is capable of exceeding a TIS of 1.0, equivalent to a temperate rise of $1^{\circ} \mathrm{C}$ (in any mode of operation), it is required to display this value to the end user [13]. The TIS depends on several parameters: the acoustic output power $\left(W_{0}\right)$, the $-12 \mathrm{~dB}$ output beam area $\left(A_{\text {aprt }}\right)$, the acoustic working frequency $\left(f_{\text {awf }}\right)$ and the derated spatialpeak, temporal-average intensity $\left(I_{\text {SPTA.3 }}\right)$ [13], [16]. The $I_{\text {SPTA.3 }}$ is the maximum derated acoustic intensity averaged over the pulse repetition period, derated (compensated) for human soft tissue attenuation by the multiplicative factor of $0.3 \mathrm{~dB} \cdot \mathrm{MHz}^{-1} \cdot \mathrm{cm}^{-1}$ [13], [17]. The standard states that ultrasound equipment is not expected to exceed a TIS of 1.0, if the requirements for acoustics parameters (Table 2.1) are met [13]. The MI is an indicator for the potential non-thermal (cavitation) bioeffects. The $\mathrm{MI}$ is directly proportional to the derated peak-rarefactional acoustic pressure $\left(P_{r .3}\right)$ and inversely related to the square root of the acoustic working frequency $\left(f_{\text {awf }}\right)[10],[13]$. Similar to the TIS, the MI has to be displayed to the end user, if ultrasound equipment is capable 
of exceeding a MI of 1.0 (in any mode of operation). However, an ultrasound device is not capable of exceeding this value if the requirements in Table $\mathbf{2 . 1}$ are met [13].

\section{Estimation of the TIS \& MI}

During the pre-clinical evaluation, two in-house experiments were carried out to estimate the parameters stated in Table 2.1. The first experiment was set-up to determine if the UBM could be capable of exceeding the TIS. First, the acoustic output power $\left(\mathrm{W}_{0}\right)$ divided by the $-12 \mathrm{~dB}$ output beam area $\left(\mathrm{A}_{\text {aprt }}\right)$, also referred to as the spatialaverage temporal-average intensity $\left(I_{\text {SATA }}\right)$, was estimated (Table 2.1).

With the available resources at hand, an experimental setup was constructed consisting of a water tank $(47 \times 29 \times 34 \mathrm{~cm})$. Against the short wall of the tank, a manual-operated, positioning system was placed, consisting of U-shaped copper frame $(35 \mathrm{~cm}$ rod, $\varnothing 15 \mathrm{~mm}$ ), which functioned as a hinge. At $3 \mathrm{~cm}$ from both ends of the vertical copper rod, two horizontal copper rods were attached (top: $19 \mathrm{~cm}$, bottom: $30 \mathrm{~cm}$ long). The lower horizontal rod served as the axial axes on which an object $(10.5 \mathrm{~cm}$ metal rod, $\varnothing 10 \mathrm{~mm}$ ) could be positioned to act as an reflector. The upper horizontal rod allowed the angular rotation of the lower horizontal rod. Through the use of a protractor, the angle of the lower horizontal rod, compared to the center axis of the transducer, could be determined. The transducer itself was attached to the short wall of the tank, in alignment with the lower horizontal rod (at $0^{\circ}$ angular rotation).

Next, the acoustic beam profile was determined by measuring the amplitude of the reflected acoustic wave, in respect to both the angle rotation and axial distance. The axial distance between the transducer and the metal rod varied between $2-30 \mathrm{~cm}$, with intervals of $2 \mathrm{~cm}$, and the metal rod was placed at angles of 0 to $\pm 25^{\circ}$ relative to beam axis at $5^{\circ}$ intervals. For each position in the 2 -dimensional acoustic plane, the peak-to-peak amplitude of the reflection (of the metal rod) was calculated. Then, the acoustic beam profile was visualized by calculating the relative reflected intensity (in respect to the maximum peak-to-peak value in the acoustic field) over the angular range (in decibels $[d B])$. Next, the $-12 d B$ output beam area $\left(A_{\text {aprt }}\right)$, were the acoustic beam enters the patient, was determined.

The maximum acoustic power $\left(W_{0}\right)$, generated at the surface of the transducer, is the results of the discharge of a capacitor. If we assume maximum transducer efficiency, the maximum acoustic power $\left(W_{0}\right)$ would be equal to the power provided by the pulseforming network, resulting in a maximum estimation of $\mathrm{I}_{\text {SATA }}$ (worst-case value).

The second experiment was set-up to estimate both the spatial-peak temporal-average intensity $\left(\mathrm{I}_{\text {SPTA.3 }}\right.$ ) (requirement for TIS) and the MI based on the measured acoustic pressures generated by the UBM transducer [13], [18]. 
With the available resources at hand, a second (distilled) water tank $(100 \times 40 \times 50 \mathrm{~cm})$ was used which contained a sliding rail on which both the transducer and a calibrated hydrophone (Precision Acoustics, $\varnothing 1.0 \mathrm{~mm}$ needle, sensitivity: $\mathrm{K}=1.11 \cdot 10^{-6} \mathrm{~V} \cdot \mathrm{Pa}^{-1}$ ) were mounted on holders (became available after the first experiment). The position of the acoustic hydrophone was manually (re)positioned between $2-30 \mathrm{~cm}$, with intervals of $2 \mathrm{~cm}$, along the axial axes. The signal of the hydrophone was received by a digital oscilloscope and saved to an USB-drive. Unfortunately, it was not possible to measure the acoustic pressures over an angular range, similar to the first experiment.

Based on measured acoustic pressures, the (derated) peak-rarefactional pressure $\left(P_{r .3}\right)$ is determined (required for $\mathrm{MI}$ ) and the $\mathrm{I}_{\text {SPTA.3 }}$ is calculated based on the (derated) pulseintensity integral $\left(\mathrm{PII}_{.3}\right.$ at maximum $\mathrm{P}_{\mathrm{r} .3}$ ) multiplied with the pulse repetition frequency (PRF) [13], [18], [19].

\section{RESULTS}

\section{First Experiment: $A_{\text {aprt }}, I_{\text {SATA }}$}

Figure 2.2A presents the acoustic beam profile measured for the $3.81 \mathrm{MHz}$ transducer of the UBM, visualized as the relative reflected intensity (RRI) over the angular range (in decibels $[\mathrm{dB}]$ ). In total, 165 measurements were recorded (15 axial positions, 11 angles of rotation). Figure 2.2B represents the RRI at the axial distance of $2 \mathrm{~cm}$, where the beam width is the narrowest $(\mathrm{d}=0.90 \mathrm{~cm})$ and enters the patient. Therefore, the $-12 \mathrm{~dB}$ output (circular) beam are $\left(\mathrm{A}_{\text {aprt }}\right)$ is equal to $0.64 \mathrm{~cm}^{2}$ (Figure 2.2B).

Next, when assuming maximum transducer efficiency $(\eta=100 \%)$, the power of the pulse-forming network, $50 \cdot 10^{-6} \mathrm{~J}$ (capacitor [10nF] charged to $100 \mathrm{~V}$ ), provided at a maximum PRF of $1 \mathrm{~Hz}$, results in a calculated maximum acoustic power $\left(\mathrm{W}_{0}\right)$ of $50 \cdot 10^{-3} \mathrm{~mW}$. Therefore, the maximum (worst-case) value of $\mathrm{I}_{\text {SATA }}$ equals $7.9 \cdot 10-2 \mathrm{~mW} / \mathrm{cm}^{2}$.
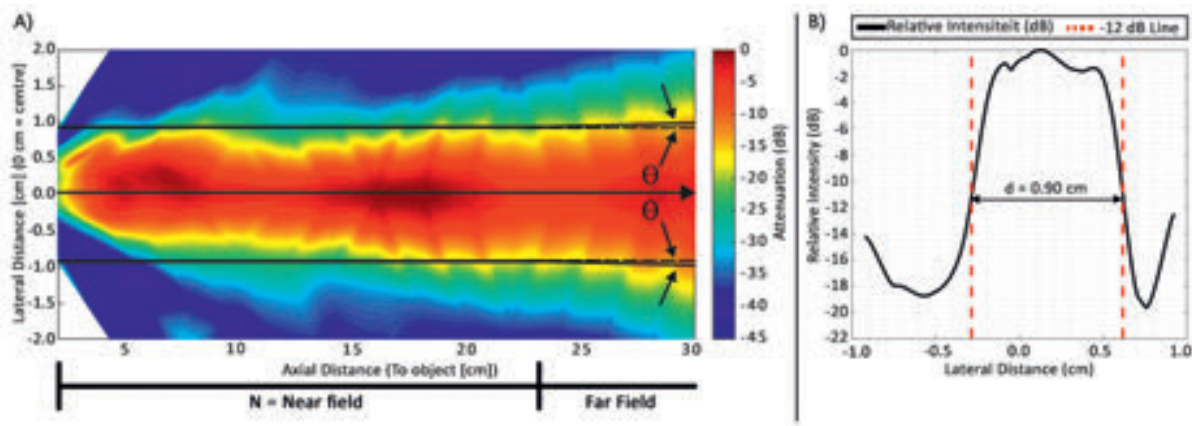

Figure 2.2A) The acoustic beam profile of the $3.81 \mathrm{MHz}, 19 \mathrm{~mm}$ transducer with a beam diverge angle of $\Theta=1.4^{\circ}$. B) The relative beam intensity at the axial distance of $2 \mathrm{~cm}, A_{\text {aprt }}=0.64 \mathrm{~cm}^{2}\left[\frac{\pi d^{2}}{4}\right]$. 


\section{Second Experiment: MI \& $\mathrm{I}_{\text {SPTA.3 }}$}

Figure 2.3A shows the measured peak rarefactional pressure $\left(P_{r}\right)$ in water for an axial depth of 2-30 cm, with its minimum negative value of $1.77 \cdot 10^{-3} \mathrm{MPa}$, at the natural focus of the transducer; the end of the near field $(z \sim 23 \mathrm{~cm})$. Compensating for human soft tissue attenuation, results in (derated) $\mathrm{P}_{\mathrm{r} .3}-$ value equal to $7.53 \cdot 10^{-3} \mathrm{MPa}$. Therefore, based on the acoustic working frequency of $3.81 \mathrm{MHz}$, the $\mathrm{MI}$ is equal to $3.9 \cdot 10^{-3}$ [13], [18].

Figure 2.3B presents both the generated acoustic pulse and the (derated) pulseintensity integral ( $\mathrm{PII}_{3}$ at maximum $\mathrm{P}_{\mathrm{r} .3}$ ) measured in water at an axial distance of $24 \mathrm{~cm}$, resulting in $\mathrm{PII}_{.3}$ - value of $8.2 \cdot 10^{-7} \mathrm{~mJ} \cdot \mathrm{cm}^{-2}$. As stated previously, the $\mathrm{I}_{\text {SPTA.3 }}$ can be calculated by multiplying the $\mathrm{PII}_{3}$ - value with the PRF $(1 \mathrm{~Hz})$, resulting in a $\mathrm{I}_{\text {SPTA. } 3}$ of $8.2 \cdot 10^{-7} \mathrm{~mW} \cdot \mathrm{cm}^{-2}$. The results of acoustic parameters are summarized in Table 2.1.
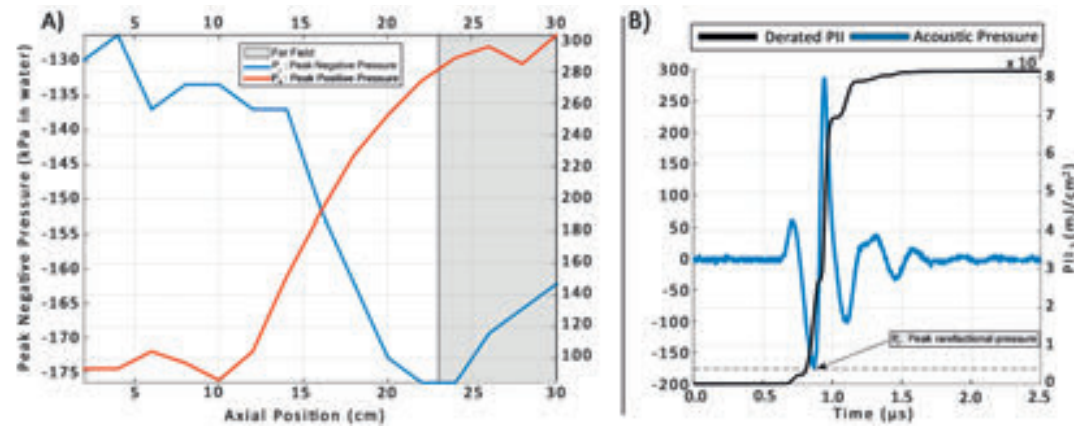

Figure 2.3A) Peak values measured for peak rarefactional $\left(P_{r}\right)$ - and peak positive pressure $\left(P_{+}\right)$ for an axial depth of 2-30 cm. B) The acoustic waveform and the cumulative estimation of the derated pulse-intensity integral $\left(\mathrm{PII}_{3}\right)$ at an axial distance of $24 \mathrm{~cm}$.

Table 2.1: Based on the acoustic output parameters stated in 201.12.4.2a of IEC 60601-2-37 [13].

Ultrasound Equipment is not expected to exceed a TIS of 1.0 if the following requirements are met:

\begin{tabular}{lllll}
\hline Parameter & Symbol & Units & Value & UBM \\
\hline OUTPUT POWER/-12 dB OUTPUT BEAM AREA & $\mathrm{I}_{\text {SATA }}$ & $\mathrm{mW} / \mathrm{cm}^{2}$ & $<20$ & $7.9 \cdot 10^{-2}$ \\
SPATIAL-PEAK TEMPORAL-AVERAGE INTENSITY & $\mathrm{I}_{\text {SPTA.3 }}$ & $\mathrm{mW} / \mathrm{cm}^{2}$ & $<100$ & $8.2 \cdot 10^{-7}$ \\
Acoustic working frequency & $\mathrm{f}_{\text {awf }}$ & $\mathrm{MHz}$ & $<10.5$ & 3.81 \\
-12 dB OUTPUT BEAM AREA & $\mathrm{A}_{\text {aprt }}$ & $\mathrm{cm}^{2}$ & $<1.25$ & 0.64 \\
\hline
\end{tabular}

Ultrasound Equipment is not capable of exceeding a MI of 1.0 if the following requirements are met:

\begin{tabular}{lllll}
\hline Parameter & Symbol & Units & Value & UBM \\
\hline derated peak rarefactional or negative pressure & $\mathrm{P}_{\mathrm{r} .3}$ & $\mathrm{MPa}$ & $<1.0$ & $7.53 \cdot 10^{-3}$ \\
Acoustic working frequency & $\mathrm{f}_{\text {awf }}$ & $\mathrm{MHz}$ & $>1.0$ & 3.81 \\
Mechanical Index & $\mathrm{MI}$ & Unitless & $<1.0$ & $3.9 \cdot 10^{-3}$ \\
\hline
\end{tabular}




\section{DISCUSSION}

This paper presents the first design of the URIKA Bladder Monitor; a new wearable, wireless ultrasonic device intended to support children with urinary incontinence by monitoring the fullness of the bladder. Next, the UBM was pre-clinically evaluated in order to determine if the device was safe to use (exclusively) for in-house clinical investigations. Related to the IEC 60601-2-37 safety guidelines, experiments were conducted (with the available resources) which concluded that the UBM is not expected to exceed a thermal index of 1.0 and is not capable of exceeding a mechanical index of 1.0 (Table 2.1) [13].

Also, the estimated values for the acoustics exposure levels $\left(I_{\text {SATA }}\right.$ and $\left.I_{\text {SPTA.3 }}\right)$ are well below the recommended limits. Finally, the potential safety concerns of continuous ultrasound exposure also needs to be addressed. Literature states that an average ultrasound intensity of $\leq 100 \mathrm{~mW} \cdot \mathrm{cm}^{-2}$ for a duration of $10000 \mathrm{~s}$ was of little or no hazard [4], [20]. Based on the maximum estimation of $I_{\text {SATA }}$ (worst-case value), the duration would be equivalent to a chronic, continuous exposure for almost 5 months. However, as stated previously, the UBM only perform active measurements every 2 min (with a pulse duration of $0.13 \mu \mathrm{s})$. As a result, the actual non-hazardous exposure time will be much higher (over tens of years). It was therefore concluded that it is highly unlikely for the UBM to cause any biological effects, and that it is therefore safe to use for in-house clinical investigations [9].

However, there were some experimental limitations during the in-house, pre-clinical safety evaluation. First, due to the in-house available resources, the acoustic output power $\left(W_{0}\right)$ of the UBM transducer, for the determination of acoustics exposure level $\mathrm{I}_{\text {SATA }}$, was not measured but estimated in worst-case scenario (assuming maximum transducer efficiency). Despite the fact that this (worst-case) value was well below the recommended limit, it is advised to repeat this experiment by measuring $\mathrm{W}_{0}$ conform the requirements of the IEC 60601-2-37, IEC 62359 and IEC 62127-1 standards [13], [21], [22], before a future medical certification procedure is initiated.

Secondly, to improve the efficiency and accuracy of conducted experiments, it is recommended to combine them into one experiment, by using a calibrated hydrophone (was not available in the first experiment) placed in a 3-dimensional (motorized, not manually) positioning system (was not available in the second experiment). With this approach, the acoustic beam pressure profile (instead of the relative reflected intensity) can be measured from which all the discussed safety parameters can be determined at once (conform IEC 62359 and IEC 62127-1 standards).

Next, as stated by the IEC 60601-2-37 standard [13], the thermal index itself was not measured, but its related acoustic parameters were calculated in the experiments. Therefore, to increase the degree of certainty that the UBM is safe and does not cause a rise in tissue temperature, it is advised to demonstrate that there is e.g. no temperature rise in a tissue mimicking (bladder) phantom or at the transducer surface. However, 
when constructed such an experiment, also the influences of the transducer assembly itself should be taking into account, because the transducer surface itself is not in direct contact with the abdominal skin (incorporated into a casing with ultrasound gel in-between the casing and the abdominal skin).

Finally, during the development process of the UBM, the intention was to develop a safe, minimal-invasive and diagnostic device with minimal risk for the patient. By doing so, specifically by keeping the pulse energy and the pulse repetition frequency as low as possible, the ALARA (As Low As Reasonably Achievable) principle was implemented [10], [11], [23].

\section{CONCLUSION}

A new wearable, wireless ultrasonic bladder monitor has been presented and preclinically evaluated in order to determine if it was safe to use (exclusively) for clinical investigations. Related to the IEC 60601-2-37 safety guidelines, experiments were conducted (with the available resources) which concluded that the UBM is not expected to exceed a thermal index of 1.0 and a mechanical index of 1.0. Also, the allowable

exposure levels $\left(\mathrm{I}_{\text {SATA }}\right.$ and $\left.\mathrm{I}_{\text {SPTA.3 }}\right)$ are well below the recommended limits. Therefore, it is concluded that it is highly unlikely for the UBM to cause any biological effects, and that it is therefore safe to use for in-house clinical investigations.

\section{Acknowledgments}

The URIKA Bladder Monitor is the outcome of a so-called Pontes Medical (Utrecht, the Netherlands, www.pontesmedical.com) project which brings technical, clinical and business expertise together to find solutions for medical needs. In this project, the University Medical Centre Utrecht (Utrecht, the Netherlands), specifically the Department of Medical Technology and Clinical Physics, cooperated with Novioscan (Nijmegen, The Netherlands, www.novioscan.com) to develop the first prototype of the URIKA Bladder Monitor to help people with urinary incontinence. The authors would like to thank Pim van den Berg, PhD, who assisted in the construction of second experiment setup for the measurement of the acoustic pressure at the University of Twente (Enschede, The Netherlands).

\section{Conflict of Interest}

The safety evaluation was conducted by a technical physician, P.G. van Leuteren, as a part of his master graduation internship for Technical Medicine (University of Twente, Enschede, The Netherlands) at the department of Pediatric Urology, Wilhelmina Children's Hospital UMC Utrecht (Utrecht, the Netherlands). Currently, P G van Leuteren is an employee of Novioscan. The other authors have no conflict of interest to declare. 


\section{REFERENCES}

1. P. F. Austin et al., "The standardization of terminology of lower urinary tract function in children and adolescents: Update report from the standardization committee of the International Children's Continence Society," Neurourol. Urodyn., vol. 35, no. 4, pp. 471481, 2016. https://doi.org/10.1002/nau.22751

2. NVU, "Richtlijn Urine incontinentie bij kinderen," Richtlijn "Incontinentie bij Kinderen," pp. 1-144, 2008.

3. A. Beauchamp-Parent and M. Sawan, "New reconfigurable ultrasonic enuresis monitoring system," Eng. Med. Biol. Soc., vol. 20, no. 2, pp. 789-792, 1998. https://doi.org/10.1109/ IEMBS.1998.745549

4. M. T. Rise, W. E. Bradley, and D. A. Frohrib, "An Ultrasonic Bladder-Volume Sensor," Trans. Biomed. Eng., vol. BME-26, no. 12, pp. 709-711, 1979. https://doi.org/10.1109/ TBME.1979.326464

5. N. K. Kristiansen, J. C. Djurhuus, and H. Nygaard, "Design and evaluation of an ultrasoundbased bladder volume monitor," Med. Biol. Eng. Comput., vol. 42, pp. 762-769, 2004. https://doi.org/10.1007/bf02345209

6. P. Petrican and M. A. Sawan, "Design of a miniaturized ultrasonic bladder volume monitor and subsequent preliminary evaluation on 41 enuretic patients.," IEEE Trans. Rehabil. Eng., vol. 6, no. 1, pp. 66-74, 1998. https://doi.org/10.1109/86.662622

7. W. E. Bradley, M. T. Rise, and D. L. Frohrib, "Clinical Bladder Use of Biocompatible Volume Ultrasonic Sensor," Urology, vol. 14, no. 3, pp. 300-302, 1979. https://doi.org/10.1016/00904295(79)90510-7

8. P. Palanchon, D. van Loon, C. H. Bangma, and N. Bom, "Bladder volume measurements with a limited number of fixed ultrasound beams.," Ultrasound Med. Biol., vol. 30, no. 3, pp. 289-94, Mar. 2004. https://doi.org/10.1016/j.ultrasmedbio.2003.11.009

9. P. G. van Leuteren, B. A. de Vries, G. C. J. de Joode-Smink, B. ten Haken, T. P. V. M. de Jong, and P. Dik, "URIKA, continuous ultrasound monitoring for the detection of a full bladder in children with dysfunctional voiding: a feasibility study," Biomed. Phys. Eng. Express, vol. 3, no. 1, pp. 1-7, 2017. https://doi.org/10.1088/2057-1976/aa589f

10. K. Maeda and A. Kurjak, "The Safe Use of Diagnostic Ultrasound in Obstetrics and Gynecology," Donald Sch. J. Ultrasound Obstet. Gynecol., vol. 6, no. September, pp. 313317, 2012. https://doi.org/ 10.5005/jp-journals-10009-1254

11. D. L. Miller, "Safety Assurance in Obstetrical Ultrasound," Semin. Ultrasound CT MR, vol. 29, no. 2, pp. 156-164, 2008. https://dx.doi.org/10.1053\%2Fj.sult.2007.12.003

12. F. Ahmadi, I. V McLoughlin, S. Chauhan, and G. Ter-Haar, "Bio-effects and safety of low intensity, low frequency ultrasonic exposure," Prog. Biophys. Mol. Biol., vol. 108, no. 3, pp. 119-38, 2012. https://doi.org/10.1016/j.pbiomolbio.2012.01.004

13. IEC 60601-2-37:2007 - Medical electrical equipment - Part 2-37: Particular requirements for the basic safety and essential performance of ultrasonic medical diagnostic and monitoring equipment. 2008.

14. F. J. Fry, G. Kossoff, R. C. Eggleton, and F. Dunn, "Threshold ultrasonic dosages for structural changes in the mammalian brain.," J. Acoust. Soc. Am., vol. 48, no. May 1970, p. Suppl 2:1413+, 1970. https://doi.org/10.1121/1.1912301

15. K. Wolf and F. Fobbe, "Color-coded duplex sonography: principles and clinical applications," New York: Thieme Medical Publishers, 1994, pp. 16-18. 
16. T. A. Bigelow et al., "The Thermal Index: Its Strengths, Weaknesses, and Proposed Improvements.," J. Ultrasound Med., vol. 30, pp. 714-734, 2011. https://doi.org/10.7863/ jum.2011.30.5.714

17. G. ter Haar, The Safe Use of Ultrasound in Medical Diagnosis, 3rd ed. London: British Institute of Radiology, 2012.

18. FDA, "Information for Manufacturers Seeking Marketing Clearance of Diagnostic Ultrasound Systems and Transducers," U.S. FDA, Rockville, MD., 2008.

19. P. A. Lewin and M. C. Ziskin, Ultrasonic Exposimetry. 1992.

20. W. D. Ulrich, "Ultrasound dosage for nontherapeutic use on human beings - extrapolations from a literature survey," IEEE Trans. Biomed. Eng., vol. 21, pp. 48-51, 1974. https://doi. org/10.1109/TBME.1974.324362

21. IEC 62359:2010/AMD1:2017 - Amendment 1 - Ultrasonics - Field characterization - Test methods for the determination of thermal and mechanical indices related to medical diagnostic ultrasonic fields.

22. IEC 62127-1:2007/AMD1:2013 - Ultrasonics - Hydrophones - Part 1: Measurement and characterization of medical ultrasonic fields up to $40 \mathrm{MHz}$.

23. D. J. Dowsett, P. A. Kenny, and R. E. Johnston, The Physics of Diagnostic Imaging Second Edition. Boca Raton: CRC Press, 2006. 



\section{URIKA: continuous ultrasound monitoring for the detection of a full bladder in children with dysfunctional voiding - a feasibility study}

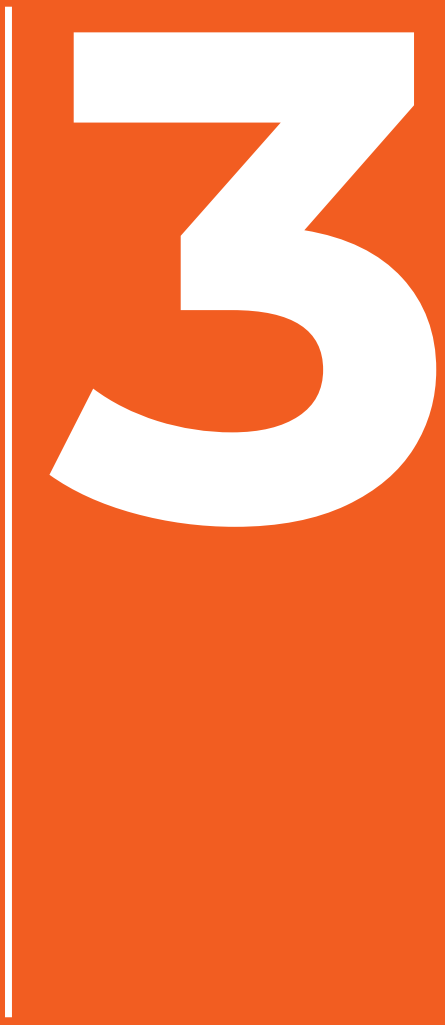

Paul G. van Leuteren Bas A. de Vries Gerrie C.J. de Joode-Smink Bennie ten Haken Tom P.V.M. de Jong Pieter Dik 


\section{ABSTRACT}

Objectives: To assess the feasibility of a new wearable, wireless ultrasonic device, the URIKA Bladder Monitor (UBM), in the detection of a full bladder in children with dysfunctional voiding (DV).

Methods: This observational study included 14 children with DV who were subjected to an UBM monitoring session of 1.5-2 hours. Transabdominal ultrasound (TUS) images were made as reference. The UBM measured the anterior-posterior bladder dimension by an ultrasound transducer, mounted in an elastic belt around the lower abdomen. Level of agreement between both methods was estimated by Bland-Altman analysis. Receiver Operating Characteristics (ROC) analysis was performed to determine a full bladder threshold for the studied population.

Results: In 13 out of 14 patients, the UBM measured properly. Maximum bladder dimensions detected by the UBM and TUS were $6.69 \pm 1.53 \mathrm{~cm}$ and $4.79 \pm 0.99 \mathrm{~cm}$ respectively. Bland-Altman analysis showed a negative bias of $-0.90 \mathrm{~cm}$ (limits of agreement: $-4.1 /+2.3 \mathrm{~cm}$ ). ROC analysis resulted in a sensitivity and specificity of $78.3 \%$ and $100 \%$, for a bladder dimension threshold of $5.03 \mathrm{~cm}$. When this threshold was implemented a priori, the full bladder detection rate would have been $71 \%$. In children younger than 10 years, this would be $100 \%(n=5)$.

Conclusion: The UBM is able to detect a full bladder with a detection rate of $71 \%$, if a $5.03 \mathrm{~cm}$ threshold would be implemented. In patients younger than 10 years, the detection rate would be $100 \%$. Future research will focus on increasing the UBM's accuracy and investigating the effect of UBM alarm treatment in children with urinary incontinence. 


\section{INTRODUCTION}

Urinary incontinence (UI) is a common problem in children [1]. The prevalence of $\mathrm{UI}$ in children between the age of 6-10 years, equals 6-9\% [2]. It is important to treat UI effectively, because of the major social impact on the child's quality of life. Children rated 'wetting their pants in class' repeatedly in the top 5 of most stressful life events between 'losing my mother or father' or 'going blind' [3], [4]. Dysfunctional voiding (DV) is a form of lower urinary tract dysfunction resulting in recurrent urinary tract infections and/or UI. DV refers to children who habitually contract the external urethral sphincter or pelvic floor during the voiding phase, resulting in a staccato or interrupted uroflow pattern [5][6]. DV is often experienced simultaneously with other storage or bladder filling symptoms, such as postponing micturition resulting in a sudden, unexpected need to void [5], [7]. The current non-pharmacological treatment options for these children are behavioral alarm treatment (clockwise voiding), cognitive treatment and pelvic floor exercises [6]. These treatments aim to improve bladder control by neglecting the full bladder and instead, void at preselected times [8]. Behavioral alarm treatment is based on the concept of negative reinforcement, in which the child responds to an alarm alerting urinary leakage by contracting the pelvic floor muscles which will avoid setting of the alarm [9]. It is suggested that positive reinforcement, by alarming the patient when the bladder is at near maximum capacity, would increase the effectiveness of the current treatment options [10]. Possible devices that are clinically used to determine the full bladder volume are conventional B-mode ultrasound and the BladderScan ${ }^{\circledR}$ (Verathon Inc., Bothell, WA). However, these systems are not able to alarm the patient of having a full bladder prior to micturition. Furthermore, each individual measurement requires actions by a trained professional and also the size of these systems is not optimal for continuous monitoring, especially in children. Small, wearable bladder monitors to automatically detect a full bladder have been developed in the past [10][13]. These systems were based on a single-element ultrasound transducer which detected the posterior bladder wall, when it rose above the symphysis pubis [14]. However, these systems were not clinically evaluated during natural bladder filling or used in children for prolonged periods. None of these systems made their way to the daily clinical practice.

In this study, a new wearable, wireless ultrasonic monitor, the URIKA Bladder Monitor (UBM) has been developed. This device automatically estimates the anterior - posterior (A-P) bladder dimension. When the A-P bladder dimension exceeds a critical threshold, the patient will be alarmed of a full bladder. With this positive feedback system, it is hypothesized that both the awareness of the bladder filling and the effectiveness of present treatment options will increase. In this feasibility study, the UBM is primarily used for observational purposes to measure changes in A-P bladder dimensions over time. The aim of this study was to estimate an alarm threshold and to determine the full bladder detection rate of the UBM in a study population of children with DV. 


\section{MATERIALS AND METHODS}

The UBM is an ambulatory A-mode based ultrasonic device, which transmits ultrasound pulses in the direction of the bladder. The UBM consists of two main parts: a transducer assembly and electronic case (Figure 3.1).

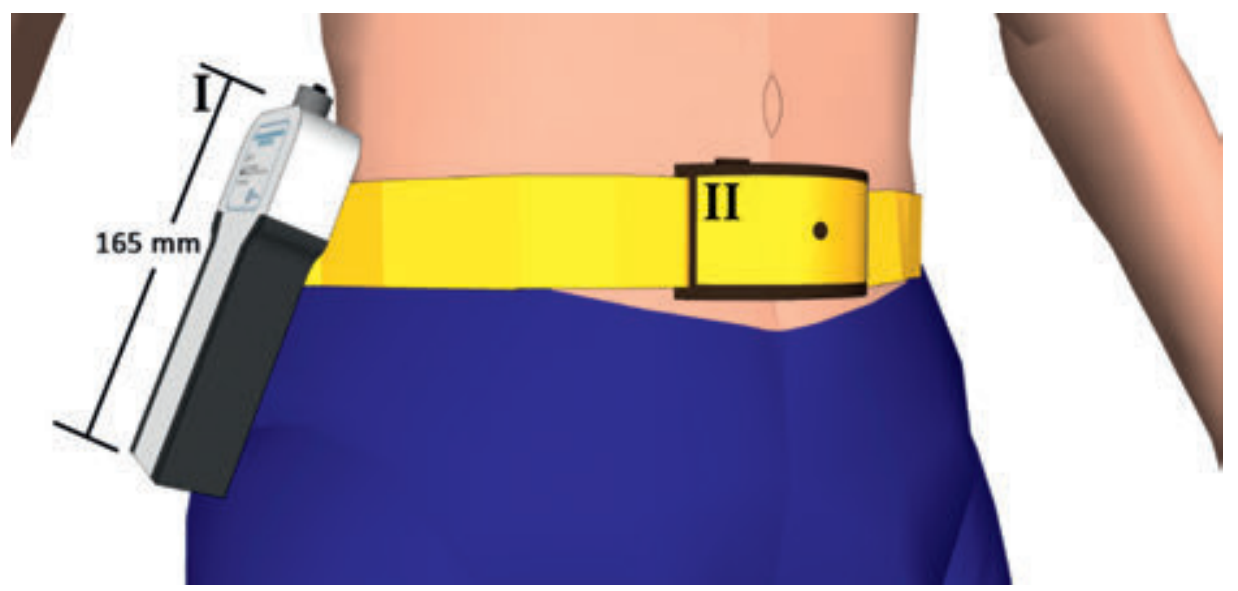

Figure 3.1: The electronic case (I) and the transducer assembly (II) of the UBM. In the centre of the assembly (II), the single - element transducer is positioned.

First, the transducer assembly $(90 \times 72 \times 21 \mathrm{~mm})$ contains a single-element, $3.81 \mathrm{MHz}$ ultrasound transducer (at a $0^{\circ}$ angle) with an active diameter of $19 \mathrm{~mm}$. The combination of this acoustic frequency and active diameter results in a near field length of $23 \mathrm{~cm}$, which is deep enough to detect the posterior wall of the urinary bladder [15], [16]. The transducer assembly is positioned perpendicular to the skin between the symphysis pubis and the umbilicus with a belt. To minimize acoustic interference with air, a liquid coupling gel is used.

Next, the electronic case is connected with a short cable to the transducer assembly, which can be fixed to the elastic belt on the hip side. The electronic case $(165 \times 80 \times 28$ $\mathrm{mm}$ ) consists of a printed circuit board (PCB), two AA-batteries and a micro-SD card. Figure 3.2 illustrates a simplified diagram of the UBM's architecture. The PCB consists of an analogue and a digital part. The analogue part contains a high voltage (HV) generator which charges a capacitor (C) of $10 \mathrm{nF}$ (red box in Figure 3.2). The capacitor is discharged by the pulse forming network (S) to excite the ultrasound transducer $(\mathrm{X})$, generating a sound wave at a frequency of $3.81 \mathrm{MHz}$ with a duration of $0.13 \mu \mathrm{s}$. $A$ radiofrequency (RF) receiver processes the returning ultrasound reflections of the anterior - and posterior bladder walls, which are amplified by a variable gain amplifier for attenuation compensation. 


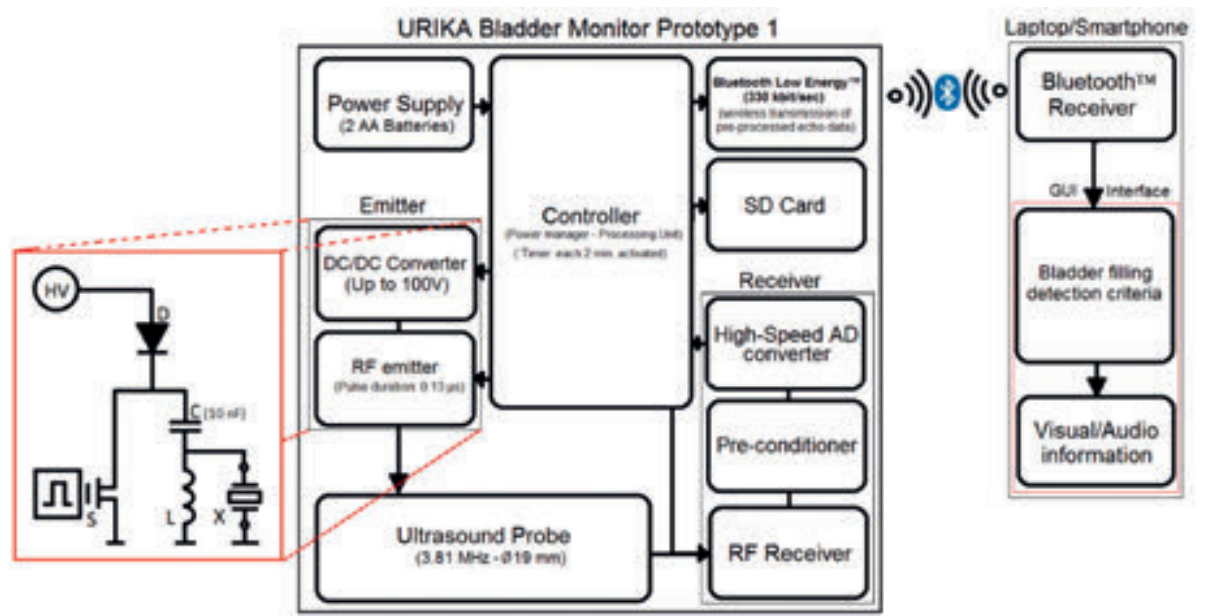

Figure 3.2: Diagram of the internal electronic structure - Red box: circuit for discharge of a 10 $\mathrm{nF}$ capacitor (C) for generation of a high-voltage (HV) pulse (S) to the transducer (X).

The received digital data is stored in a memory, which is controlled by a complex programmable logic device (CPLD). The stored data can be uploaded to a PC for visual inspection through a low energy wireless link (Bluetooth ${ }^{\circledast}$ ). Furthermore, the digital data is transferred to the internal micro-SD card for off-line evaluation. The distance between the anterior - and posterior bladder wall is calculated through a software algorithm installed on a laptop or smartphone. First, the raw data is pre-processed by applying a low-pass filter to detect the envelope of the signal and to minimize the influence of noise. Next, a threshold value was calculated by adding the minimum value of the signal to its standard deviation [17]. The position of the anterior wall is detected when the first time-sample of the envelope is below the threshold value (for an axial depth $>0.5$ $\mathrm{cm}$ ). Secondly, the posterior wall is detected when the next consecutive time-sample exceeds the threshold value [17]. The time difference between the recorded reflections of both bladder walls $(\Delta t)$ is transposed to an estimated A-P bladder dimension, based on a speed of sound (c) in urine of $1540 \mathrm{~m} \cdot \mathrm{s}^{-1}$ (Eq. 1).

$$
\text { A-P bladder dimension }=\frac{c \cdot \Delta t}{2}
$$

Figure 3.3 shows a received signal of a full bladder from one of the patients. 


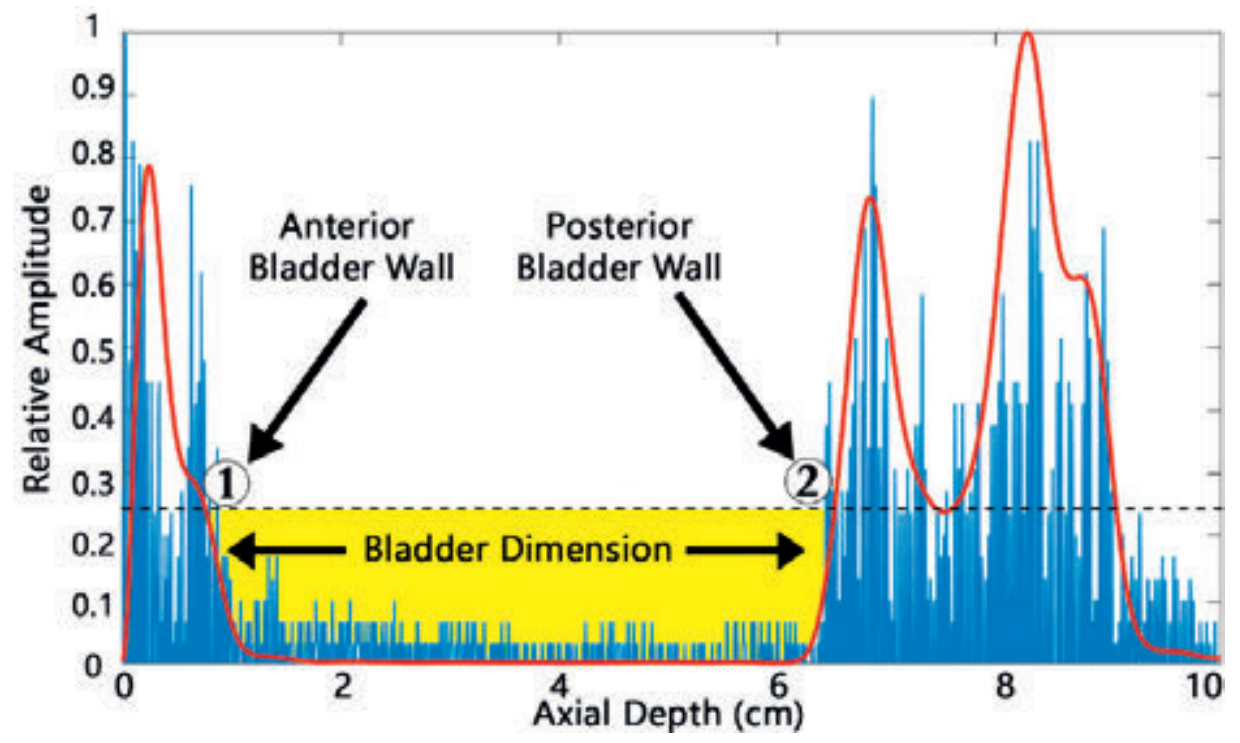

Figure 3.3: The normalized raw data (blue) and the envelope data (red) of a full bladder in patient 2. The axial position of the anterior (1) - and posterior (2) wall of the bladder are found by comparing the filtered echo to the detection threshold (horizontal, broken line). When the amplitude exceeds the threshold, the position of the bladder walls are found.

\section{Experimental protocol}

To evaluate the UBM, a feasibility study for the UBM was conducted in a group of children with DV who were scheduled for clinical bladder training at the department of Pediatric Urology. After approval from the Local Ethical Committee of the University Medical Centre Utrecht, written informed consent was obtained. Children were included between the ages of 6 and 12 years with a positive diagnosis for DV, based on their patient history and repeated staccato uroflow measurements [6]. Patients with a history of constipation and a transverse rectum diameter of more than $35 \mathrm{~mm}$, measured by ultrasonography, were excluded. An enlarged rectum will displace the posterior wall of the bladder, which will influence the detection of the A-P bladder dimension [18].

At study entrance, the patients presented on the ward and an initial transabdominal ultrasound image (TUS) of the bladder was obtained. For TUS, conventional $4 \mathrm{MHz}$ convex probe (Philips Medical Systems HD11 XE) was applied to the lower abdomen above the symphysis with the patient lying supine, corresponding to standard clinical practice. By using the digital calliper system, the A-P bladder dimension was measured by the researcher. Next, the UBM was placed on the abdomen of the patient recording the A-P bladder dimension every 2 minutes. As a reference, TUS of the bladder was performed every half hour to monitor the A-P bladder dimension. When the patient felt the urge to void, TUS was performed before and after micturition. To minimize the 
impact of the study procedure on the bladder training, the patients were free to move around while wearing the UBM.

The measured A-P bladder dimensions were analyzed by descriptive statistics, calculating the maximum and standard deviation, which will serve as an indication for the future alarm threshold. To determine the level of agreement between the UBM and TUS, Bland-Altman analysis was performed. Due to the same transducer position of the UBM and the TUS probe, it was not possible to record the bladder dimension for both methods simultaneously. For this reason, the calculated A-P bladder dimensions of the UBM were averaged, using the data before and after TUS. But in case the UBM was repositioned too high on the abdomen after TUS, the UBM measured above the superior dome of the bladder. As a result, the A-P bladder dimension could not be detected. In this situation, only one measurement was used for the Bland-Altman analysis.

To determine a full bladder alarm threshold for the UBM, a Receiver Operating Characteristics (ROC) analysis was performed. In the ROC analysis, the UBM was compared to TUS, calculating sensitivity, specificity and the Area Under the Curve (AUC). Based on the estimated full bladder alarm threshold, the full bladder detection rate will be determined.

\section{RESULTS}

A total of 14 patients (12 girls, 2 boys) [mean age: $9.2 \pm 1.8$ years] have been enrolled in this study. With a sample size of 14 patients, it is possible to estimate a full bladder detection rate of $85 \%$ within a $90 \%$ confidence interval of $\pm 15 \%$, which is considered to be acceptable in this first feasibility study [19]. Before conducting descriptive analysis, the first patient was excluded due to an internal malfunction of the UBM. Furthermore, UBM data was excluded when the bladder was temporarily out of the detection range due to incorrect repositioning. When the bladder was out of range, a measurement error of less than one centimeter was found corresponding to the abdominal wall thickness. For this reason, all calculated A-P bladder dimension values below $1 \mathrm{~cm}$ were excluded.

\section{Level of Agreement}

In this study population, the UBM measured a higher maximum ( \pm SD) A-P bladder dimension compared to TUS, respectively $6.69 \pm 1.53 \mathrm{~cm}$ and $4.79 \pm 0.99 \mathrm{~cm}$. This trend is illustrated by Figure $\mathbf{3 . 4}$ which presents the changes in A-P bladder dimension over time, measured by the UBM and TUS. Despite this difference, both the UBM and TUS were able to estimate the filling status and detect a full bladder. Also, the decrease in A-P bladder dimension around the time of micturition is visible.

Figure 3.5A represents the results of the Bland-Altman analysis, resulting in a mean difference (d) between both methods equal to $-0.90 \mathrm{~cm}$. This also states that the UBM tends to measure a higher A-P bladder dimension compared to TUS. The limits of agreement were equal to -4.1 and $+2.3 \mathrm{~cm}$. 


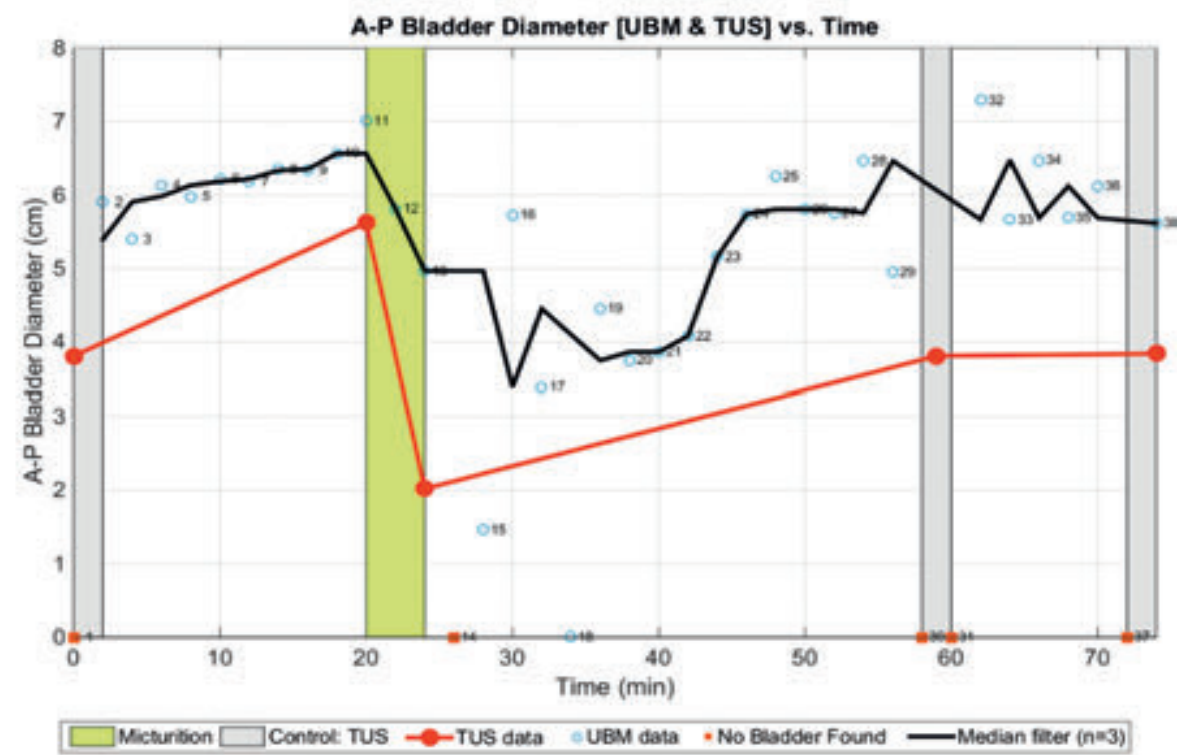

Figure 3.4: Results of a 7 year old girl showing a correlation between the bladder filling and the estimated bladder dimension over time, for the UBM and TUS. Yellow area: Period of micturition (residue present), grey area: period of transabdominal ultrasound.

\section{Alarm Threshold}

The table in Figure 3.5B reports the results of the ROC analysis of the UBM, for a range of TUS cut-off values of $3-5 \mathrm{~cm}$. It is noted that the highest specificity (1.00) and AUC (0.90) are found for a TUS cut-off value of $3.5 \mathrm{~cm}$, which is related to an UBM alarm threshold of $5.03 \mathrm{~cm}$. Figure 3.5B visualizes the corresponding ROC curve.

In this study, 17 periods of micturition were reported: five patients voided twice, one patient did not void and the remaining seven children all voided once. In 12 out of 17 times, the A-P bladder dimension of a full bladder, prior to micturition, exceeded the alarm threshold of $5.03 \mathrm{~cm}$, which corresponds to a detection rate of $71 \%$. In the five patients who voided twice, the UBM detected a full bladder in 8 out of 10 times (detection rate: $80 \%$ ).

In three patients, it was not possible to detect a full bladder based on this threshold. In one patient, the full bladder was detected once, instead of the two times it was full. Comparing these four patients to the remaining population, showed that the mean age of these four patients was higher (10.7 \pm 1.0 years) compared to the other subjects ( 8.9 \pm 1.6 years). When considering the patients younger than 10 years, it was possible to detect a full bladder in all patients $(n=5)$. 


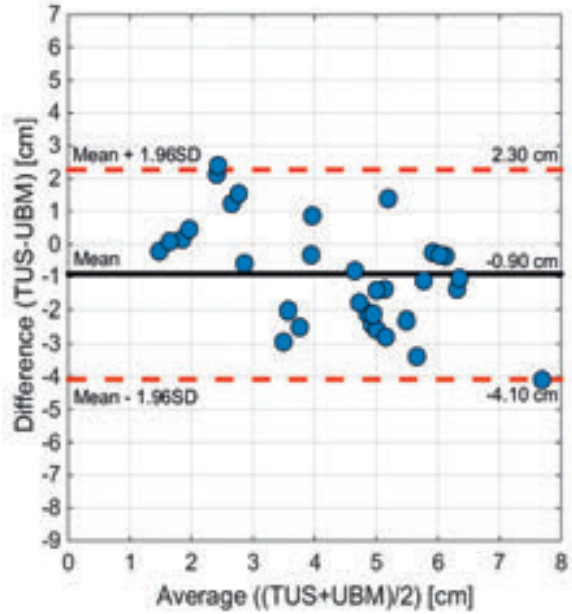

Figure 3.5A: Bland-Altman plot of estimated A-P bladder dimensions by the UBM and TUS.

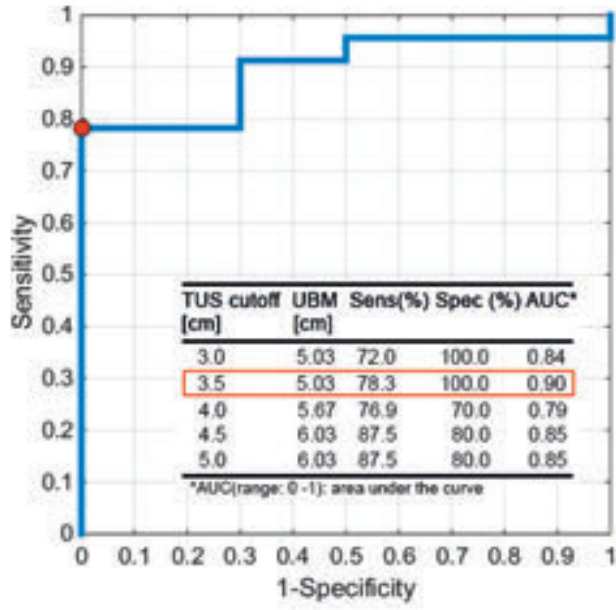

Figure 3.5B: ROC curve for TUS $>3.5 \mathrm{~cm}$, and the corresponding sensitivity, specificity and AUC values (TUS-cut-off values: $3-5 \mathrm{~cm}$ ). The red dot indicate the curve value at highest accuracy.

\section{DISCUSSION}

The purpose of this feasibility study was to determine the full bladder detection rate and the detection precision of the UBM, in a study population of children with DV. Comparing the results of the UBM and TUS showed that there is a discrepancy between these two methods. The estimated A-P bladder dimensions for the TUS were smaller compared to the UBM. This trend was also visible in the Bland-Altman analysis, resulting in a mean negative difference and the wide limits of agreement. This is partly caused by the postural position of the patient. The UBM measured the patients mostly in upright - or sitting position, while TUS was performed in supine position. Gould et al. [20] showed that there is a two - to threefold rise in bladder pressure when tipping a subject from a supine to an upright position, due to the weight of the abdominal organs. Due to the pressure increase, the bladder expands in the A-P dimension and reduces in height. Kirchleitner et al. [21] also showed that the A-P dimension of the bladder increases when changing from a seated to an upright position. Due to the difference in posture between both detection methods, TUS showed smaller A-P bladder dimensions compared to the UBM. This level of influence was higher than initially expected.

Furthermore, the accuracy is also influenced by movement of the transducer belt. Despite repositioning of the UBM after TUS, intermittent movement of the child resulted in an upwards movement of the UBM, only estimating the superior dome of the bladder. As a result, the A-P bladder dimension is smaller than the present maximum dimension, which results in a positive limit of agreement (Figure 3.5A). Furthermore, upwards 
movement could also cause loss of contact or air interference between the UBM and the skin, resulting in a dimension value equal to zero.

\section{Alarm Threshold}

Despite the previous factors of influence, the UBM alarm threshold of $5.03 \mathrm{~cm}$, resulted in an AUC of 0.90 , a sensitivity of $78.3 \%$ and a specificity of $100 \%$. When this threshold would have been implemented as an alarm a priori, a detection rate of $71 \%$ should have been found in the studied population. In four patients, the maximum A-P bladder dimension did not exceed this threshold prior to micturition. It was noted that these four patients were all familiar with a relative small bladder capacity combined with the diagnosis of DV [22]. For these four patients, the maximum voided volume during behavioral bladder training varied between 107-254 cc, compared to the age-expected volume of 330-390 cc [6]. Due to a small bladder volume for age, the bladder can be easily situated out of the UBM detection range. Furthermore, these four patients were relatively older, compared to the remaining population. In children, the bladder is considered to be abdominal organ, positioned between the pubic bone and the umbilicus. In general, the bladder can be detected with a transducer in a perpendicular position relative to the abdominal wall. When a child grows older, the full bladder is situated somewhat lower within the small pelvis, behind the pubic bone [13]. Therefore, the bladder is more difficult to detect with an ultrasound transducer positioned perpendicular to the abdominal wall [13]. In combination with a relatively obese abdomen in upright position, the UBM transducer orientation changed in a more upward direction measuring in the plane above the bladder, which resulted in a lower detection rate [13].

Due to differences in the expected - and actual bladder capacities found in the studied population, we advise to set the threshold of $5.03 \mathrm{~cm}$ merely as an initial threshold. To optimize the UBM for each individual patient, the healthcare specialists (e.g. urologists, urotherapists) are advised to measure the child's maximum A-P bladder dimension in supine position before micturition, by means of TUS [15]. The UBM threshold can be adjusted by adding the mean difference $(\mathrm{d}=0.90 \mathrm{~cm})$ to the measured TUS value.

\section{Future research}

Future research will focus on redesigning the current UBM model and adjusting the alarm algorithm to increase the UBM's stability and detection rate. First, the UBM will be combined with an adhesive silicone coupling layer, which will fixate the transducer to the skin which prevents upwards movement. Secondly, to increase the detection rate in older patients, multiple transducers will be implemented at an angle $0-30^{\circ}$ pointing downwards into the pelvic region [15], [23]. Furthermore, a body position sensor will be installed to change the alarm threshold in respect to body position. Finally, in order to personalize the UBM, an adaptive algorithm will be developed, which will adjust the alarm threshold based on the maximum A-P bladder dimensions previously detected 
before micturition. When these conditions are met, the focus will be on the clinical evaluation of this new volume-based alarm. In the near future, we hope to prove that this device will be a useful product, supporting biofeedback treatment of children with lower urinary tract symptoms (LUTS).

\section{CONCLUSION}

This article described the URIKA Bladder Monitor, which is developed to detect a full bladder and alarm the user before micturition. In the studied population, the UBM was able to detect a full bladder with a proper sensitivity, specificity and detection rate. For children younger than 10 years, it was possible to detect a full bladder in all patients. Future research will focus on increasing the accuracy of the UBM and investigating the effect of positive alarm treatment by the UBM.

\section{Acknowledgements}

This work was supported by Pontes Medical (Utrecht, The Netherlands, www. pontesmedical.com), Novioscan (Nijmegen, The Netherlands, www.novioscan.nl) and the Dutch Technology Foundation STW (Utrecht, The Netherlands). The authors would like to thank all the pediatric urologists, nurse practitioners and urotherapists at the department of Pediatric Urology in the Wilhelmina Children's Hospital (Utrecht, The Netherlands) for their help in the recruitment of the patients. They thank the department of Medical Technology and Clinical Physics (University Medical Centre Utrecht, Utrecht, The Netherlands) for their help and advice in the design and development process of the UBM.

\section{Conflict of Interest}

This feasibility study was performed by P.G. van Leuteren, as a part of his master graduation internship for Technical Medicine (University of Twente, Enschede, The Netherlands) at the department of Pediatric Urology. Currently, P.G. van Leuteren is an employee of Novioscan BV. The other authors have no conflict of interest to declare. 


\section{REFERENCES}

1. A. J. Schaeffer and D. A. Diamond, "Pediatric urinary incontinence: Classification, evaluation, and management," African J. Urol., vol. 20, no. 1, pp. 1-13, Mar. 2014. https://doi. org/10.1016/j.afju.2013.10.001

2. Nederlandse Vereniging voor Urologie (NVU), Nederlandse Vereniging voor Kindergeneeskunde (NVK), Vereniging van Nederlandse Incontinentie Verpleegkundigen (CV\&V), Richtlijn: Incontinentie bij kinderen, 2010. pp 1-144.

3. K. Yamamoto, O. L. Davis, S. Dylak, J. Whittaker, C. Marsh, and P. C. van der Westhuizen, "Across six nations: stressful events in the lives of children.," Child Psychiatry Hum. Dev., vol. 26, no. 3, pp. 139-50, Jan. 1996. https://doi.org/10.1007/BF02353355

4. K. Yamamoto, J. Whittaker, and O. L. Davis, "Stressful Events in the Lives of UK Children: a glimpse," Educ. Stud., vol. 24, no. 3, pp. 305-314, Nov. 1998. https://doi. org/10.1080/0305569980240304

5. J. F. Koenig and P. H. McKenna, "Biofeedback Therapy for Dysfunctional Voiding in Children," Curr. Urol. Rep., vol. 12, no. 2, pp. 144-152, 2011. https://doi.org/10.1007/s11934-0100166-9

6. T. Nevéus, A. von Gontard, P. Hoebeke, K. Hjälmås, S. Bauer, W. Bower, T. M. Jørgensen, S. Rittig, J. Vande Walle, C.-K. Yeung, and J. C. Djurhuus, "The standardization of terminology of lower urinary tract function in children and adolescents: report from the Standardisation Committee of the International Children's Continence Society.," J. Urol., vol. 176, no. 1, pp. 314-24, Jul. 2006. https://doi.org/10.1016/S0022-5347(06)00305-3

7. I. Franco, "Functional Bladder Problems in Children," Pediatr. Clin. North Am., vol. 59, no. 4, pp. 783-817, 2012. https://doi.org/10.1016/j.pcl.2012.05.007

8. D. Schultz-Lampel, C. Steuber, P. F. Hoyer, C. J. Bachmann, D. Marschall-Kehrel, and H. Bachmann, "Urinary incontinence in children.," Dtsch. Arztebl. Int., vol. 108, no. 37, pp. 613-20, Sep. 2011. https://doi.org/10.3238/arztebl.2011.0613

9. R. F. Pereira, E. F. M. Silvares, and P. F. Braga, "Behavioral alarm treatment for nocturnal enuresis," Int. Braz J Urol, vol. 36, no. 3, pp. 332-338, 2010. https://doi.org/10.1590/S167755382010000300010

10. R. A. Pretlow, "Treatment of nocturnal enuresis with an ultrasound bladder volume controlled alarm device," in Journal of Urology, 1999, vol. 162, no. 3 II, pp. 1224-1228. https://doi.org/10.1016/S0022-5347(01)68141-2

11. W. E. Bradley, M. T. Rise, and D. L. Frohrib, "Clinical Bladder Use of Biocompatible Volume Ultrasonic Sensor," Urology, vol. 14, no. 3, pp. 300-302, 1979. https://doi.org/10.1016/00904295(79)90510-7

12. M. T. Rise, W. E. Bradley, and D. A. Frohrib, "An Ultrasonic Bladder-Volume Sensor," Trans. Biomed. Eng., vol. BME-26, no. 12, pp. 709-711, 1979. https://doi.org/10.1109/ TBME.1979.326464

13. P. Petrican and M. A. Sawan, "Design of a miniaturized ultrasonic bladder volume monitor and subsequent preliminary evaluation on 41 enuretic patients.," IEEE Trans. Rehabil. Eng., vol. 6, no. 1, pp. 66-74, Mar. 1998. https://doi.org/10.1109/86.662622

14. N. K. Kristiansen, H. Nygaard, and J. C. Djurhuus, "Clinical evaluation of a novel ultrasoundbased bladder volume monitor.," Scand. J. Urol. Nephrol., vol. 39, no. 4, pp. 321-8, Jan. 2005. https://doi.org/10.1080/00365590510031165 
15. A. Beauchamp-Parent and M. Sawan, "New reconfigurable ultrasonic enuresis monitoring system," Eng. Med. Biol. Soc., vol. 20, no. 2, pp. 789-792, 1998, https://doi.org/10.1109/ IEMBS.1998.745549

16. W. D. O'Brien Jr, "AAPM Tutorial - Single-element Transducers," RadioGraphics, vol. 13, no. 4, pp. 947-957, 1993. https://doi.org/10.1148/radiographics.13.4.8356282

17. D. Ganguly and D. Giuliani, "Apparatus and Method for Non-Invasively and Automatically Measuring The Volume of Urine in a Human Bladder.," 4,926,871, 1990.

18. A. J. Klijn, M. Asselman, M. A. W. Vijverberg, P. Dik, and T. P. V. M. de Jong, "the Diameter of the Rectum on Ultrasonography As a Diagnostic Tool for Constipation in Children With Dysfunctional Voiding," J. Urol., vol. 172, no. 5, pp. 1986-1988, Nov. 2004. https://doi. org/10.1097/01.ju.0000142686.09532.46

19. C. Moore and R. Carter, "Recommendations for planning pilot studies in clinical and translational research," Clin. Transl. Sci., vol. 4, no. 5, pp. 332-337, 2011. https://doi. org/10.1111/j.1752-8062.2011.00347.x

20. D. W. Gould, A. C. L. Hsieh, and L. F. Tinckler, "The effect of posture on bladder pressure," J. Physiol., vol. 129, no. 3, pp. 448-453, 1955. https://doi.org/10.1113/jphysiol.1955.sp005369

21. D. Kirchleitner, M. Roth, H. Wassermann, and D. Jocham, "Investigation of bladder deformability within the development process of the artificial urinary diversion system - a pilot study," Int. J. Artif. Organs, vol. 34, no. 12, pp. 1147-1154, 2011. https://doi. org/10.5301\%2Fijao.5000016

22. K. Bro, B. Berghmans, S. Morkved, and M. Van Kampen, "Voiding Dysfunction," in EvidenceBased Physical Therapy for the Pelvic Floor: Bridging Science and Clinical Practice, 2014, p. 356.

23. P. Palanchon, D. van Loon, C. H. Bangma, and N. Bom, "Bladder volume measurements with a limited number of fixed ultrasound beams.," Ultrasound Med. Biol., vol. 30, no. 3, pp. 289-94, Mar. 2004. https://doi.org/10.1016/j.ultrasmedbio.2003.11.009 



\section{SENS-U: validation of a wearable ultrasonic bladder monitor in children during urodynamic studies}

J Pediatr Urol. 2018;14(6): 569.e1-569.e6

Paul G. van Leuteren

Aart J. Klijn

Tom P.V.M. de Jong

Pieter Dik

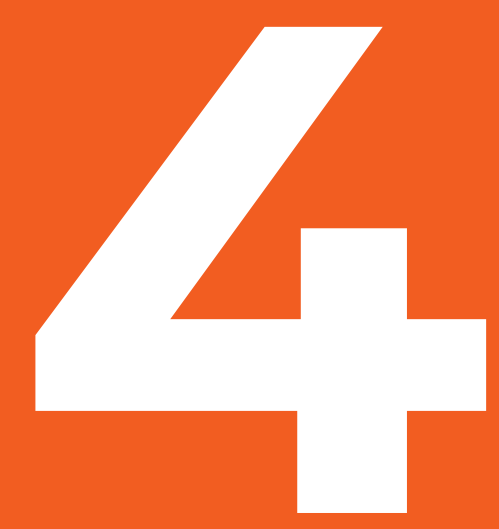




\section{SUMMARY}

Purpose: Urinary incontinence is a common problem in school-age children. Because many children remain unaware of a full-bladder sensation, the SENS-U Bladder Sensor was developed. The SENS-U is a small, wearable ultrasound sensor, which is positioned on the lower abdomen using a skin-friendly adhesive. The sensor continuously estimates the bladder filling status and informs the user when it is time to go to the toilet. In this study, the clinical performance of the SENS-U is evaluated in children during (video) urodynamics.

Material and Methods: In this study, 30 children (6-12 years) were included who were scheduled for a (video) urodynamic study. During urodynamics, the SENS-U determined the average anterior - posterior ( $A-P$ ) bladder dimension (every $30 \mathrm{~s}$ ) to estimate the filling status. The correlation between the average A-P bladder dimension and the infused volume is analyzed by Spearman's correlation.

Results: Thirty patients (boys/girls: 15/15; mean age: $7.9 \pm 1.4$ years) were included, in whom the SENS-U detected the full bladder before voiding in $90 \%$ of the patients (27/30). In the other patients, the bladder was outside the detection area due to either erroneous sensor placement $(n=1)$ or an (relative) obese abdomen in the upright position $(n=2)$. There was a strong correlation (median $\left.r_{s}=0.94\right)$ between the average A-P bladder dimension and the infused volume. The detectable maximum bladder volume ranged between 71-463 $\mathrm{ml}$.

Conclusion: The SENS-U is able to detect a full bladder with a success rate of $90 \%$. When excluding erroneous data due to sensor misplacement or an (relative) obese abdomen, the detection rate may even be higher. Future research will focus on investigating the effect of the SENS-U in incontinence training. 


\section{INTRODUCTION}

Pediatric urinary incontinence (UI) is a common disorder in children of all ages [1]. At school-age (6-10 years), the prevalence of UI equals 6-9\%, gradually diminishing to an average of $2 \%$ at the age of 12 [2]. Adequate treatment of UI is important because it deeply affects both the child and his/her family socially, emotionally, and behaviorally [3]. In general, initial treatment focusses on achieving initial dryness by following a timed schedule for drinking and voiding [4]. Then, treatment may include pharmacotherapy (e.g. anticholinergics), pelvic floor exercises, and biofeedback (i.e. enhancing pelvic floor awareness by using uroflow pattern, auditory stimulus, or non-invasive abdominal or perineal electromyography (EMG) [5]), either combined or stand alone [4]. Despite promising results, many children do not respond to current treatment options and are no longer aware that UI occurs, resulting in wet pants [6]. Pretlow (1999) hypothesized that receiving a notification a short time before micturition may contribute to a more effective treatment by appropriate classic conditioning [7]. To increase the level of full-bladder awareness, the development of a belt-based, non-invasive ultrasonic bladder monitor, which continuously estimated the bladder filling status, based on the changes in anterior-posterior (A-P) bladder dimension over time, was initiated [8]. The first prototype consisted of a (single element at $0^{\circ}$ ) transducer assembly connected to an electronic case, which were both mounted on an elastic belt around the lower abdomen of the patient. When the bladder capacity was at near maximum and the bladder dimension exceeded a preset threshold, the child could be notified of a full bladder [8]. The initial in vivo evaluation in children with dysfunctional voiding demonstrated that this device was able to detect a full bladder before micturition with a detection rate of $71 \%$. In children younger than 10 years, the detection rate was equal to $100 \%$ [8]. However, the evaluation also stated that intermittent movement of the transducer belt and a small detection area influenced the accuracy of the device [8]. Especially for children older than 10 years, in whom the bladder is situated lower within the small pelvic, and for children with a smaller-than age-expected bladder capacity, the detection area was too small. These results led to the development of the miniaturized SENS-U Bladder Sensor (SENS-U). To prevent transducer movement, the ultrasonic transducer(s) and accompanying electronics were integrated into one device and fixated on the lower abdomen using a skin-friendly adhesive. Furthermore, the detection area of the sensor was adjusted to a field of view of $30^{\circ}$.

In this feasibility study, the performance of the SENS-U Bladder Sensor is clinically evaluated over a broad range of bladder volumes in children during (video) urodynamic evaluation. The aim of the study was to determine the full-bladder detection rate and the measurable bladder volume range. 


\section{MATERIALS AND METHODS}

The SENS-U is a small, wearable, wireless, battery-operated ultrasound device (95x55×16 mm) that is fixated on the lower abdomen using a double-sided adhesive, in combination with standard ultrasound gel (Figure 4.1). The SENS-U is based on a combination of four ultrasonic transducers within a field of view (FOV) of $30^{\circ}$, which transmits ultrasound waves in the direction of the bladder perpendicular to the abdominal wall. The internal firmware of the SENS-U automatically determines the axial position of the anterior (AW) and posterior (PW) bladder wall, by comparing the received ultrasound reflection (for each transducer) with a threshold based on the maximum amplitude of the reflection. The A-P bladder dimension is defined as the difference between the axial positions of both bladder walls. Then, the average A-P bladder dimension $(\mathrm{mm})$ is determined based on the A-P bladder dimensions measured by the four individual transducers. By calculating the average A-P bladder dimensions (within a field of view of $30^{\circ}$ ), the height of the bladder is measured indirectly, resulting in an estimated sagittal cross section of the (infused) bladder volume. Based on an individualized preset threshold for the average A-P bladder dimension, the personal bladder filling status is determined.

The SENS-U uses Bluetooth ${ }^{\circledR}$ Low Energy to transmit this real-time information to a specially designed application on the user's smartphone (Figure 4.1). With the help of changing weather symbols, the child is kept informed of his/her bladder filling status. As soon as the SENS-U states that the bladder is almost full (at $80 \%$ and $100 \%$ of the preset threshold), the child receives a vibration notification of the sensor (on their abdomen), and the application screen will start changing to a (rain) cloud to inform the child that it is time to go to the toilet. Data measured of a prolonged period can be transferred to a computer for both clinical and research purposes.

\section{Experimental protocol}

To evaluate the SENS-U, 30 patients who were referred to the department of Pediatric Urology (University Medical Centre Utrecht) for a (video) urodynamic evaluation were consecutively enrolled. Patients aged between 6 and 12 years were included because the prevalence of UI gradually diminishes to an average of $2 \%$ at the age of 12 [2]. With a sample size of 30 patients, it would be possible to estimate a full-bladder detection rate of $90 \%$ within a $95 \%$ confidence interval of $\pm 10.7 \%$, which was considered to be acceptable in this feasibility study [9]. Patients with abnormalities of the suprapubic skin region (e.g. breached skin, open wounds or sutures) were excluded because of the same sensor position [10]. This study was approved by the Local Ethical Committee of the University Medical Centre Utrecht.

After written informed consent was obtained, the patient arrived at the urodynamic clinic for the scheduled standard cystometry procedure. During standard preparation, the patient receives a transurethral and transrectal catheter to enable the bladder filling, measure the bladder and abdominal pressures, and empty the bladder through the transurethral catheter. 


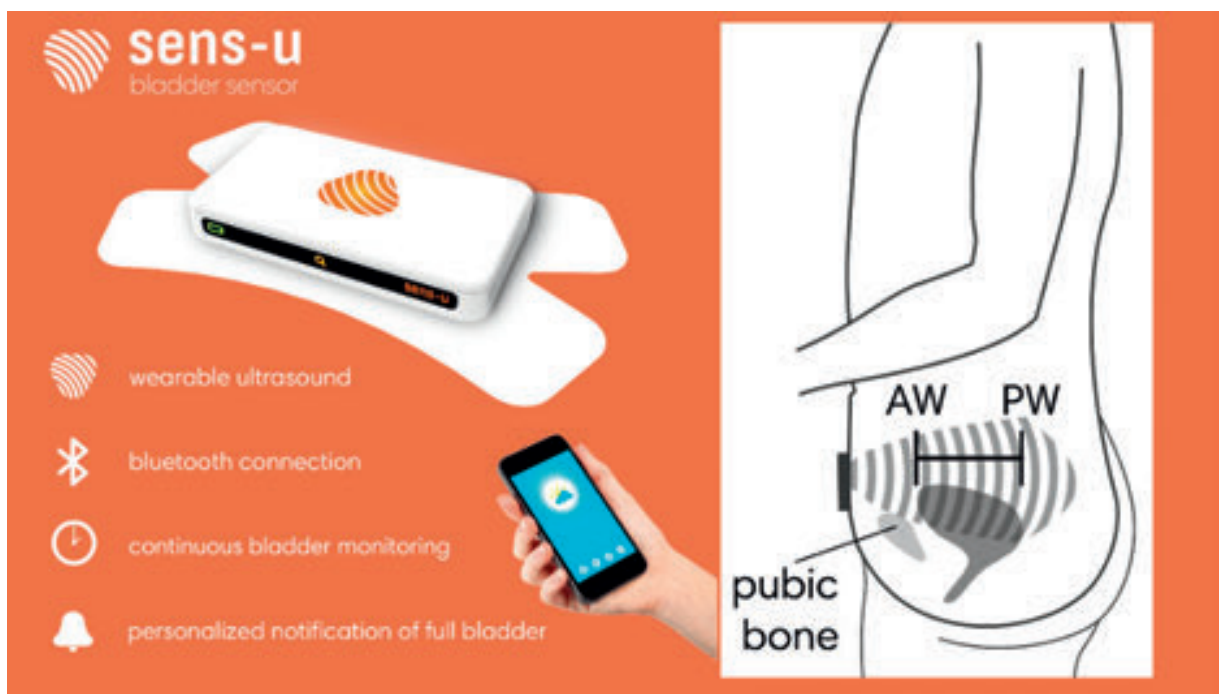

Figure 4.1: The SENS-U Bladder Sensor; (left) the device is positioned just above the pubic bone to monitor the axial position of the anterior (AW) and posterior (PW) bladder wall to notify the user of a full bladder (right).

Then, the SENS-U was positioned using the double-sided adhesive on the lower abdomen (combined with standard ultrasound gel) just above $(1 \mathrm{~cm})$ the pubic bone, by palpation of the pubic symphysis while seated (Figure 4.1). After the preparation, the patient would take part in the uroflowmetry in a sitting position. During the procedure, the bladder was filled with saline (or contrast) at a rate between $8-30 \mathrm{ml} / \mathrm{min}$ (depends on age-expected bladder capacity) by using an Ellipse uroflowmeter system (Andromeda Urodynamic System, Taufkirchen/Potzham, Germany), while registering the infused volume every second. Once the maximum bladder capacity (MBC) was reached, the patient was asked to start voiding. If clinically relevant, the procedure was repeated once or twice. During the entire procedure, the SENS-U measured the bladder dimensions every $30 \mathrm{~s}$ and the data were saved to the internal memory. After the last voiding procedure, the SENS-U was removed from the lower abdomen, and the SENS-U data and (video) urodynamics data were stored for offline post processing using Matlab (MathWorks, Natick, MA). To minimize the impact on the standard cystometry procedure, the full-bladder notifications of the SENS-U were deactivated.

The measured bladder volumes and corresponding bladder dimensions were analyzed by descriptive statistics. To determine the relation between the infused bladder volume and the average A-P bladder dimension, linear regression analysis was used, estimating the Spearman's rank correlation, slope, and intercept. Statistical analysis was performed using SPSS (version 22.0; SPSS Inc., IBM Corp., USA). 


\section{RESULTS}

\section{Population}

In total, 30 patients ( 15 boys, 15 girls; mean age: $7.9 \pm 1.4$ years; mean body mass index [BMI]: $16.1 \pm 2.6 \mathrm{~kg} / \mathrm{m}^{2}$, range $13.3-23.6 \mathrm{~kg} / \mathrm{m}^{2}$ ) have been enrolled. Categorizing the population on (differential) diagnosis (including [video] urodynamic findings), results in the following distribution: $33 \%$ neurogenic bladder, $27 \%$ urge incontinence/overactive bladder, $10 \%$ dysfunctional voiding, $10 \%$ urethral valves, $7 \%$ vesicoureteral reflux, and $13 \%$ others (i.e. congenital anomalies such as bladder exstrophy).

For 17 patients, video urodynamics was applied; 13 patients received standard urodynamics. In $40 \%(n=12)$ of the patients, two $(n=11)$ or three filling $(n=1)$ procedures were recorded. The remaining $60 \%(n=18)$ were recorded during one filling cycle, resulting in 43 recordings. Patients were measured in a sitting position, except for the first subject (supine; due to nausea). The average infused and voided volume were equal to $198.2 \mathrm{ml}$ (range: $72-439 \mathrm{ml}$ ) and $201.1 \mathrm{ml}$ (range: 66-463 ml), respectively. The residual volume (after voiding) ranged from 0 to $180 \mathrm{ml}$ (mean \pm standard deviation [SD]: $24.0 \pm 48.3 \mathrm{ml}$ ). Relating the maximum voided volume to the expected bladder capacity (EBC) (\%) (conform the International Children Continence Society (ICCS) guidelines [11]) resulted in mean ( \pm SD) percentage of $83.7 \%$ ( $\pm 35.1 \%$; range: $34.3-171.5 \%)$. Maximum voided volume was considered small $(<65 \%$ of $\mathrm{EBC})$ in $40.0 \%(n=12)$ and large $(>150 \%$ of $\mathrm{EBC})$ in $3.3 \%(n=1)$ of the patients.

\section{SENS-U performance}

In this study, the SENS-U was able to detect a full bladder before voiding in $90 \%(27 / 30)$ of the patients and in $88 \%(38 / 43)$ of cystometric procedures. In the remaining three patients (10\%; patient no. 4, 22, and 26), it was not possible to detect a full bladder.

The detectable (infused) bladder volume (of 38 procedures) ranged between a minimum volume of $27.5 \pm 23.3 \mathrm{ml}$ (mean $\pm \mathrm{SD}$; range min. volume: $1.2-78.3 \mathrm{ml}$ ) and a MBC of $210.8 \pm 104.7 \mathrm{ml}$ (mean \pm SD; range MBC: $71-463 \mathrm{ml}$ ). The maximum average A-P bladder dimension ranged between $14.2 \mathrm{~mm}$ to $71.1 \mathrm{~mm}$, with mean value $( \pm \mathrm{SD}$ ) of $41.4 \pm 11.5 \mathrm{~mm}$. To illustrate the performance of the SENS-U, Figure 4.2A shows the cystometric recording and the SENS-U data obtained from one of the male patients for two consecutive procedures (infusion rates of 10 and $20 \mathrm{ml} / \mathrm{min}$ ). This figure shows that the SENS-U is able to measure the average A-P bladder dimension (black line) successfully over a broad range of infused bladder volumes (Figure 4.2A: first procedure: $30.1-253 \mathrm{ml}$ ).

To determine the relation between the infused bladder volume and the average A-P bladder dimension, linear regression analysis was performed by using the data of 37 of 38 procedures. One procedure was excluded for the statistical analysis because the obtained dataset only contained two data points. At the start of the cystometric procedure, this subject experienced an instant feeling of urge (due to an unknown 
start residue). Therefore, the subject was given permission to void, resulting in a small, infused volume (14 ml) and only two SENS-U measurements (every $30 \mathrm{~s}$ ), which would result in a false-positive coefficient of 1.0.

Spearman's rank correlation $\left(r_{s}\right)$ was used for the 37 data sets resulting in a strong, positive relation (mean \pm SD: $r_{s}=0.86 \pm 0.24$ ) with a median value of $r_{s}=0.94$ (median $\mathrm{p}<0.05)$. The mean slope was $0.21 \mathrm{~mm} / \mathrm{ml}$ ( \pm SD: $0.13 \mathrm{~mm} / \mathrm{ml}$ ), and the intercepts ranged from $-15.9 \mathrm{~mm}$ to $44.1 \mathrm{~mm}$, with a mean value of $4.88 \mathrm{~mm}$ ( $\pm S D: 11.4 \mathrm{~mm}$ ). As an example, Figure 4.2B presents a strong, positive relation between the average A-P bladder dimension and the infused volume of the first cystometric procedure (gray area in Figure 4.2A). This figure also illustrates the minimum (infused) bladder volume that could be detected $\left(\mathrm{V}_{\mathrm{INF}}[\mathrm{min}]=30.1 \mathrm{ml}\right)$ by the SENS-U.
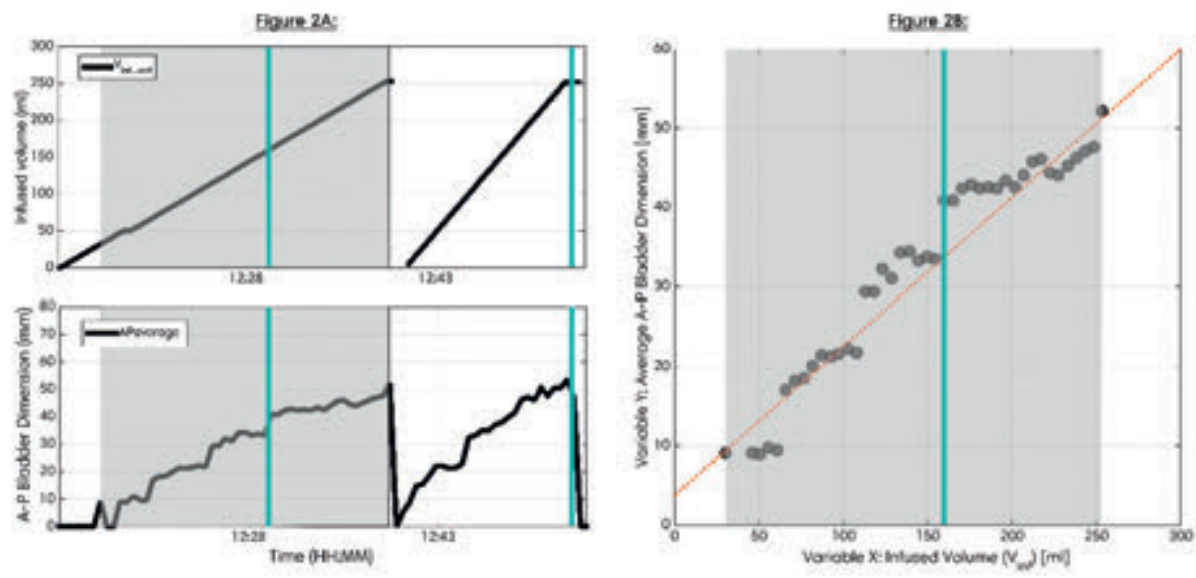

Figure 4.2(A) (A) Results of a 7-year-old male patient. Top figure: infused volume over time. Vertical cyan line, moment of first urge sensation; bottom figure, measured average A-P bladder dimension (based on four transducer) by the SENS-U Bladder Sensor over time; gray area, detectable bladder volume (range: $30.1-253 \mathrm{ml}$ ) in first cystometric procedure. (B) Strong, positive relation between the infused volume and the average A-P bladder dimension $\left(r_{s}: 0.99\right.$; $p<0.05$, slope: $0.20 \mathrm{~mm} / \mathrm{ml}$, intercept: $3.78 \mathrm{~mm}$ ) of the first cystometric procedure (gray area). A-P, anterior-posterior.

\section{SENS-U threshold}

Based on linear regression, the mean slope was equal to $0.21 \mathrm{~mm} / \mathrm{ml}$. This gradient can serve as a guideline for setting the proper average A-P bladder dimension as a fullbladder notification threshold, based on the patient's maximum voided volume. The mean intercept value is not included because this value is influenced by incomplete bladder catheterization before the cystometric procedure. As an example, Figure 4.3 visualizes the implemented volume-based threshold (red line) for subject no. 11. During this procedure, the measured maximum voided volume was equal to $159 \mathrm{ml}$, resulting in a notification threshold of $33.4 \mathrm{~mm}$ (red line). 

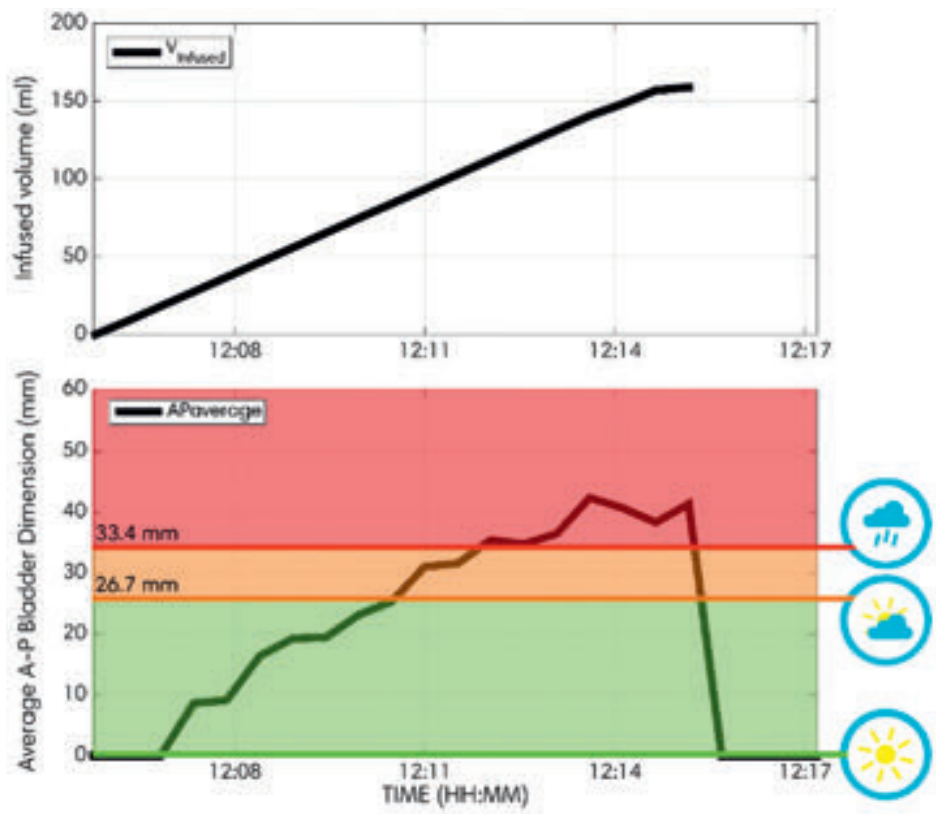

Figure 4.3: Results of subject no. 11, an 8-year-old boy, showing the average A-P bladder dimension threshold $(33.4 \mathrm{~mm}$ ) based on a voided volume of $159 \mathrm{ml}$. If this threshold was implemented, a priori, the SENS-U would have provided a notification at $80 \%$ (CLOUD) and at $100 \%$ (RAIN) of this value (max A-P: $42.4 \mathrm{~mm}$ ), until the subject would have proceeded to the toilet. A-P, anterior-posterior.

Furthermore, the orange line is visualized, which indicates $80 \%$ of the pre-set threshold $(26.7 \mathrm{~mm}$ ) (SENS-U software settings). If these thresholds were implemented a priori, this subject would have been notified of a full bladder before micturition.

When this method would be applied for all cystometric procedures $(n=37)$, a notification would have been given a priori in $86.5 \%$ (at $80 \%$ of the set threshold) and $64.9 \%$ (at $100 \%$ of the set threshold) of the procedures (Table 4.1). For three patients, subjects 7,13 , and 18 (only the $2^{\mathrm{e}}$ cystometric procedure), a notification would not be provided with this volume-based threshold.

Table 4.1: Volume-based threshold - notification-rate (\%)

\begin{tabular}{lll}
\hline Thresholds $^{\text {a }}$ & $\begin{array}{l}\text { Frequency } \\
\text { ( } \mathbf{n}=\mathbf{3 7} \text { fillings) }\end{array}$ & $\begin{array}{l}\text { Percentage } \\
\mathbf{( \% )}\end{array}$ \\
\hline$>80 \%$ (orange line) & 32 & $86.5 \%$ \\
$>100 \%$ (red line) & 24 & $64.9 \%$ \\
\hline
\end{tabular}

a Threshold percentage are current SENS-U notification software settings. 


\section{DISCUSSION}

The purpose of this feasibility study was to clinically validate the SENS-U in 30 children during urodynamics. In $10 \%$ of the patients (patient no. 4,22 , and 26 ), it was not possible to detect a full bladder. In two of these three patients (no. 4 and no. 26, boys), the device could not detect the bladder properly due to the (relatively) obese abdomen of these patients in upright position. Owing to the curvature of the lower abdomen, the transducer orientation is shifted, pointing upward away from the bladder region. In addition, owing to a thicker abdominal wall, the ultrasound transmission is also lower, which results in less ultrasound energy that could be reflected from the posterior bladder wall which decreases detectability. When all subjects are ranked according to their body weight, these two subjects had the two highest body weight ( $\geq 2 \cdot S D)$. Comparing them to their BMI-for-age percentiles [12], patient no. 4 and 26 are graded respectively as (almost) overweight and obese.

Therefore, it is advised to redesign the transducer module of the SENS-U for patients with a BMI index greater than the 95th percentile (obese), by increasing the FOV (correcting shift in transducer orientation) and increasing the ultrasound intensity (higher ultrasound transmission).

\section{Initial sensor positioning}

In the other patient (no. 22), the device was initially not positioned properly. The device was placed too high above the pubic bone. Raw ultrasound data showed that minor reflections of the posterior bladder wall were found in the lowest part of the FOV, which were too low in amplitude to be detected by the internal algorithm.

The notification rate was also influenced by initial sensor positioning. In three patients (no. 7, 13, and 18), the maximum average A-P bladder dimension did not exceed the volume-based threshold because the SENS-U was not able to detect the entire bladder region. This results in a lower-than-expected average A-P bladder dimension in relation to the maximum voided volume. In subject no. 7, the SENS-U was initially positioned too low, which resulted in the acoustic interaction with the pubic bone in the lower part of the FOV. In subject no. 18, the device was positioned too high, missing the lower part of the bladder region and resulting in the highest, minimal detectable volume $\left(\mathrm{V}_{\text {INF }}[\mathrm{min}]=78.3 \mathrm{ml}\right)$ in the population. Finally, in subject no. 13, an unexpected, cranial shift in sensor orientation occurred at the beginning of the cystometric procedure, missing the lower part of the bladder region.

However, when focusing on the positioning of the device, the SENS-U was positioned at the beginning of the filling procedure, when the bladder was empty. Therefore, no position verification (functionality included in smartphone application) could be used because the device requires a minimal bladder volume to be detected. Nevertheless, even without the position verification procedure, the SENS-U was still able to detect the bladder accurately in $90 \%$ of the patients. When focusing on the performance of the sensor and excluding erroneous data due to initial sensor misplacement or an 
(relative) obese abdomen, the detection rate may even be higher. However, when using the SENS-U in daily clinical practice, proper sensor positioning and childhood obesity are factors that should be kept in mind.

\section{CONCLUSIONS}

This article describes the SENS-U Bladder Sensor, which is developed to detect a full bladder and notify the user before micturition. In the studied population, the SENS-U was able to detect a full bladder with a success rate of $90 \%(27 / 30)$ and notify the user in almost $90 \%$ of the time, based on the presented volume-based personalized threshold.

However, when focusing on the performance of the SENS-U and excluding erroneous data due to initial misplacement of the SENS-U or an obese abdomen (10\%), the detection rate may even be higher. Nevertheless, proper sensor positioning and childhood obesity are factors of influence which should be kept in mind when using the SENS-U in daily clinical practice. Future research will focus on investigating the effect of the SENS-U in incontinence training, evaluating the children's level of compliance to the full-bladder notifications.

\section{Acknowledgements}

The authors would like to thank all the pediatric urologists, nurse practitioners and nurses at the department of Pediatric Urology in the Wilhelmina Children's Hospital UMC Utrecht (Utrecht, The Netherlands), for their help in the recruitment of the patients and their assistance during the study procedure.

\section{Ethical approval}

This study was approved by the Local Ethical Committee of the University Medical Centre Utrecht.

\section{Funding}

This work was supported by Pontes Medical (Utrecht, The Netherlands, www.pontesmedical.com), Novioscan (Nijmegen, The Netherlands, www.novioscan. com), the European Union, and the European Funds for Regional Development.

\section{Conflict of Interest}

This feasibility study was performed by technical physician P.G. van Leuteren in close collaboration with the department of Pediatric Urology, Wilhelmina Children's Hospital UMC Utrecht (Utrecht, The Netherlands). P.G. van Leuteren is also an employee of Novioscan. The other authors have no conflict of interest to declare. 


\section{REFERENCES}

1. A. J. Schaeffer and D. A. Diamond, "Pediatric urinary incontinence: Classification, evaluation, and management," African J. Urol., vol. 20, no. 1, pp. 1-13, Mar. 2014. https://doi. org/10.1016/j.afju.2013.10.001

2. Nederlandse Vereniging voor Urologie (NVU), "Richtlijn Urine incontinentie bij kinderen," Richtlijn "Incontinentie bij Kinderen," pp. 1-144, 2008.

3. B. A. Thibodeau, P. Metcalfe, P. Koop, and K. Moore, "Urinary incontinence and quality of life in children.," J. Pediatr. Urol., vol. 9, no. 1, pp. 78-83, Feb. 2013. https://doi.org/10.1016/j. jpurol.2011.12.005

4. P. Sureshkumar, W. Bower, J. C. Craig, and J. F. Knight, "Treatment of Daytime Urinary Incontinence in Children: A Systematic Review of Randomized Controlled Trials," J. Urol., vol. 170, no. 1, pp. 196-200, 2003. https://doi.org/10.1097/01.ju.0000072341.34333.43

5. J. Chase, P. Austin, P. Hoebeke, and P. McKenna, "The Management of Dysfunctional Voiding in Children: A Report From the Standardisation Committee of the International Children's Continence Society," J. Urol., vol. 183, no. 4, pp. 1296-1302, 2010. https://doi.org/10.1016/j. juro.2009.12.059

6. E. Van Laecke et al., "The Daytime Alarm: A Useful Device for the Treatment of Children With Daytime Incontinence," J. Urol., vol. 176, no. 1, pp. 325-327, 2006. https://doi.org/10.1016/ S0022-5347(06)00303-X

7. R. A. Pretlow, "Treatment of nocturnal enuresis with an ultrasound bladder volume controlled alarm device," in Journal of Urology, 1999, vol. 162, no. 3 II, pp. 1224-1228. https://doi.org/10.1016/S0022-5347(01)68141-2

8. P. G. van Leuteren, B. A. de Vries, G. C. J. de Joode-Smink, B. ten Haken, T. P. V. M. de Jong, and P. Dik, "URIKA, continuous ultrasound monitoring for the detection of a full bladder in children with dysfunctional voiding: a feasibility study," Biomed. Phys. Eng. Express, vol. 3, no. 1, pp. 1-7, 2017. https://doi.org/10.1088/2057-1976/aa589f

9. C. Moore and R. Carter, "Recommendations for planning pilot studies in clinical and translational research," Clin. Transl. Sci., vol. 4, no. 5, pp. 332-337, 2011. https://doi. org/10.1111/j.1752-8062.2011.00347.x.

10. N. K. Kristiansen, H. Nygaard, and J. C. Djurhuus, "Clinical evaluation of a novel ultrasoundbased bladder volume monitor.," Scand. J. Urol. Nephrol., vol. 39, no. 4, pp. 321-8, Jan. 2005. https://doi.org/10.1080/00365590510031165.

11. T. Nevéus et al., "The standardization of terminology of lower urinary tract function in children and adolescents: report from the Standardisation Committee of the International Children's Continence Society.," J. Urol., vol. 176, no. 1, pp. 314-24, Jul. 2006. https://doi. org/10.1016/S0022-5347(06)00305-3.

12. National Center for Health Statistics in collaboration with the National Center for Chronic Disease Prevention and Health Promotion (2000)., "2 to 20 years Boys: Body mass indexfor-age percentiles," https://www.cdc.gov/growthcharts/. [Online]. Available: https://www. cdc.gov/growthcharts/data/set1clinical/cj41l023.pdf. [Accessed: 12-Jan-2018]. 



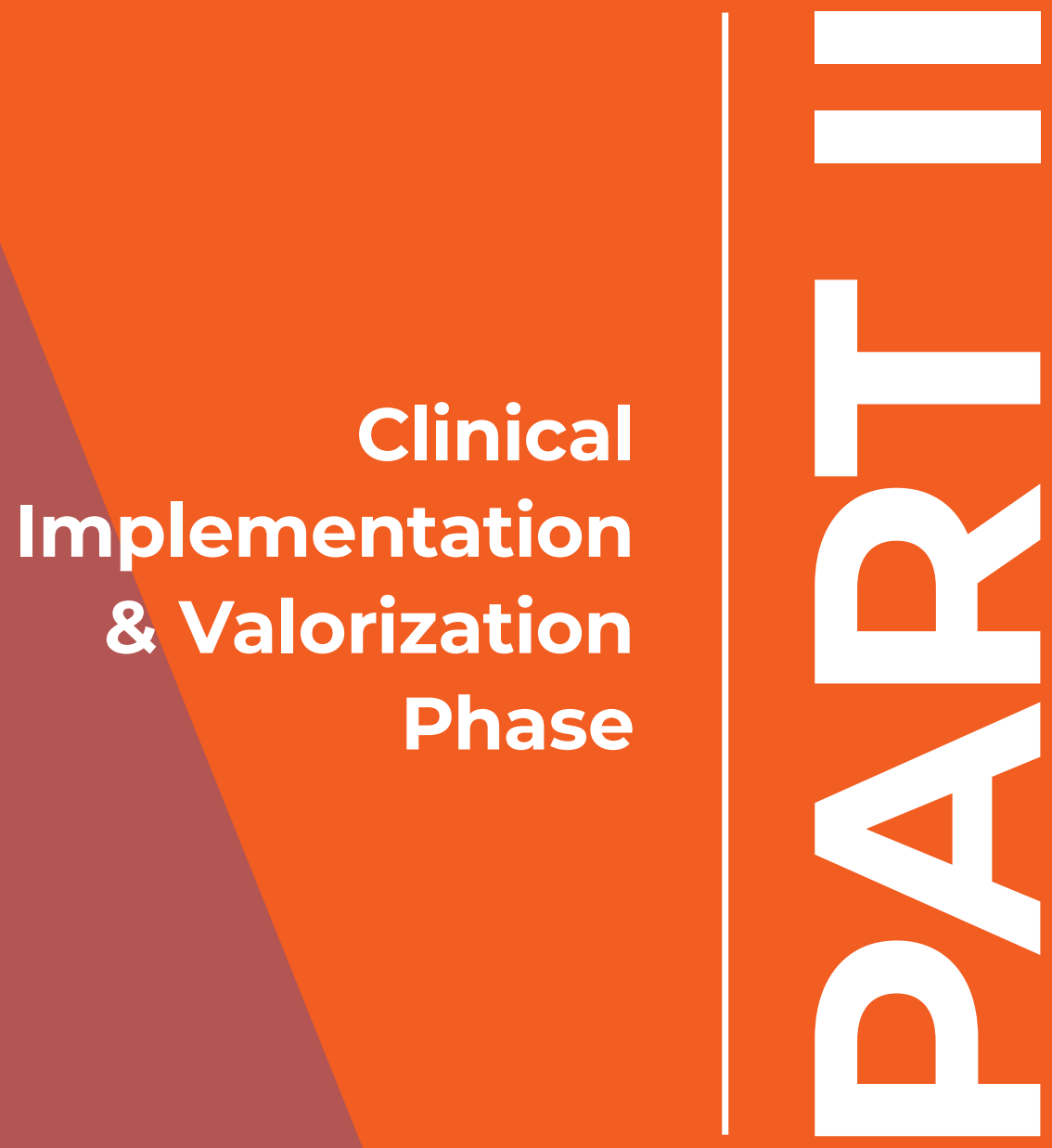





\section{SENS-U: clinical evaluation of a full bladder notification - a pilot study}

J Pediatr Urol. 2019;15(4): 381.e1-381.e5

Paul G. van Leuteren

Anka J. Nieuwhof-Leppink Pieter Dik

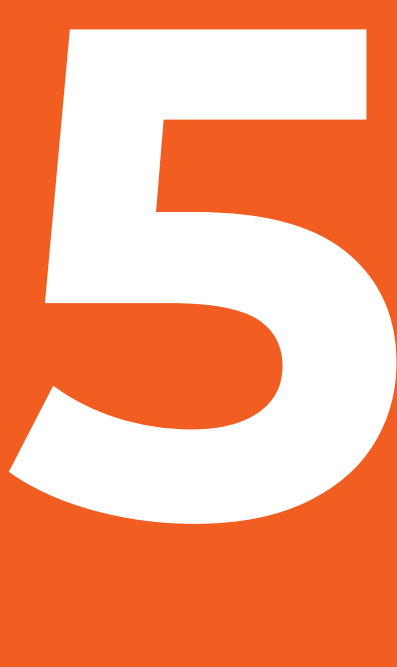




\section{SUMMARY}

Introduction: Urinary incontinence is one of the most commonly treated disorders in children at school age. Recently, a new, wearable bladder sensor became available, the SENS-U Bladder Sensor. The SENS-U is a small, wireless ultrasonic sensor, which continuously monitors the bladder filling and provides a personalized notification when it is time to go to the toilet. In this study, the aim was to examine the performance of the SENS-U as a full-bladder-based notification system in children during daily life activities.

Patients and Methods: In this pilot study, children (6-16 years) who were admitted for an inpatient bladder training were included. Parallel to one training day, the child would wear the SENS-U to estimate the bladder filling and it informed the child when the bladder was almost full. When the child received a full-bladder notification, the child was taught to inform the urotherapist/researcher, in order to determine the level of response.

Results: Fifteen patients (boys/girls: 7/8; mean age: $11.5 \pm 1.7$ years) were included. Based on a personalized volume-based threshold, the SENS-U notified these children of a full bladder with a median notification rate of $92.9 \%$. In the remaining cases, children voided before the threshold was reached (e.g. defecation). Children responded positively to the notification of the SENS-U, resulting in a median level of response equal to $100 \%$.

Conclusion: The SENS-U was able to monitor the natural bladder filling accurately during activities of daily living and provided a personalized notification to the children when it was almost time to go to the toilet. Future research will focus on investigating the efficacy of the SENS-U compared to daily clinical practices. 


\section{INTRODUCTION}

One of the most commonly treated disorders in children remains urinary incontinence. The reported prevalence of daytime wetting varies from 6 to $9 \%$ at school age (6-10 years) and decreases with age [1]. In accordance with the International Children's Continence Society, urotherapy is recommended for treating incontinence in children. Urotherapy is conservative-based management program for lower urinary tract dysfunction. Urotherapy includes explanation, demystification, lifestyle advice, pelvic floor training, biofeedback, and behavioral modification [2]. An important part of the treatment is that children are taught how to respond adequately to their bladder filling and bladder signal.

Recently, a new, wearable ultrasonic bladder sensor became available, the SENS-U Bladder Sensor (SENS-U) (Novioscan, Nijmegen, the Netherlands), which is intended to support children who have involuntary urine loss by increasing their awareness of a full-bladder sensation. By continuously (i.e. $30 \mathrm{~s}$ ) monitoring the bladder filling status, the SENS-U provides the child a personalized notification when it is almost time to go to the toilet.

The SENS-U has previously been clinically evaluated in 30 children during (video) urodynamics [3]. Parallel to the standard cystometric procedure, the SENS-U estimated the anterior-posterior (A-P) bladder dimension to evaluate the filling status and relate it to the infused volume. This resulted in a full-bladder detection rate of more than $90 \%$ over a broad range of maximum voided volumes $(71-463 \mathrm{ml})$. Next, relating the infused volume to the estimated bladder dimensions resulted in a strong, positive correlation (median $r_{s}=0.94$ ) [3]. Despite accurate performance during the (video) urodynamics, there were several differences when comparing it to using the SENS-U in daily (clinical) practice. First, the children maintained a static sitting position throughout the entire procedure. Next, the personalized notifications of the SENS-U were deactivated to minimize the impact on the clinically required (video) urodynamic procedure. Finally, (video) urodynamics is not the same as natural bladder filling, which may result in a different voiding behavior compared to daily life activities (e.g. differences in maximum voided volume).

Therefore, this pilot study clinically evaluated the performance of the SENS-U in a group of children during regular physical activity and natural bladder filling. It was hypothesized that the SENS-U would be equally accurate during activities of daily living as during (video)urodynamics. In addition, the level of response to the provided fullbladder notification was assessed. 


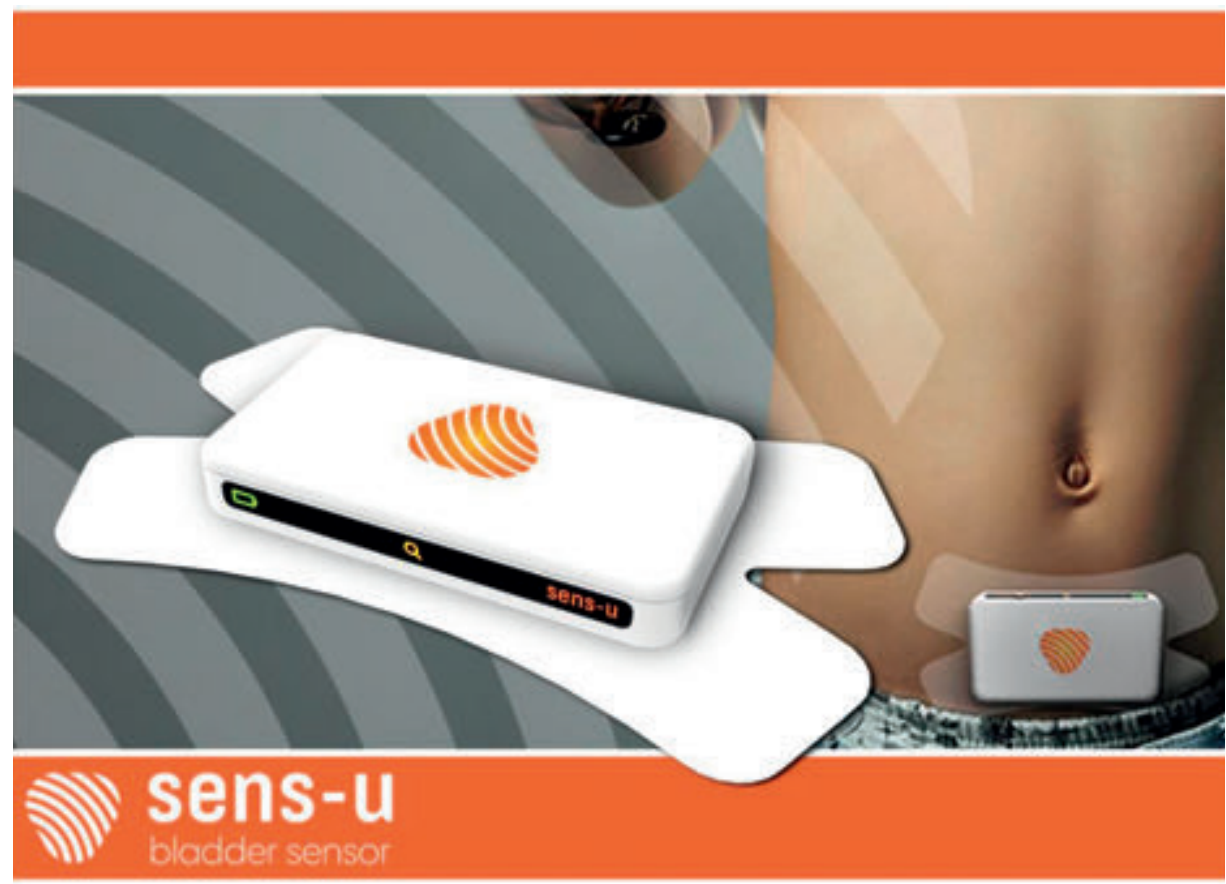

Figure 5.1: The SENS-U Bladder Sensor is positioned on the lower abdomen by a skin-friendly adhesive and provides the child a personalized (vibration) notification when it is almost time to go to the toilet.

\section{PATIENTS AND METHODS}

\section{SENS-U Bladder Sensor}

The SENS-U is a small ( $95 \times 55 \times 16 \mathrm{~mm}$ ), wearable, battery-operated sensor which is positioned on the lower abdomen (each day) using a double-sided adhesive (combined with standard ultrasound gel) (Figure 5.1). The sensor is based on a combination of four ultrasonic transducers, arranged with a field of view of $30^{\circ}$ [3]. The SENS-U transmits ultrasonic waves towards the bladder region and an internal algorithm automatically processes the received ultrasonic reflections of the bladder walls. This results in an average A-P bladder dimension which is related to estimate the bladder filling status [3]. Based on the patient's maximum voided volume, a personalized threshold is set by the medical professional (i.e. pediatric urologist or a urotherapist) using the SENS-U mobile application. The SENS-U uses Bluetooth ${ }^{\circledR}$ Low Energy to wirelessly connect with the mobile application, which also allows the child, his or her caregivers, and his or her physician to be informed of the bladder filling status in real time. As soon as the personalized threshold is (almost, at $80 \%$ ) reached (at 100\%), the SENS-U will provide a vibration notification on the child's abdomen and a message is sent to the mobile application, allowing to the child to go to the toilet in time. 


\section{Experimental protocol}

To evaluate the SENS-U as a full-bladder-based notification system during activities of daily living, 15 patients were consecutively enrolled who were admitted to the Department of Pediatric Urology (University Medical Centre Utrecht) for an intensive inpatient bladder training program, which focuses on relearning, concentration, and awareness of the bladder filling [4]. Patients were included between the ages of 6 and 16 years. With a sample size of 15 patients, it would be possible to estimate a full-bladder notification rate of $90 \%$ within a $95 \%$ confidence interval of $\pm 15.2 \%$, which was considered to be acceptable in this pilot study [5]. Patients were excluded based on their body mass index (BMI) (obese $>95^{\text {th }}$ percentile, according to age and gender) and when they had abnormalities in the suprapubic skin region (e.g. breached skin, open wounds, sutures or a suprapubic catheter) [6]. These two factors influence proper sensor positioning and therefore the accuracy of the SENS-U [3].

After written informed consent was obtained, the patient wore the SENS- $U$ during one (daytime) training day, parallel to the inpatient bladder training. At the start of the training day, the SENS-U was positioned on the lower abdomen using the required double-sided adhesive (combined with standard ultrasound gel) just above $(1 \mathrm{~cm})$ the pubic bone, by palpation of the pubic symphysis. For each child, a personalized threshold was set, based on the uroflowmetry recordings from the previous training days. At $80 \%$ of this threshold, the SENS-U would provide the first notification, enabling the patient to go to the toilet in time. If the patient postponed micturition and ignored the device, a second notification (at $100 \%$ of the threshold) would be given once more to remind and to encourage the patient to go to the toilet. The patient was instructed to inform the urotherapist (or researcher) when the (vibration) notification was provided by the SENS-U, in order to determine the level of response. Furthermore, each time the patient needed to void, uroflowmetry was performed in order to assess the voiding pattern and voided volume.

During the procedure, data were documented on age, gender, length, weight, diagnoses (for medical files), micturition frequency, measured voided volumes, time of voiding, number of wet incidents, the notification frequency, and the response rate using an online case report form (Castor Electronic Data Capture, Ciwit BV, Amsterdam, the Netherlands). The acquired data were analyzed by descriptive statistics using SPSS (version 25.0; SPSS Inc., IBM Corp., USA). At the end of the training day, the SENS-U was removed from the lower abdomen and a short usability questionnaire was completed, examining the patient's experience on receiving the current type of notification. The patient was asked if he/she clearly felt the vibration notification and what kind of notification he/she would prefer (Table 5.1). The SENS-U data itself were stored for offline post-processing using MATLAB R2018 (MathWorks, Natick, MA). This study was approved by the Local Ethical Committee of the University Medical Centre Utrecht. 
Table 5.1: Reponses to the Usability Questionnaire

\begin{tabular}{lll}
\hline $\mathbf{N}=\mathbf{1 5}$ & Yes & No \\
\hline $\begin{array}{l}\text { Did you feel the vibration notification } \\
\text { clearly? }\end{array}$ & $13(87 \%)$ & $2(13 \%)$ \\
\hline & & $\mathbf{N}=15$ \\
\hline & Vibration & $14(93 \%)$ \\
What kind of notification do you prefer? & Push Notification (mobile app) & $2(13 \%)$ \\
& Other, such as e.g. sound & $3(20 \%)$ \\
\hline
\end{tabular}

\section{RESULTS}

\section{Population}

In total, 15 patients ( 7 boys, 8 girls; mean age: $11.5 \pm 1.7$ years; mean BMI: $18.5 \pm 2.9$ $\mathrm{kg} / \mathrm{m}^{2}$, range: $15.2-25.7 \mathrm{~kg} / \mathrm{m}^{2}$ ) have been enrolled. Categorizing the population on (differential) diagnosis results in the following distribution: $47 \%$ urge incontinence / overactive bladder, $27 \%$ dysfunctional voiding and $26 \%$ others (i.e. underactive bladder, small bladder capacity).

In this study, 56 uroflowmetry recordings were documented while the volumebased threshold was activated. In $78.6 \%$ ( $n=11 / 14$ patients), the uroflow pattern was smooth and bell shaped. In the remaining patients $(21.4 \%, n=3 / 14)$, the uroflow pattern was tower shaped $(n=1)$, plateau shaped $(n=1)$ and staccato $(n=1)$. One patient was excluded from analysis (patient no. 4, voided twice, plateau shaped) because despite receiving an accurate notification of the SENS-U, he was unable to empty his bladder properly due to his underactive bladder. As a result, the SENS-U kept on reminding this patient of a full bladder. To minimize the impact on his bladder training, the full-bladder notification of the SENS-U was deactivated (only used for observational purposes). Relating each child's maximum voided volume (based on the 56 uroflowmetry recordings) to its expected bladder capacity (EBC) [7] resulted in 11 children $(78.6 \%)$ with a small maximum voided volume $(<65 \%$ of EBC). For the other children $(n=3,21.4 \%)$, the maximum voided volume was considered normal $(65-150 \%$ of EBC). Only in 1 of 56 uroflowmetry recordings a minor wet accident occurred (a few drops of urine).

\section{Notification Rate (\%)}

In this study, the SENS-U was able to monitor the natural bladder filling during activities of daily living $(n=14)$. It notified the child of a full bladder (based on the preset volumebased threshold) with a median notification rate equal to $92.9 \%$ (range: $0-100 \%$ ) (Table 5.2, left skewed distribution). Patient no. 5 did not receive any notification ( $n=2 / 56$ micturitions, outlier [ $>1.5 \cdot$ interquartile range $\{I Q R\}])$. In the remaining cases (13 of 56), children voided before the volume-based threshold was reached. 
Table 5.2: Descriptive Statistics for the Notification-rate ${ }^{1}(\%)$ and the Level of Response ${ }^{1}(\%)$

\begin{tabular}{lcccc}
\hline & Median & $\begin{array}{c}\text { Range } \\
\text { (MIN - MAX) }\end{array}$ & $\begin{array}{c}\text { IQR } \\
\left(\mathbf{2 5}^{\text {th }}-\mathbf{7 5}^{\text {th }} \text { Percentile) }\right.\end{array}$ & $\begin{array}{c}\text { Outliers } \\
(>\mathbf{1 . 5} \cdot \text { IQR })\end{array}$ \\
\hline $\begin{array}{l}\text { Notification Rate } \\
\text { (\%) }[\mathrm{n}=14]\end{array}$ & 92.9 & $0-100$ & $61.7-100$ & $\begin{array}{c}\text { Patient no.5 } \\
(0 \%)\end{array}$ \\
$\begin{array}{l}\text { Level of Response } \\
(\%)[\mathrm{n}=13]\end{array}$ & 100.0 & $0-100$ & $100-100$ & $\begin{array}{c}\text { Patient no.1 } \\
\end{array}$ \\
& & & & $(0 \%)$ \\
& & & Patient no.11 \\
& & & $(66.7 \%)$ \\
\hline
\end{tabular}

${ }^{1}$ Left skewed distribution, IQR: Interquartile range. MIN: minimum, MAX: maximum

To illustrate the functionality of the SENS-U in clinical practice, Figure $\mathbf{5 . 2}$ presents several consecutive natural filling cycles of subject no. 13, a 10-year-old girl.

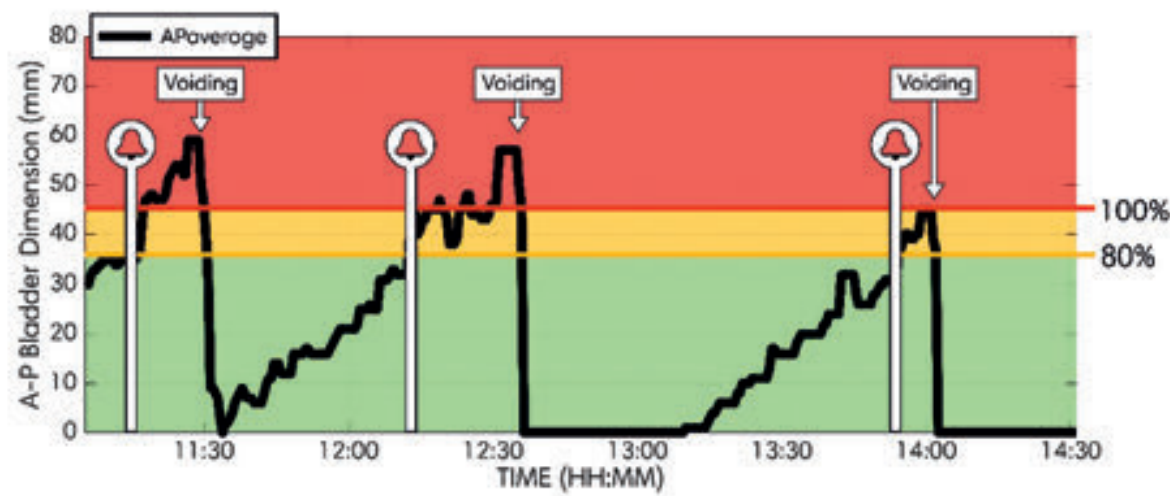

Figure 5.2: Three consecutive natural filling cycles stating the time of a provided, personalized notifications ([$\delta]$, at $80 \%$ (orange area) and at $100 \%$ (red area)) and the moment of voiding.

\section{Level of response (\%)}

In total, 13 children received a (vibration) notification from the SENS-U, prior to voiding, resulting in a total of 41 provided notifications. The children responded positively to the notifications ( $n=39 / 41$ ), resulting in a median level of response equal to $100.0 \%$ (range: 0 - 100\%) (Table 5.2, left skewed distribution). However, for one time, both patient no. 1 and no. 11 did not notify the urotherapist (or researcher) of a provided full-bladder (vibration) notification ( $n=2 / 41$, both outliers [ $>1.5 \cdot I Q R])$.

Considering the final usability questionnaire, children clearly had a preference for the discrete, vibration notification (93\%) (Table 5.1). Next, $13 \%$ of the patients thought the smartphone notification would be beneficial. Finally, $20 \%$ of the children also had other ideas for a notification, like a (minor) sound, similar to the wetting alarms, or direct notification between the device and the urotherapist (or researcher). 


\section{DISCUSSION}

The current pilot study was initiated to clinically assess the performance of the SENS-U for monitoring natural bladder filling in children during activities of daily living. This evaluation demonstrated that the SENS-U is an accurate, easy to use, and patientaccepted method for detecting the bladder filling and notifying children before a full bladder.

\section{Notification rate (\%)}

However, in several cases, the SENS- $U$ did not provide the child with a notification before he/she went to the bathroom. Reasons for this can be divided into two categories: device related and study design related. Considering device-related reasons, two patients (no. 2 and 5) were identified for whom the device could not detect the bladder properly because of a (relatively) obese abdomen, resulting in a misalignment between the bladder position and the field of view of the SENS-U [3]. Despite excluding subjects based on their BMI (obese $>95^{\text {th }}$ percentile, according to age and gender), these two patients were still classified as overweight $\left(85^{\text {th }}-95^{\text {th }}\right.$ percentile). Therefore, it is advised to be aware of the influence of the abdominal curvature when implementing the SENS-U during clinical practice. Next, initial sensor positioning also influenced the notification rate in some patients. For example, in patient no. 9 and 12, the device was positioned slightly too low, resulting in the acoustic interaction between the SENS-U and the pubic bone. As a result, the SENS-U did not monitor the entire bladder region, underestimating the actual bladder volume present and therefore unable to reach the personalized preset threshold. It is advised to further optimize the internal algorithm to compensate for partial sensor misplacement.

When considering study design-related reasons, first of all, the SENS-U was positioned at the start of the training day, when the bladder was (often) empty after the first-morning void. Therefore, often no position verification (device functionality) could be initiated because it requires a certain amount of volume present. Secondly, to minimize the impact on the child's bladder training program, the children were informed to first act on their own full-bladder sensation and training instructions. Consequently, some children (especially with urge incontinence / overactive bladder or due to defecation) sometimes went to the toilet before the bladder volume reached their personalized threshold (based on their maximum voided volume). Finally, for the first two included patients (no. 1 and 2), the notification rate was relatively low $(16.7 \%$ and $60.0 \%$, respectively) because their voiding behavior was significantly influenced by the fact that these patients were monitored in parallel during their inpatient bladder training. Analysis of their voiding data showed that as soon as patient no. 2 went to the toilet, patient no. 1 followed her within minutes. In combination with a strictly followed voiding schedule, these two patients both did not experience a natural bladder filling, emptying their bladder before they reached their personalized, volume-based threshold. 


\section{Level of response (\%)}

From all the provided full-bladder notifications ( $n=41$ ), only twice (patient no. 1 and 11) the patients did not inform their urotherapist (or researcher). In patient no. 1, a notification was provided by the SENS-U, followed by proceeding to the toilet. Despite a clear change in facial expression (indicating the awareness of the vibration), she said that she had not felt the notification of the SENS-U. Therefore, the level of response for this particular patient was equal to zero (outlier [>1.5 - IQR]). Next, patient no. 11 received a notification three times of which she alerted the urotherapist two times (level of response: $66.7 \%$, outlier [ $>1.5 \cdot I Q R]$ ). She did not alert the urotherapist because her attention was too focused on a demanding activity, playing a game. Nevertheless, she responded to the full-bladder notification naturally by going to the toilet in time and remained dry. Finally, when considering the user experience, almost all children preferred the provided vibration notification. Only one child preferred a direct notification between the device and the urotherapist (or researcher).

\section{Perspective}

Future research will focus on investigating the efficacy of the SENS-U in comparison to daily clinical practice, e.g. as a new adjunct in (inpatient or outpatient) bladder training (compared to i.e. timed voiding, alarm wrist watches) and to assist in guiding the timing for volume-dependent intermittent catheterization.

\section{CONCLUSIONS}

This study demonstrated that the SENS-U Bladder Sensor is able to monitor the natural bladder filling in children during activities of daily living and to notify them of a full bladder with a median notification rate of $92.9 \%$ (based on a personalized volumebased threshold) and a median level of response equal to $100 \%$, supporting the initial hypothesis that the SENS-U would be equally accurate during activities of daily living as during (video)urodynamics. Despite the generally high clinical performance of the SENS-U, childhood obesity and accurate sensor positioning are factors of influence which should be considered. Future research will focus on investigating the efficacy of the SENS-U compared to daily clinical practices.

\section{Acknowledgments}

The authors would like to thank all the pediatric urologists, urotherapists and nurses at the Department of Pediatric Urology in the Wilhelmina Children's Hospital UMC Utrecht (Utrecht, The Netherlands) for their help in the recruitment of the patients and their assistance during the study procedure.

\section{Ethical approval}

This study was approved by the Local Ethical Committee of the University Medical Centre Utrecht. 


\section{Funding}

This work was supported by Pontes Medical (Utrecht, The Netherlands, www.pontesmedical.com) and Novioscan (Nijmegen, The Netherlands, www.novioscan. com). This work is partly funded in the ULIMPIA project funded by PENTA under grant number PENTA-2017-Call2-16101-ULIMPIA, www.ulimpia-project.eu.

\section{Conflict of interest statement}

This pilot study was performed by technical physician P.G. van Leuteren in close collaboration with the Department of Pediatric Urology, Wilhelmina Children's Hospital UMC Utrecht (Utrecht, The Netherlands). P.G. van Leuteren is also an employee of Novioscan. The other authors have no conflict of interest to declare. 


\section{REFERENCES}

1. NVU, "Richtlijn Urine incontinentie bij kinderen," Richtlijn "Incontinentie bij Kinderen," pp. 1-144, 2008.

2. S.-J. Chang et al., "Treatment of daytime urinary incontinence: A standardization document from the International Children's Continence Society," Neurourol. Urodyn., vol. 36, no. 1, pp. 43-50, Jan. 2017. http://doi.wiley.com/10.1002/nau.22911.

3. P. G. van Leuteren, A. J. Klijn, T. P. V. M. De Jong, and P. Dik, "SENS-U: Validation of a wearable ultrasonic bladder monitor in children during urodynamic studies," J. Pediatr. Urol., vol. 14, no. 6, pp. 569.e1-569.e6, 2018. https://doi.org/10.1016/j.jpurol.2018.07.018.

4. M. A. W. Vijverberg, E. Stortelder, L. M. O. De Kort, E. T. Kok, and T. P. V. M. De Jong, "Longterm follow-up of incontinence and urge complaints after intensive urotherapy in childhood (75 patients followed up for 16.2-21.8 years)," Urology, vol. 78, no. 6, pp. 1391-1396, 2011. https://doi.org/10.1016/j.urology.2011.08.055.

5. C. Moore and R. Carter, "Recommendations for planning pilot studies in clinical and translational research," Clin. Transl. Sci., vol. 4, no. 5, pp. 332-337, 2011. https://doi.org/10. 1111/j.1752-8062.2011.00347.x

6. National Center for Health Statistics in collaboration with the National Center for Chronic Disease Prevention and Health Promotion (2000)., "2 to 20 years Boys: Body mass indexfor-age percentiles," https://www.cdc.gov/growthcharts/. [Online]. Available: https://www. cdc.gov/growthcharts/data/set1clinical/cj411023.pdf. [Accessed: 12-Jan-2018].

7. P. F. Austin et al., "The standardization of terminology of lower urinary tract function in children and adolescents: Update report from the standardization committee of the International Children's Continence Society," Neurourol. Urodyn., vol. 35, no. 4, pp. 471481, 2016. http://doi.wiley.com/10.1002/nau.22751. 



\section{SENS-U: continuous home monitoring of natural nocturnal bladder filling in children with nocturnal enuresis - a feasibility study}

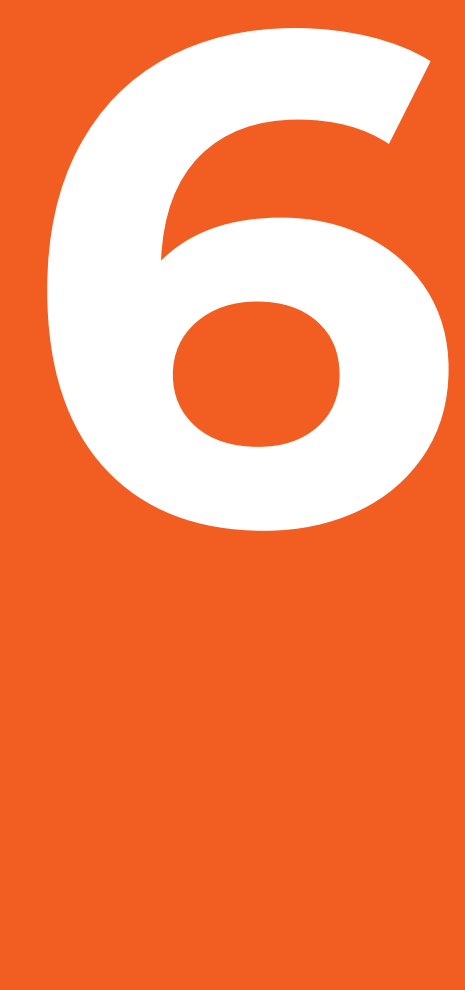

Wenche M.J. Kwinten

Paul G. van Leuteren Miranda van Duren - van lersel Pieter Dik Petr E. Jira 


\section{SUMMARY}

Introduction: Enuresis is a common problem in children. One treatment option is a wetting alarm that provides an alarm when incontinence occurs. A drawback of this approach is that the child is still awakened by wet sheets. Recently, a wearable, wireless ultrasonic bladder sensor became available, the SENS-U, which has the potential to prevent the enuretic event by waking up the child before the bladder is full. In this first feasibility study, the aim is to perform a night-time, home-based evaluation of the SENS-U in children with monosymptomatic nocturnal enuresis (MNE).

Patients and Methods: In this study, children (6-12 years) with MNE were included for a one-night monitoring session. During the night, the SENS-U continuously (i.e. every $30 \mathrm{~s}$ ) estimated the filling status [notifications were deactivated]. In addition, urine volume was collected in a measurement cup (or diaper weight). The total measured natural nocturnal bladder filling (NNBF) cycles was analyzed by descriptive statistics. Before and after the measurement, sleep behavior was assessed by a selection of the Children's Sleep Habits Questionnaire.

Results: Fifteen patients (boys/girls: 13/2) [mean age: $8.6 \pm 1.5$ years] have been enrolled. One patient was excluded due to inadequate sensor-to-skin contact. For 14 children, 18 NNBF cycles were recorded (voiding diary) of which three patients (21\%) had more than one NNBF cycle. The SENS-U was able to successfully detect $83 \%$ of the NNBF cycles. The three missed NNBF cycles had a voided volume $\leq 30 \mathrm{ml}$, which was at the lower limit of the sensor's detection range. The SENS-U had no effect on sleeping behavior.

Conclusion: The SENS-U was able to monitor the natural nocturnal bladder filling successfully in children with monosymptomatic nocturnal enuresis at home, without disturbing their sleep. Future research focuses on investigating the usability of the SENS-U for both diagnostic - and treatment purposes. 


\section{INTRODUCTION}

Enuresis is defined as intermittent urinary incontinence occurring exclusively during sleeping periods and is a common problem in school-aged children [1], [2]. Approximately $5-10 \%$ of 5 -year-olds suffer from enuresis, gradually decreasing with age to $1 \%$ among 15 years and older [3], [4]. The general consensus is that enuresis is an heterogeneous problem which is either caused by: (1) nocturnal polyuria (enuretic voided volume (EVV) $>130 \%$ of expected bladder capacity (EBC)); (2) a low or reduced nocturnal bladder capacity (EVV $<65 \%$ of EBC); or by (3) nocturnal detrusor overactivity, combined with a decreased arousability from sleep [5], [6]. The main treatment options for children with enuresis (above the age of 6 years) included general lifestyle advice, use of medication (i.e. desmopressin, anticholinergics) and alarm therapy (or combined) [7]. The initial success rate of medication is often high, but there is a significant relapse after discontinuing the medication. Also, medication can cause potential side-effects. During alarm therapy, a moisture-sensitive device is used which provides a strong (often acoustic) signal when incontinence occurs [1]. Alarm therapy is based on the concept of negative reinforcement by increasing the awareness of a full-bladder sensation through contraction of the pelvic floor muscles, which will avoid setting of the alarm [3], [8]. Alarm therapy has shown to be effective in $65-75 \%$ of the patients (dry for 14 consecutive nights) within 5-12 weeks of treatment and a 6-month relapse rate of $15-30 \%$ [3], [8]. However, drawbacks of this approach are that the child and parents are still awakened by wet sheets during treatment and that it requires a high level of (parental) motivation [4], [9]. Alarm therapy can also be combined with medication. However, the results regarding effectiveness are inconsistent [7]. Pretlow (1999) has suggested that the optimal treatment method for enuresis should provide a notification when the bladder is almost at its maximum capacity, preventing bedwetting and facilitating associative conditioning between a full bladder and the notification [9]. Therefore, Pretlow used a modified, portable, battery-powered ultrasonic bladder volume recorder, which estimated the bladder volume every 15 min during the night and provided an alarm at $80 \%$ of the maximum bladder capacity [9]. Despite promising results, the configuration of this device had several (practical) limitations which could influence both the recordings as well as the child's sleeping behavior. For example, ensuring correct, stable fixation of the ultrasound probe on the abdomen (e.g. elastic garment or sticky gel pads), the use of a cabled connection to a bedside processing - and alarm unit, and taking printouts every morning at a docking station [6], [9]. Despite these (practical) limitations, Nevéus (2019) recently stated that real-time ultrasound could also be beneficial for diagnostic purposes, gaining insight in the enuresis pathogenesis of the individual child, monitoring e.g. the amount of urine voided in bed or the number of times per night a child wets the bed [5]. He stated that "the only way to overcome the problems of detecting multiple or incomplete enuretic episodes without disturbing the patient would be continuous overnight assessment of bladder volume using body-worn ultrasonographic probes" [5]. 
In a recent study, a small, wearable, wireless ultrasonic bladder sensor, the SENS-U (Novioscan, Nijmegen, the Netherlands), was clinically evaluated in children during (daytime) daily life activities. The SENS-U was able to monitor the natural bladder filling successfully and provided a personalized notification before the bladder was full, to which the children responded positively [10]. The SENS-U has the potential to be used in children with nocturnal enuresis for both treatment - and diagnostic purposes, i.e. notifying the child before the enuretic event, preventing wet sheets and training the child to awaken to the signs of a full bladder or by assessing the nocturnal bladder function, without interrupting the sleep of the child.

This feasibility study evaluated the initial monitoring performance of the SENS-U during a night-time, home-based evaluation in children with monosymptomatic nocturnal enuresis (MNE) for the first time. It was hypothesized that the SENS-U would be equally accurate for both daytime - and nighttime registrations.

\section{PATIENTS AND METHODS}

The SENS-U is a small, wearable, wireless ultrasonic bladder sensor which is worn on the lower abdomen using a double-sided adhesive and continuously monitors the bladder filling in children [10], [11]. Based on the child's maximum voided volume, a personalized threshold is set by a medical professional using the mobile application. When the threshold is almost reached (at $80 \%$ and $100 \%$ ), the SENS-U gives a vibration notification on the belly. If connected, using Bluetooth ${ }^{\circledR}$ Low Energy, a message is sent to the mobile application, informing the child and/or caregivers that it is time to go to the toilet [10], [11].

To evaluate the SENS-U for ambulatory care in children with nocturnal enuresis, patients with MNE were consecutively recruited by a specialized nurse at the Department of Pediatrics (Jeroen Bosch Hospital, the Netherlands). Conforming to the intended usage of the SENS-U, patients were included between the age of 6 to 12 years in this study. Exclusion criteria were: (1) patients with a small bladder capacity $<65 \%$ of the EBC) and (2) patients with abnormalities in the suprapubic skin region (e.g. breached skin, open wounds, sutures or major scar tissue or a (suprapubic) catheter) [11]. After informed consent was signed by the parents/caregivers of the patient, an appointment was scheduled for a nocturnal SENS-U measurement at home.

On the day of the measurement, the researcher visited the patient's home before bedtime. Prior to positioning the SENS-U, parents and child were asked to fill in selected questions from the children's sleep habit questionnaire (CSHQ, Table 6.1). Next, the SENS-U was positioned on the lower abdomen of the child, according to the instructions for use (in line with umbilicus, $1 \mathrm{~cm}$ above the pubic bone combined with standard ultrasound gel). From this moment, until the next morning, the SENS-U continuously (i.e. every $30 \mathrm{~s}$ ) estimated the nocturnal bladder filling [10]. To minimize the impact on the child's night rest and current treatment, the full-bladder notifications of the SENS-U were deactivated. Next morning, the researcher visited the patient again to remove the 
SENS-U from the lower abdomen and to (re)evaluate the patient's sleep behavior while wearing the SENS-U by answering selected CSHQ questions once more.

Before the procedure, descriptive patient data were retrieved from medical files on age, gender, length, weight, abdominal girth (AG), diagnoses and maximum bladder capacity (based on maximum voided volume). Missing information were collected during the patient's home visit. During the night, the parents were asked to report the time $\left(\mathrm{T}_{\text {void }}\right)$ and urinary volume $\left(\mathrm{V}_{\text {void }}\right)$ (using e.g. a measuring cup/home flowmeter or weighing diapers) of nightly voiding, wetting incidents and early morning volume (EMV), by recording a voiding diary.

All the collected data were stored in an online case report form using Castor Electronic Data Capture (Ciwit BV, Amsterdam, the Netherlands) and were analyzed by descriptive statistics. The measurement data saved by the SENS-U were exported using the Bluetooth $^{\circledR}$ Low Energy connectivity and were processed offline using MATLAB R2018 (MathWorks, Natick, MA). This study was approved by the Medical Ethics Review Committee Brabant, the Netherlands.

Table 6.1: The pre-selected children's sleep habit questionnaire (CSHQ), N.A.: Not Applicable

\begin{tabular}{|c|c|c|c|c|c|}
\hline \multirow{2}{*}{$\begin{array}{l}\text { Category } \\
\text { Bedtime }\end{array}$} & \multirow{2}{*}{ No. } & \multirow{2}{*}{$\begin{array}{l}\text { Selected Questions } \\
\text { Child falls asleep within } 20 \text { minutes after } \\
\text { going to bed. }\end{array}$} & \multicolumn{3}{|c|}{ Answers } \\
\hline & & & Yes & No & N.A. \\
\hline Sleep Behavior & 2 & Child sleeps the right amount. & Yes & No & N.A. \\
\hline \multirow{2}{*}{$\begin{array}{l}\text { Waking during the } \\
\text { Night }\end{array}$} & 3 & Child wakes up once during the night. & Yes & No & N.A. \\
\hline & 4 & $\begin{array}{l}\text { Child wakes up more than once during } \\
\text { the night. }\end{array}$ & Yes & No & N.A. \\
\hline Morning Waking & 5 & Child wakes up by him/herself. & Yes & No & N.A. \\
\hline
\end{tabular}

\section{RESULTS}

\section{Subject demographics}

A total of 15 patients (13 boys, 2 girls; mean age: $8.6 \pm 1.5$ years; mean body mass index [BMI]: $16.7 \pm 1.7 \mathrm{~kg} / \mathrm{m} 2, \mathrm{AG}: 61.5 \pm 5.9 \mathrm{~cm}$ ) have been enrolled in this feasibility study. Based on the retrieved medical file data, the average maximum bladder capacity (during holding exercise) was $240 \pm 75 \mathrm{ml}$ and the children had moderate-to-severe monosymptomatic nocturnal enuresis (MNE).

Before further analyses, one patient was excluded because of inadequate sensor-toskin contact. Next, another patient woke-up during the night, using a wetting alarm, and immediately went voiding. The urine loss was negligible and therefore this patient was 
considered dry. During the measurement night six children (43\%) happened to be dry, while eight children (57\%) had bedwetting incidents. The children with wet incidents had an average urine loss of $128 \pm 82 \mathrm{~mL}$ over the night.

\section{SENS-U Nocturnal Performance}

For the 14 included children, a total of 18 natural nocturnal bladder filling (NNBF) cycles were recorded using a voiding diary, of which three patients $(21 \%)$ had more than one NNBF cycle. The requirement set for the SENS-U to successfully detect a NNBF cycle, was stated as an increase in the average anterior - posterior bladder dimension over time: from time of placement $\left(T_{0}\right)$ or time of voiding $\left(T_{\text {void }}\right)$ until the next recorded voiding. The SENS-U observed 15 of the 18 documented NNBF cycles, resulting in a success rate of $83 \%(n=15 / 18$ ) (see Table 6.2 ). The three missed NNBF cycles by the SENS-U had a volume of less than $30 \mathrm{~mL}$, which was at the lower limit of the detection range of the sensor (see Table 6.2) [11]. However, when the NNBF cycles with a volume $\leq 30 \mathrm{~mL}$ were excluded $(n=3,17 \%)$, the success rate of the SENS-U would probably even be higher.

Figure 6.1 illustrates the SENS-U as a potential new diagnostic tool to assess the nocturnal bladder function, without interrupting the sleep of the child. Figure 6.1 shows the results of subject no. 5, an 8-year-old girl, who had multiple enuretic episodes during the measurement. First of all, this figure clearly shows that the child did not empty her bladder properly before bedtime (blue arrow), indicating inadequate voiding behavior. Next, the patient appears to have had multiple enuretic events during the night (green circles, not recorded in voiding diary), indicating nocturnal detrusor overactivity, resulting in a total urinary leakage of $244 \mathrm{ml}$. Consequently, the EMV of the child was very low compared to her maximum voided volume (MVV) of $200 \mathrm{ml}\left(\mathrm{V}_{\text {void }}=65 \mathrm{ml}\right.$, $32.5 \%$ of MVV).

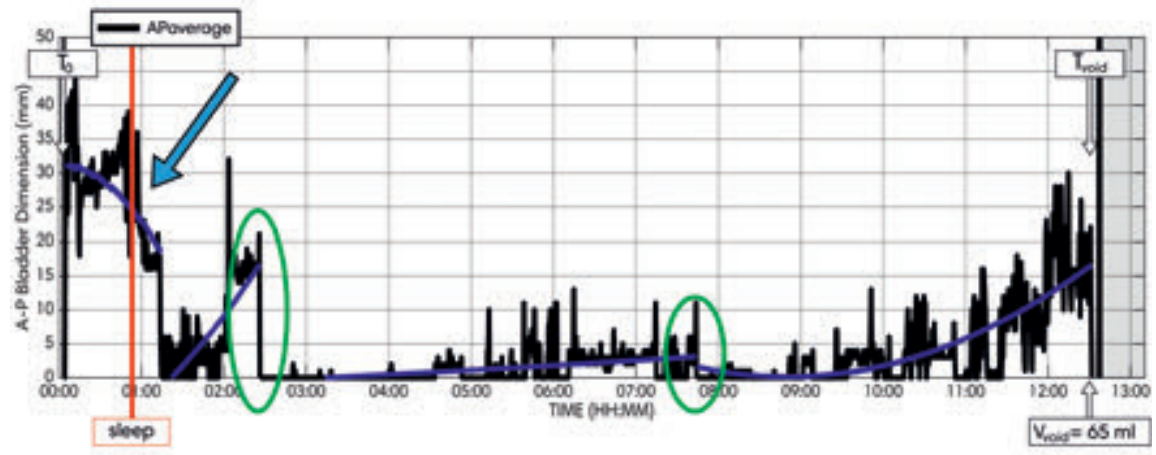

Figure 6.1: Results of an 8-year-old girl. She did not empty her bladder before bedtime (blue arrow). Next, she had multiple enuretic events during the night (green circles). Total urine loss of $244 \mathrm{ml}$. Blue lines are included as a visual aid represented by a (second order) polynomial trendline. 
Table 6.2: The obtained data during the nocturnal measurements. Grey: Not detected by the SENS-U

\begin{tabular}{|c|c|c|c|c|c|c|}
\hline \multirow{2}{*}{$\begin{array}{c}\text { Patient No. } \\
2\end{array}$} & \multirow{2}{*}{$\begin{array}{c}\text { Urine loss } \\
(\mathrm{ml})\end{array}$} & \multirow{2}{*}{$\begin{array}{c}\begin{array}{c}\text { Micturition } \\
\text { frequency }\end{array} \\
1\end{array}$} & \multicolumn{3}{|c|}{ Voided volumes (ml) } & \multirow{2}{*}{$\begin{array}{c}\text { NNBF cycles } \\
\text { detected by SENS-U } \\
1\end{array}$} \\
\hline & & & 220 & & & \\
\hline 3 & 48 & 1 & 125 & & & 1 \\
\hline 4 & - & 1 & 140 & & & 1 \\
\hline 5 & 244 & 1 & 65 & & & 1 \\
\hline 6 & 100 & 1 & 145 & & & 1 \\
\hline 7 & 100 & 1 & 50 & & & 1 \\
\hline 8 & - & 1 & 200 & & & 1 \\
\hline 9 & - & 1 & 190 & & & 1 \\
\hline 10 & - & 2 & 160 & 140 & & 2 \\
\hline 11 & - & 1 & 150 & & & 1 \\
\hline 12 & 138 & 2 & 30 & 70 & & 1 \\
\hline 13 & - & 3 & 110 & 10 & 140 & 2 \\
\hline 14 & 158 & 1 & 30 & & & 0 \\
\hline 15 & 232 & 1 & 85 & & & 1 \\
\hline Total: & & 18 & & & & 15 \\
\hline
\end{tabular}

Figure 6.2 illustrates the performance of the SENS-U as an potential treatment tool, showing the results of subject no. 10, a 7 year old boy, with a nocturnal episode after $6 \mathrm{~h}$ of sleep, voiding $160 \mathrm{ml}$, followed (after 4h) by the EMV of $140 \mathrm{ml}$. Figure 6.2 presents the theoretical notification threshold (at 80 and 100\%) of the SENS-U based on the mean night-time diuresis (incl. diaper weight, nocturia, and morning void) [1], [6], [9], [11], indicating that the child would theoretically be notified before the event, preventing wet sheets and training the child to awaken to the signs of a full bladder [9]. Figure 6.2 also shows that the child woke up at night to void at a bladder volume $\left(\mathrm{V}_{\text {void }}=160 \mathrm{ml}\right.$ ) well below (at 50\%) his known maximum voided volume (MVV = $\left.320 \mathrm{ml}\right)$.

Finally, regarding the impact of the SENS-U on the children's sleep habits, the (shortened) CSHQ showed that wearing the SENS-U had no effect on falling asleep and the duration of sleep. However, five children (36\%) woke-up during the night once, while wearing the SENS-U, while they did not wake up generally. 


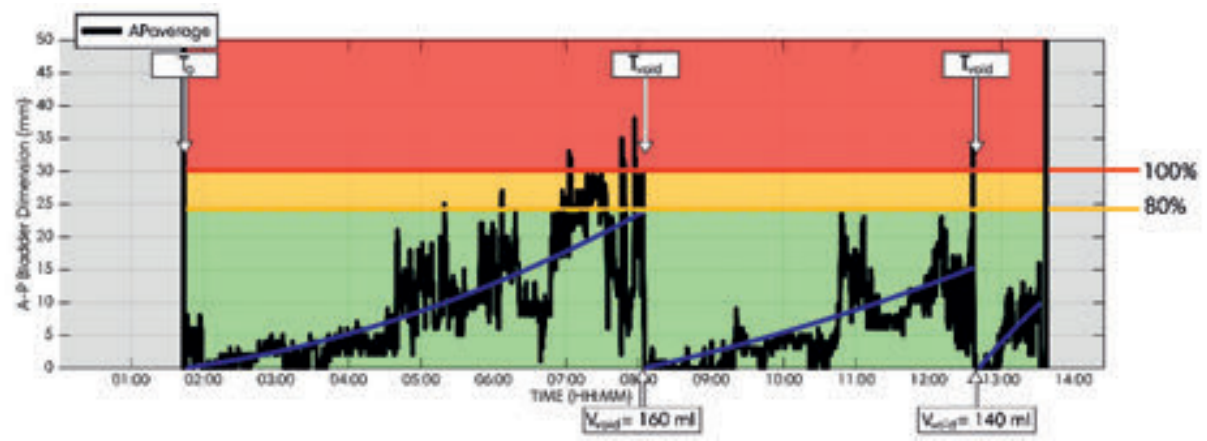

Figure 6.2: Result of a 7-year-old boy. He was dry during the night, woke up and voided twice while wearing the SENS-U. Theoretical notifications settings ( 80 - and $100 \%)$ of the average voided volume $(=150 \mathrm{ml}$ ). Blue lines are included as a visual aid represented by a (second order) polynomial trendline.

\section{DISCUSSION}

This is the first observational, feasibility study which assessed the performance of the SENS-U for monitoring the natural nocturnal bladder filling in children with enuresis in the home-environment. These results show that the SENS-U is capable of measuring the nocturnal bladder filling successfully within its detection range and it doesn't influences the child's sleeping behavior (i.e. falling asleep and the duration of sleep). Regarding the children who woke-up during the night, this effect was stated as not statistically significant as result of the population size for this initial feasibility study.

Next, these findings indicate the potential of the SENS-U as a new, practice- changing diagnostic tool to gain more insight in the condition of nocturnal enuresis. For example, SENS-U data showed that one of the children went to sleep with a full bladder and had multiple wetting accidents of a small urinary volume during the night. These findings correspond to common parental observations and are often potentially related to nocturnal bladder overactivity [5]. However, there is still a lot unclear about the prevalence of frequent night-time voiding [5].

Nevertheless, there were several limitations to this study. First of all, 57\% of the children experienced bedwetting accidents while wearing the SENS-U. Unfortunately, these children did not wake up as result of their enuresis, resulting in missing voiding diary data. Therefore, not all NNBF cycles, which seemed to be measured with the SENS-U could be verified (Figure 6.2). For future validation-research, it is recommended to use an additional moisture-sensitive device in addition to the described protocol, to record the exact time and volume of each wetting accident. Second, in this initial feasibility study, children used the SENS-U for one monitoring night, to minimize the impact on their current treatment. To further investigate the accuracy and validity of the device, it is recommended to increase the population size and monitor for multiple 
nights which will enable cross case validation and between case comparison. Next, as Figure 6.1 indicates, the bladder filling estimated by the SENS-U fluctuates during the night within one NNBF cycle. A decrease in value might therefore be interpreted as a (partial) enuretic event. However, the SENS-U estimates the bladder dimension in a sagittal field of view (FOV) of $30^{\circ}$. As a result, when a child lies in bed in a supine or prone position, the bladder is aligned with the sensor's FOV. However, when the child lies on its left or right side, the bladder shifts within the FOV, influencing the accuracy of the bladder filling estimation. Therefore, it is advised to optimize the internal algorithms to correct for the posture-dependency.

Finally, future research will also focus on investigating the validity and usability of the SENS-U for treatment purposes. For example for children with nocturnal polyuria, the SENS-U can be used as an adjunct treatment tool, by notifying the child before the bladder is (too) full, waking up and preventing the enuretic event. Relating to the configuration and features of the SENS-U to previously developed portable bladder monitors shows that it has several advantages regarding this intended use. First of all, the SENS-U provides a (vibration) notification every $3 \mathrm{~min}$. (with increasing intensity) until it detects that the bladder is emptied properly, which might be beneficial for children with decreased arousability from sleep. Also, this functionality ensures that the child is unable to turn off the notification and go back to sleep and wet the bed. Second, due to the Bluetooth-connectivity with the child's mobile application, parents/ caregivers can also be notified prior to the potentially enuretic event (by a forwarded text message / call to their own phones), enabling them to wake up their child, empty the bladder properly and preventing wet sheets.

\section{CONCLUSIONS}

For the first time, the SENS-U Bladder Sensor was validated as a diagnostic tool for monitoring nocturnal bladder filling in children with monosymptomatic nocturnal enuresis at home, without disturbing their sleep behavior. The SENS-U was able to monitor the nocturnal bladder filling with a success rate of $83 \%$. However, when correcting for the sensor's lower limit of the detection, the success rate would even be higher. Future research will focus on investigating the usability of the SENS-U for both diagnostic - and treatment purposes.

\section{Acknowledgments}

The authors would like to thank all the pediatricians and nurses at the Department of Pediatrics in the Jeroen Bosch Hospital ('s-Hertogenbosch, the Netherlands) for their help in the recruitment of the patients and their assistance during the study procedure. Next, the authors would like to thank pediatric urologists and nurses at the Department of Pediatric Urology in the Wilhelmina Children's Hospital UMC Utrecht (Utrecht, the Netherlands) for their input in constructing the study protocol. 


\section{Ethical approval}

This study was approved by the Medical Ethics Review Committee Brabant, the Netherlands.

\section{Funding}

This work was supported by Novioscan (Nijmegen, the Netherlands, www.novioscan.com). This work is partly funded in the ULIMPIA project funded by PENTA under grant number PENTA-2017-Call2-16101-ULIMPIA. www.ulimpia-project.eu.

\section{Conflict of interest statement}

This feasibility study was performed by W.M.J. Kwinten, as part of her master graduation internship for Technical Medicine (University of Twente, Enschede, the Netherlands) at the Department of Pediatric Urology, Wilhelmina Children's Hospital UMC Utrecht (Utrecht, the Netherlands). Technical physician P.G. van Leuteren was one of her supervisor and is also an employee of Novioscan. The other authors have no conflict of interest to declare. 


\section{REFERENCES}

1. Austin P.F., Bauwer S.B., Bower W., Chase J., Franco I., Hoebeke P., et al The standardization of terminology of lower urinary tract function in children and adolescents: update report from the standardization committee of the International Children's Continence Society. Neurourol Urodyn 2016;35(4):471-481. https://doi.org/10.1002/nau.22751

2. Pereira R.F., Silvares E.F.M., Braga P.F. Behavioral alarm treatment for nocturnal enuresis. Int Braz J Urol 2010;36(3):332-338. https://doi.org/10.1590/S1677-55382010000300010

3. Brown M.L., Pope A.W., Brown E.J. Treatment of primary nocturnal enuresis in children: a review. Child Care Health Dev 2011;37(2):153-160. https://doi.org/10.1111/j.13652214.2010.01146.x

4. Petrican P., Sawan M.A. Design of a miniaturized ultrasonic bladder volume monitor and subsequent preliminary evaluation on 41 enuretic patients. IEEE Trans Rehabil Eng Mar. 1998;6(1):66-74. https://doi.org/10.1109/86.662622

5. Nevéus T. The amount of urine voided in bed by children with enuresis. J Pediatr Urol 2019;15(1):31.e1-31.e5. https://doi.org/10.1016/j.jpurol.2018.08.006

6. Mattsson S., Persson D., Glad Mattsson G., Lindström S. Night-time diuresis pattern in children with and without primary monosymptomatic nocturnal enuresis. J Pediatr Urol 2019;15(3):229.e1-229.e8. https://doi.org/10.1016/j.jpurol.2019.02.002

7. Neveus T., Eggert P., Evans J., Macedo A., Rittig S., Tekgül S., et al. Evaluation of and treatment for monosymptomatic enuresis: a standardization document from the International Children's Continence Society. J Urol 2010; 183(2):441-447. https://doi. org/10.1016/j.juro.2009.10.043

8. Friman P.C., Jones K.M. Behavioral Treatment for Nocturnal Enuresis. J Early Intensive Behav Interv 2005;2(4):259-267. https://dx.doi.org/10.1037/h0100319

9. Pretlow R.A. Treatment of nocturnal enuresis with an ultrasound bladder volume controlled alarm device. J Urol 1999;162(3 II):1224-1228. https://doi.org/10.1016/S00225347(01)68141-2

10. van Leuteren P.G., Nieuwhof-Leppink A.J., Dik P. SENS-U: clinical evaluation of a fullbladder notification - a pilot study. J Pediatr Urol 2019;15(4):381.e1-381.e5. https://doi. org/10.1016/j.jpurol.2019.04.006

11. van Leuteren P.G., Klijn A.J., De Jong T.P.V.M., Dik P. SENS-U: validation of a wearable ultrasonic bladder monitor in children during urodynamic studies. J Pediatr Urol 2018;14(6):569.e1-569.e6. https://doi.org/10.1016/j.jpurol.2018.07.018 



\section{SENS-U: a Series of Cases Reports}

Cases reports accepted and presented at: ICCS Meeting, Rome, Italy, September 2018 [1]

30th Congress ESPU(Nurses), Lyon, France, April 2019 [2] 5th Joint Meeting ESPU-SPU, Lisbon, Portugal, April 2021 [3] 


\section{INTRODUCTION}

Since the European certification of the SENS-U as a CE-marked, class Ila medical device (MDD 93/42/EEC), the SENS-U has been introduced to the European Healthcare Market by manufacturer Novioscan (Nijmegen, the Netherlands). This enables (pediatric) urologists, pediatricians and nurses to support their patients in the treatment of urinary incontinence by continuously monitoring the bladder filling status and providing personalized notifications to go to the bathroom in time. Until now, the SENS-U has been released in the following markets: the Netherlands, Belgium, Germany, United Kingdom, France, Scandinavia, and Poland [4].

To illustrate the first steps towards a broader clinical implementation and valorization of the SENS-U, a series of (inter)national, clinical (research) case reports are presented to discuss the clinical impact of using the SENS-U in the treatment of children with different types of (refractory) urinary incontinence [1]-[3].

In addition, (pediatric) urologists, pediatricians and nurses in hospitals throughout the Netherlands who currently use the SENS-U in their daily clinical practice were contacted, to share their user experiences with this new sensor technology.

\section{PATIENTS AND METHODS}

In July 2020, (pediatric) urologists, pediatricians and nurses of several (inter)national medical institutions were contacted. They were asked to share their experiences with the SENS-U, as a potential new adjunct tool for both diagnostic - and treatment purposes for children with urinary incontinence, both from a clinical - and user perspective (Table 7.1).

In total, the experiences of $\underline{21}$ patients were retrieved from the department of (Pediatric) Urology or Pediatrics of five (inter)national medical institutions in the Netherlands and Belgium. Table 7.1 presents both the number of cases retrieved per medical institution, and describes the subdivision based on whether it concern a clinical case, a user (evaluation) case or a clinical research case.

\section{RESULTS}

\section{Experiences Retrieved}

In total, the experiences of 21 patients (11 boys (52\%), 10 girls (48\%)) were retrieved. Their ages ranged from 5-12 years with a mean value ( \pm SD) of $9.0 \pm 2.0$ years. For 9 patients (43\%) the SENS-U was used as an adjunct tool in their clinical treatment: the treatment group. 
Table 7.1: Contacted (inter)national medical institutions.

\begin{tabular}{|c|c|c|c|c|}
\hline \multicolumn{2}{|r|}{ (Inter)national medical institutions } & \multirow{2}{*}{$\begin{array}{c}\begin{array}{c}\text { Clinical } \\
\text { Case }\end{array} \\
1\end{array}$} & \multirow{2}{*}{$\begin{array}{c}\text { User } \\
\text { Case }\end{array}$} & \multirow{2}{*}{$\begin{array}{c}\begin{array}{c}\text { Research } \\
\text { Case }\end{array} \\
3\end{array}$} \\
\hline $74^{\prime}$ & $\begin{array}{l}\text { University Hospital Antwerp } \\
\text { (Antwerp, Belgium) [UZA] }\end{array}$ & & & \\
\hline 4 masstichn Umo- & $\begin{array}{l}\text { Maastricht University Medical Center } \\
\text { (Maastricht, the Netherlands) [MUMC] }\end{array}$ & 3 & - & - \\
\hline $\begin{array}{l}\text { Jeroen ioscr in } \\
\text { ziekentuls }\end{array}$ & $\begin{array}{l}\text { Jeroen Bosch Hospital [JBZ] } \\
\text { ('s-Hertogenbosch, the Netherlands) }\end{array}$ & 1 & - & - \\
\hline$C_{\text {Calm }}^{\text {Erasmus }}$ & $\begin{array}{l}\text { Erasmus MC Sophia Children's Hospital } \\
\text { (Rotterdam, the Netherlands) [EMCR] }\end{array}$ & $3^{*}$ & 5 & - \\
\hline 结 & $\begin{array}{l}\text { Wilhelmina Children's Hospital [WKZ] } \\
\text { (UMC Utrecht, Utrecht, the Netherlands) }\end{array}$ & 1 & 4 & - \\
\hline Total: & & 9 & 9 & 3 \\
\hline
\end{tabular}

*Participated also in User Case

Categorizing this treatment group based on their medical history, results in the following distribution: $22 \%$ with a neurogenic bladder $(n=2$ retrieved from UZA / WKZ), 67\% $(n=6)$ suffering from urinary incontinence (day / night) (cases received from MUMC / JBZ / EMCR), and one case (11\%, retrieved from EMCR) suffered from residual volume and urinary tract infections.

Considering the user (evaluation) cases; 12 children (57\%) (3 children of EMCR user cases also progress to the treatment group, see $\left({ }^{*}\right)$ Table 7.1) participated into an user evaluation phase: the evaluation group.

Categorizing the evaluation group based on their medical history, presents the following distribution: 33\% with an Overactive Bladder ( $n=4$, retrieved from WKZ), 33\% suffering from urinary incontinence (day / night) ( $n=4$, retrieved from EMCR), and 33\% ( $n=4$, received from EMCR) suffered from residual volume (or others).

Next, 3 cases $(14 \%$, from UZA) were retrieved from the first inclusions of a clinical investigation (the research group) determining the feasibility of using the SENS-U for volume-dependent intermittent self-catheterization (VDIC) in patients with a neurogenic bladder. This investigation was initiated after the first clinical case described by department of Urology of University Hospital Antwerp (Antwerp, Belgium).

\section{Treatment Group}

This section describes each individual clinical case retrieved from its related (inter) national medical institutions. 


\section{- $\quad$ University Hospital Antwerp [1]}

Patient(s) and method

We present a case of 11-year-old patient [152 cm, $37 \mathrm{~kg}, \mathrm{BMI}: 16.0 \mathrm{~kg} / \mathrm{m}^{2}$ ], who had history of PUV and detrusor overactivity, eventually resulting in bladder hypocontractility $(\mathrm{MBC}=390 \mathrm{ml}$ ). He experiences wet accidents of his (under)pants three times a day. The boy started time-dependent intermittent self-catheterization (TDIC) ( 5 times/day), reducing the number of wet accidents. However, the patient still suffered from urinary leakage. Therefore, it was decided to start him on a VDIC training, based on a maximum SENS-U volume-range of $300-324 \mathrm{ml}$, for a period of 16 days. One week after, an evaluation was scheduled.

\section{Results/Discussion}

While performing SENS-U - assisted VDIC, he was able to stay dry during the entire period of 16 days. With this approach, the number of catheterizations was reduced to 4 times/day (11am is cancelled) with similar volumes. In addition, the patient reported satisfaction due to the appropriateness of catheterization and the degrees of freedom he experienced while wearing the SENS-U (i.e. going to school, no monitoring of fluidintake). One week later, he restarted TDIC, followed by an increased number of wet accidents.

\section{Conclusions}

Based on this first case, the SENS-U Bladder Sensor is feasible approach to assist in volume-dependent intermittent self-catheterization.

NOTE: This case report was presented at the 2018-meeting of the International Children's Continence Society (ICCS), entitled: 'VOLUME-DEPENDENT CATHETERIZATION WITH A WEARABLE ULTRASONIC BLADDER SENSOR IN A TEENAGE BOY' by P.G. VAN LEUTEREN ${ }^{1}$ and G. DE WIN"2,

\section{- Maastricht University Medical Center [3]}

\section{Patient(s) and method}

Patient A: 10 years, autism, urethral valve ablation, nephrectomy of non-functioning right kidney, small voiding volumes, temporary response to all medication and urotherapy. Relapsing incontinence.

1 University Children's Hospitals UMC Utrecht, Department of Pediatric Urology, Utrecht, NETHERLANDS

2 Faculty of Medicine and Health Sciences, University of Antwerp, Antwerp, Belgium.

3 Department of Urology, Antwerp University Hospital, Edegem, Belgium. 
Patient B: 11 years, autism and Asperger syndrome, day and night incontinence for feces and urine. All treatments so far without effect. Thick walled bladder. Interrupted urinary flow. Cystoscopy without signs of obstruction.

Patient C: 12 years, autism, urethral valve ablation, urinary infections, Deflux left ostium Urotherapy. Dilated rectum, fecal incontinence. Postponement and urinary (overflow) incontinence. Unawareness of a full bladder.

These 3 boys were treated with the SENS-U in order to continuously measure the bladder volume and to notify to go to the toilet at a filling of $80 \%$ of the expected voiding volume.

\section{Results/Discussion}

Patient A: The SENS-U device showed always a residual volume after micturition. He became more aware of his condition and produced better volumes and less residuals. He is dry now.

Patient B: The notifications made him aware of the true bladder filling and he became more confident. He became dry during night and day.

Patient C: Postponement disappeared and he is passing urine more regularly. He became dry.

It was remarkable how soon these autistic boys seemed to learn from direct biofeedback of the SENS-U and to use the notifications to regain complete bladder control.

\section{Conclusions}

The SENS-U made these 3 autistic patients more aware of the filling status of the bladder and they became continent without further treatment.

NOTE: This case report will be presented at the $5^{\text {th }}$ Join Meeting of the European Society of Pediatric Urology (ESPU), entitled: 'THREE CASES OF AUTISTIC BOYS WITH REFRACTORY URINARY INCONTINENCE BUT RESPONDING WELL TO A BLADDER SENSOR DEVICE' by P.G. VAN LEUTEREN ${ }^{1}$, P.R.H. CALLEWAERT $T^{4}, P . D^{1} K^{1}$.

\section{- $\quad$ Jeroen Bosch Hospital}

Patient(s) and method

A case is presented of a 9-year old boy [145 cm, $34 \mathrm{~kg}$, BMI: $16.2 \mathrm{~kg} / \mathrm{m}^{2}, \mathrm{MBC}=200 \mathrm{ml}$, who suffers from fecal incontinence and secondary urinary incontinence during day and night, which has a major impact on the boy's (and its parents) quality of life. 
After becoming continent for one year during the day, and for six months during the night, wetting accidents started occurring again as result of voiding postponement (3-4 times/day during the daytime, 2-3 times/week during the night from which he does not wake up).

Treatment initially focused on fecal incontinence, starting with laxatives, which also reduced the number of wetting accidents. Next, the boy started with (standard) urotherapy, combined with oxybutynin. After a period of nine months, the boy became almost continent during the day, and started with desmopressin for his enuresis. However, eight months later, he experienced refractory daytime incontinence for which he started using an alarm wrist watch, but he was still wet on a daily basis.

Approximately six months later, the boy received treatment for daytime incontinence with the SENS-U for a period of 4 weeks ( 1 week intermittently, 3 weeks consistently), based on a personalized (vibration) threshold of 175-199 ml.

\section{Results/Discussion}

While using the SENS-U, the boy responded immediately at each notification, allowing him to proceed to the toilet in time and remain dry (except sometimes for a single drop of urine) (initial success: complete response - 100\% reduction). Two weeks after the treatment period, he was still able to remain dry. However, after six weeks, wetting accidents increased slightly to $2-3$ times/week (initially: 3-4 times/day, $\pm 90 \%$ reduction).

The boy and his parents were very positive about the clinical effectiveness of the SENS-U. However, there were several observations made regarding the size (and weight) of the device (too big), and the notice of skin irritation (minor redness) as result of the double-sided adhesive used to position the device.

\section{Conclusions}

Based on this case, the SENS-U is a potentially, new, feasible adjunct treatment tool for children with secondary urinary incontinence, by increasing their awareness of the bladder filling status, and assisting them to relearn the proper sense of urgency. However, a 4-week treatment period might be to short, to result in a continues success.

\section{- $\quad$ Wilhelmina Children's Hospital}

\section{Patient(s) and method}

This case presents an 11-year old boy with neurogenic bladder dysfunction based on a meningocele with a thickened filum terminale. He has a maximum bladder capacity of $390 \mathrm{ml}$ and experiences a sense of urgency at $240 \mathrm{ml}$ (based on urodynamic data). In order to empty his bladder properly and prevent urinary retention, he performs 
Clean Intermittent Self Catheterization (CISC) 7 times/day at a maximum volume of 300 $\mathrm{ml}$. Unfortunately, the boy experiences wet accidents in-between the catheterization attempts, often because he forgets to perform CISC on time (he has to be warned by his parents).

\section{Results/Discussion}

To support the boy, he started using the SENS-U to perform volume-dependent intermittent self-catheterization (VDIC) with a personalized threshold of 300-324 ml. While using the SENS-U, the boy was able to reduce the number of wetting accidents in-between the catheterization attempts, and his level of independence increased significantly. He was very positive about using the new adjunct tool as part of his treatment. However, unfortunately after he (temporally) stopped using the SENS-U

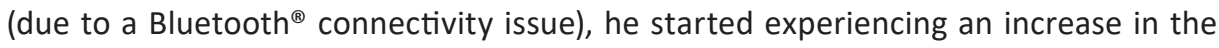
number of wetting accidents again.

\section{Conclusions}

Based on the results of this first treatment period, the boy will restart using the SENS-U to support him during volume-dependent intermittent self-catheterization.

\section{Research Group}

This section describes the research cases retrieved from its related (inter)national medical institution.

\section{- $\quad$ University Hospital Antwerp [2]}

\section{Patient(s) and methods}

Based on the first clinical observation [1], the department of Urology of University Hospital Antwerp (Antwerp, Belgium) started to evaluate the feasibility of the SENS-U for volume-dependent intermittent self-catheterization (VDIC) during one week in 15 children with a neurogenic bladder, compared to time-dependent intermittent selfcatheterization (TDIC) (for one week). To assess the feasibility, 1) the appropriateness of intermittent self catheterization (no. catheterization \& volume $(\mathrm{ml})$ ), 2) the degree of urinary incontinence (based on number of incontinence episodes \& leakage (ml)), and 3 ) the financial and Quality of Life (QoL) impact was determined. During the clinical investigation, the patient kept a voiding diary, recorded fluid intake, catheterization attempts, urinary volume and periods of incontinence. In addition, the protocol started and ended with a QoL questionnaire. During the $30^{\text {th }}$ congress of the ESPU, the preliminary results of the first three children were presented (Table 7.2, Table 7.3) [2].

\section{Results/Discussion}

The preliminary results indicated that the SENS-U could be a feasible approach to VDIC. First, during VDIC, the mean catheterized volume (green box, Table 7.3) shifted towards 
the pre-set personalized notification threshold (green box, Table 7.2). For example, in subject no. 01, the mean catheterized volume $\left(\mathrm{V}_{\text {TDIC }}=241 \mathrm{ml}\right)$ during TDIC decreased to the SENS-U volume range of $150-174 \mathrm{ml}\left(\mathrm{V}_{\mathrm{VDIC}}=178 \mathrm{ml}\right)$. Consequently, the number of average catheterization attempts increased by one / day.

The opposite occurred for subject no. 02, whose notification threshold was set higher (range: 275-299 ml, green box in Table 7.2) compared to his average catheterized volume during TDIC $\left(\mathrm{V}_{\text {TDIC }}=177 \mathrm{ml}\right)$, resulting in a higher catheterized volume while using the SENS-U $\left(\mathrm{V}_{\mathrm{vDIC}}=224 \mathrm{ml}\right.$ ) (green box, Table 7.3).

Next, the level of incontinence reduced significantly to (almost be) able to stay dry during day and night. The preliminary results are summarized in Table 7.3.

Table 7.2: Patient characteristics and SENS-U notification settings.

\begin{tabular}{|c|c|c|c|}
\hline ID: & 01 & 02 & $03^{\#}$ \\
\hline Age (years) & 6 & 9 & 8 \\
\hline Gender ( $\left.0^{\pi} / \$\right)$ & $0^{\pi}$ & $0^{\pi}$ & $0^{\pi}$ \\
\hline Wheelchair & $\xi$ & $\mathrm{N} / \mathrm{A}$ & $\xi$ \\
\hline SENS-U settings & $\begin{array}{c}6 \\
(150-174 \mathrm{ml})\end{array}$ & $\begin{array}{c}11 \\
(275-299 \mathrm{ml})\end{array}$ & $\begin{array}{c}11 \\
(275-299 \mathrm{ml})\end{array}$ \\
\hline
\end{tabular}

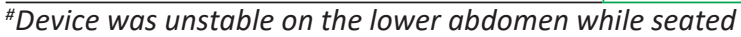

However, there was also several practical limitations observed. First, the stability of the SENS-U on the lower abdomen was compromised in children who are in a wheelchair, especially during transfers for example to the bed or to a chair (see Table $\mathbf{7 . 2}$, subject no. 1 \& 3).

As a result, subject no. 3 was unable to continue using the SENS-U (see (\#) Table 7.3) during the second measurement week. Next, subject no. 1 (see $\left(^{*}\right)$ Table 7.3) experienced skin irritation (minor redness) from the double-sided skin adhesive which positions the SENS-U. As a result, this subject did not finish the complete measurement protocol (5 out of 7 days).

Finally, the preliminary results suggested that performing intermittent catheterization based on the SENS-U would particularly be beneficial for children who can perform intermittent catheterization independently from their parents/caregivers. Otherwise, the parents/caregivers should assist their child at the time of an actual full bladder (can be any moment in time), which might be less practical in daily life (e.g. parents at work) compared to a predetermined time-schedule. 
Table 7.3: First Observations in the research group

\begin{tabular}{|c|c|c|c|c|}
\hline ID: & $\begin{array}{l}\text { TDIC / } \\
\text { VDIC }\end{array}$ & $01 *$ & 02 & $03^{\#}$ \\
\hline \multirow{3}{*}{$\begin{array}{l}\text { No. Catheterizations } \\
\text { (Mean) }\end{array}$} & TDIC & 5 & 6 & 4 \\
\hline & VDIC & 6 & 4 & $\mathrm{~N} / \mathrm{A}$ \\
\hline & $\Delta$ & +1 & -2 & $\mathrm{~N} / \mathrm{A}$ \\
\hline \multirow{3}{*}{$\begin{array}{l}\text { Catheterized Volume (ml) } \\
\text { (Mean) }\end{array}$} & TDIC & 241 & 177 & 89 \\
\hline & VDIC & 178 & 224 & $\mathrm{~N} / \mathrm{A}$ \\
\hline & $\Delta$ & -63 & +47 & $\mathrm{~N} / \mathrm{A}$ \\
\hline \multirow[t]{3}{*}{ Incontinence episodes } & TDIC & 8 & 1 & 18 \\
\hline & VDIC & 1 & $1^{* *}$ & N/A \\
\hline & $\Delta$ & -7 & 0 & $\mathrm{~N} / \mathrm{A}$ \\
\hline
\end{tabular}

*Based on a 5 day observation (i.e. skin irritation), **Wet before positioning the SENS-U, "Sensor unstable while seated.

Also, physician(s) indicated that the accuracy of the SENS-U could be compromised in children with a neurogenic bladder and a ventriculoperitoneal shunt (e.g. a child with spina bifida and hydrocephalus), due to the presence of additional (cerebrospinal) fluid in the peritoneal cavity, which might be interpreted as additional urinary volume (artefact).

\section{Conclusions}

These preliminary results suggested that the SENS-U could be a feasible approach to assist VDIC by monitoring the bladder filling, providing a personalized notification and reducing the number of incontinence episodes, through a more appropriate way of intermittent self catheterization. However, it is advised to further reduce the size of the SENS-U, ensure a more comfortable and stable device, especially when the (independent) child is in a wheelchair.

NOTE: These preliminary results were presented at the $30^{\text {th }}$ Meeting of the European Society of Pediatric Urology (ESPU), entitled: 'VOLUME-DEPENDENT CATHETERIZATION WITH A WEARABLE ULTRASONIC BLADDER SENSOR - A FEASIBILITY STUDY' by G. DE WIN ${ }^{5}$, T. JACOBS 5 , S. EERENS ${ }^{6}$, K. DE BAETS ${ }^{5}$, and P.G. VAN LEUTEREN ${ }^{1}$. 


\section{Evaluation Group}

This section describes the user (evaluation) cases retrieved from its related (inter) national medical institutions.

\section{- $\quad$ Erasmus MC Sophia Children's Hospital}

Patient(s) and method

In total, 9 patients ( 9 girls; mean age $( \pm S D$ ): $7.9 \pm 2.1$ years; range: $5-12$ years) have been enrolled in an evaluation phase with the SENS-U at the Erasmus MC Sophia Children's Hospital (see Table 7.4). During this first evaluation, all children were treated at least one week with the SENS-U by notifying them to go to the toilet at a filling of $80 \%$ of the expected bladder capacity. For all children, the SENS-U was used during the daytime, while both the vibration - and smartphone notification were activated.

In general, for each child an initial follow-up consultation is planned after one week (see Table 7.4). In case of patient no. 8, the follow-up consultation is yet to be scheduled. Next, three girls used the SENS-U for a longer period as part of their bladder training program (referred to as treatment group); patient no. 1 used the device for 4 weeks, patient no. 4 for 13 weeks, and patient no. 6 for 21 weeks.

Table 7.4: Population demographics

\begin{tabular}{lllllll}
\hline & & & \multicolumn{5}{c}{ Follow-Up Period } \\
\hline ID & Age & Boy/Girl & WK 1 & WK 4 & WK 13 & WK 21 \\
\hline 1 & 9 & Girl & X & X & - & - \\
2 & 7 & Girl & X & - & - & - \\
3 & 6 & Girl & X & - & - & - \\
4 & 8 & Girl & X & - & X & - \\
5 & 5 & Girl & X & - & - & - \\
6 & 7 & Girl & X & - & - & X \\
7 & 10 & Girl & X & - & - & - \\
8 & 7 & Girl & N/A & - & - & - \\
9 & 12 & Girl & X & - & - & - \\
\hline
\end{tabular}

Categorizing the children (who had their initial follow-up consultation) based on bladder capacity, recurrent urinary tract infection, residual volume, urinary incontinence (daytime or enuresis) and sense of urgency, results in the following distribution (Table 7.5): 
Table 7.5: Population distribution based on clinical parameters (for $n=8$ )

\begin{tabular}{|c|c|c|c|c|c|}
\hline & & \multicolumn{2}{|c|}{ YES } & \multicolumn{2}{|c|}{ NO } \\
\hline & & $\mathbf{N}$ & $\%$ & $\mathbf{N}$ & $\%$ \\
\hline \multicolumn{2}{|c|}{ Bladder capacity (as expected) } & 4 & $50 \%$ & 4 & $50 \%$ \\
\hline \multicolumn{2}{|c|}{ Recurrent urinary tract infections } & 6 & $75 \%$ & 2 & $25 \%$ \\
\hline \multicolumn{2}{|l|}{ Residual volume } & 6 & $75 \%$ & 2 & $25 \%$ \\
\hline & Daytime & 4 & $50 \%$ & 4 & $50 \%$ \\
\hline \multirow[t]{2}{*}{ Urinary incontinence } & Enuresis & 3 & $38 \%$ & 5 & $63 \%$ \\
\hline & Both & 3 & $38 \%$ & 5 & $63 \%$ \\
\hline
\end{tabular}

\section{Results/Discussion}

\section{Clinical Parameters}

Based on this initial evaluation (follow-up: 1 week), 38\% ( $n=3)$ of the children experienced an improvement in their sense of urgency (Table 7.6). From the children suffering for daytime urinary incontinence $(n=4)$, two $(50 \%)$ of them had a complete response (initial success: dry, 100\% improvement), and one child partially responded (initial success: improved, 50-99\% improvement) [5], [6].

For the children with enuresis $(n=3)$, one $(33 \%)$ child had a complete response (initial success: dry, 100\% improvement). Considering residual volume after voiding; a decrease in cases was observed of $-33 \%(n=2)$. These results are summarized in Table 7.6.

Table 7.6: Clinical Parameters after 1 week $(n=7)$

\begin{tabular}{|c|c|c|c|c|c|c|c|}
\hline & & \multicolumn{2}{|c|}{ YES } & \multicolumn{2}{|c|}{ NO } & \multicolumn{2}{|c|}{ TOTAL } \\
\hline & & $\mathbf{N}$ & $\%$ & $\mathbf{N}$ & $\%$ & $\mathbf{N}$ & $\%$ \\
\hline \multicolumn{2}{|c|}{ Improvement in their sense of urgency } & 3 & $38 \%$ & 5 & $63 \%$ & 8 & $100 \%$ \\
\hline \multirow{3}{*}{$\begin{array}{l}\text { Daytime } \\
\text { incontinence }\end{array}$} & Initial success: & & & & & & \\
\hline & Complete response (dry) & 2 & $50 \%$ & 2 & $50 \%$ & 4 & $100 \%$ \\
\hline & Partially responded & 1 & $25 \%$ & 3 & $75 \%$ & 4 & $100 \%$ \\
\hline \multirow[t]{3}{*}{ Enuresis } & Initial success: & & & & & & \\
\hline & Complete response (dry) & 1 & $33 \%$ & 2 & $67 \%$ & 3 & $100 \%$ \\
\hline & Partially responded & 0 & $0 \%$ & 3 & $100 \%$ & 3 & $100 \%$ \\
\hline \multicolumn{2}{|c|}{ No residual volume after voiding } & 2 & $33 \%$ & 3 & $67 \%$ & 6 & $100 \%$ \\
\hline
\end{tabular}


Regarding the treatment group; for child no. 1 and 4, the treatment objective was to prevent urinary incontinence during day/night and become more aware of her sense of urgency. After a follow-up period of 4 weeks, child no. 1 unfortunately experienced an (slight) increase in wetting accidents during day and night. After a follow-up period of 13 weeks, child no. 4 was still able to remain continent and experienced a lower frequency in residual volume. However, the girl (and caregiver(s)) also indicated that she became dependent on the SENS-U to stay dry, due to her unawareness of a sense of urgency. For child no. 6, the treatment objective was to minimize residual volume and prevent urinary tract infections. After the treatment period of 21 weeks, the girl stopped using the SENS- $U$ and ended her antibiotics to treat the urinary tract infection(s)). During the time of the latest (telephone) consultation, the girl was cleared from any urinary tract infection(s) (frequency of residual volume = unknown).

\section{User Experience}

During the 1-week follow-up, several aspects regarding user experience were evaluated: the size of the SENS-U, the double-sided adhesive to position the SENS-U (i.e. positioning, removal), the level of comfort, and the position verification (device functionality, "Position Check").

In general, all children (and caregiver(s), 100\%) indicate that the size of the device was too big or bulky. Next, the used double-sided adhesive often resulted in skin irritation (minor redness, $75 \%(n=6)$ ), and was reported as too strong, especially during the removal of the SENS-U from the skin. Therefore, these two factors influenced the level of comfort during daily life activities. In addition, it was also stated that the device itself sometimes came loose from the adhesive during use. However, determining the correct position of the device on the skin ("Position Check"), and the subsequent positioning of the SENS-U on the lower abdomen, went well.

Finally, it was concluded that the children (and caregiver(s)) who evaluated the SENS-U for an evaluation period of 1-week ( $n=5,63 \%$ ), did not immediately see an added value to their current treatment, because it did not significantly reduce the level of urinary incontinence or reduced the occurrence of urinary residue. Also, several practical limitations (i.e. device size, adhesive) were stated which have to be addressed in order to increase the level of comfort, ensure a high level of compliance, and potentially increase the effectiveness of current treatment.

Nevertheless, the treatment group (patient no. 1, 4 and 6; 38\%), who used the SENS-U of a longer period did see an added value to their bladder training; for them, the SENS-U helped to relearn of the sense of urgency, and thereby reduce their number of wetting accidents, or reduced residual volume and the risk of urinary tract infections. Based on this first evaluation, it appears that a longer (then 1 week) treatment period with (intensive) supervision and guidance of a urotherapist is required to result in a potential, positive long-term success of the treatment. 


\section{Conclusions}

The Erasmus MC Sophia Children's Hospital evaluated the SENS-U Bladder Sensor for the first time in their daily clinical practices in children with urinary incontinence and/or with residual volume after voiding. Based on the observations after an 1-week evaluation period, it was stated that $63 \%$ of the children (and caregiver(s)) did not yet see a clear added value of the SENS-U to their current treatment (e.g. less wetting accidents). However, these observations might be influenced by several practical limitations (i.e. device size, adhesive) of the device.

For the treatment group (38\%), there was an added value of the SENS-U; reducing the level of urinary incontinence, becoming more aware of a sense of urgency, reducing residual volume, and reducing the risk of urinary tract infections. Therefore, it is advised to continue the evaluation period, and extend the SENS-U treatment period with (intensive) supervision and guidance of a urotherapist for those children (and their families) who were initially positive about this new adjunct treatment tool.

Finally, based on the user experiences, it is advised to further (significantly) reduce the size of the SENS-U, and optimize the double-sided adhesive to increase the level of comfort. In addition, it is advised to further investigate the possibilities to wear the SENS-U for consecutive days (instead of $1 /$ day), potentially reducing the frequency the double-sided adhesive needs to applied and removed, which will be beneficial for the skin integrity.

\section{- Wilhelmina Children's Hospital}

\section{Patient(s) and method}

From September 2019 until November 2019, an internal evaluation phase was initiated with the SENS-U at the department of Pediatric Urology of the Wilhelmina Children's Hospital UMC Utrecht (Utrecht, the Netherlands). Parallel to the scheduled inpatient bladder training, four children ( 2 boys, 2 girls; mean age $( \pm S D$ ): $9.3 \pm 1.5$ years; range: 8-11 years) with an Overactive Bladder (OAB) were asked to wear the SENS-U for one day (Table 7.7).

The objective was to assess if this new tool could potentially be used to teach children central inhibition of their bladder in order to suppress bladder overactivity. Furthermore, the children were asked to share their experiences while wearing this new sensor. 
Table 7.7: Population demographics

\begin{tabular}{|c|c|c|c|c|c|}
\hline ID & Age & Boy/Girl & Diagnosis & $\begin{array}{l}\text { MBC } \\
(\mathrm{ml})\end{array}$ & $\begin{array}{l}\text { SENS-U }{ }^{1} \\
\text { threshold }\end{array}$ \\
\hline 1 & 8 & Boy & $\begin{array}{l}\text { Daytime incontinence, enuresis, Overactive } \\
\text { Bladder (OAB) }\end{array}$ & 121 & $125-149$ \\
\hline 2 & 8 & Girl & $\begin{array}{l}\text { Overactive Bladder (OAB), constipation, } \\
\text { enuresis }\end{array}$ & 218 & $200-224$ \\
\hline 3 & 10 & Girl & $\begin{array}{l}\text { Daytime incontinence based on Overactive } \\
\text { Bladder (OAB) and postponement. Familiar } \\
\text { with urinary tract infections. }\end{array}$ & 221 & $300-324$ \\
\hline 4 & 11 & Boy & $\begin{array}{l}\text { Urinary incontinence based on Overactive } \\
\text { Bladder }(\mathrm{OAB}) \text { and a small maximum voided } \\
\text { volume (MVV). }\end{array}$ & $251^{*}$ & $250-274$ \\
\hline
\end{tabular}

* While using medication; without medication: $170 \mathrm{ml},{ }^{1}$ At the start of the evaluation session.

Results/Discussion

\section{Clinical Parameters}

During the SENS-U evaluation session, the four participating children wore the SENS-U for an average duration of 04:41 hours (range: 04:00 - 06:15 hours), and went to the bathroom with an average micturition frequency of 4 times/session (range: 4-5) (Table 7.8) and an average voided volume of $149 \mathrm{ml}$ (range: 95-197 ml).

In $61 \%$ ( $n=11 / 18$ ) of the cases, children experienced notifications before going to the bathroom (see blue boxes in Table 7.8). In 22\% ( $n=4 / 18$ ), the child voided before the notification was provided, and in $17 \%$ the cases $(n=3 / 18)$ it was unclear whether the child was notified (the urotherapist was out of sight).

Based on Table 7.8, it has to be stated that generally, the voided volume was lower then expected, compared to the pre-set personalized notification threshold (100\%). It appears that the SENS-U overestimated the actual bladder volume present for these children. However, when the threshold is changed to a higher value, the voided volume also increases slightly.

\section{User Experience}

At the end of the training day, children were asked to share their experiences while wearing the SENS-U. In $75 \%(n=3)$ of the children, the double-sided adhesive resulted in skin irritation (minor redness), or felt ticklish $(25 \%, n=1)$ and in one case the device came loose. 
SENS-U: a Series of Cases Reports

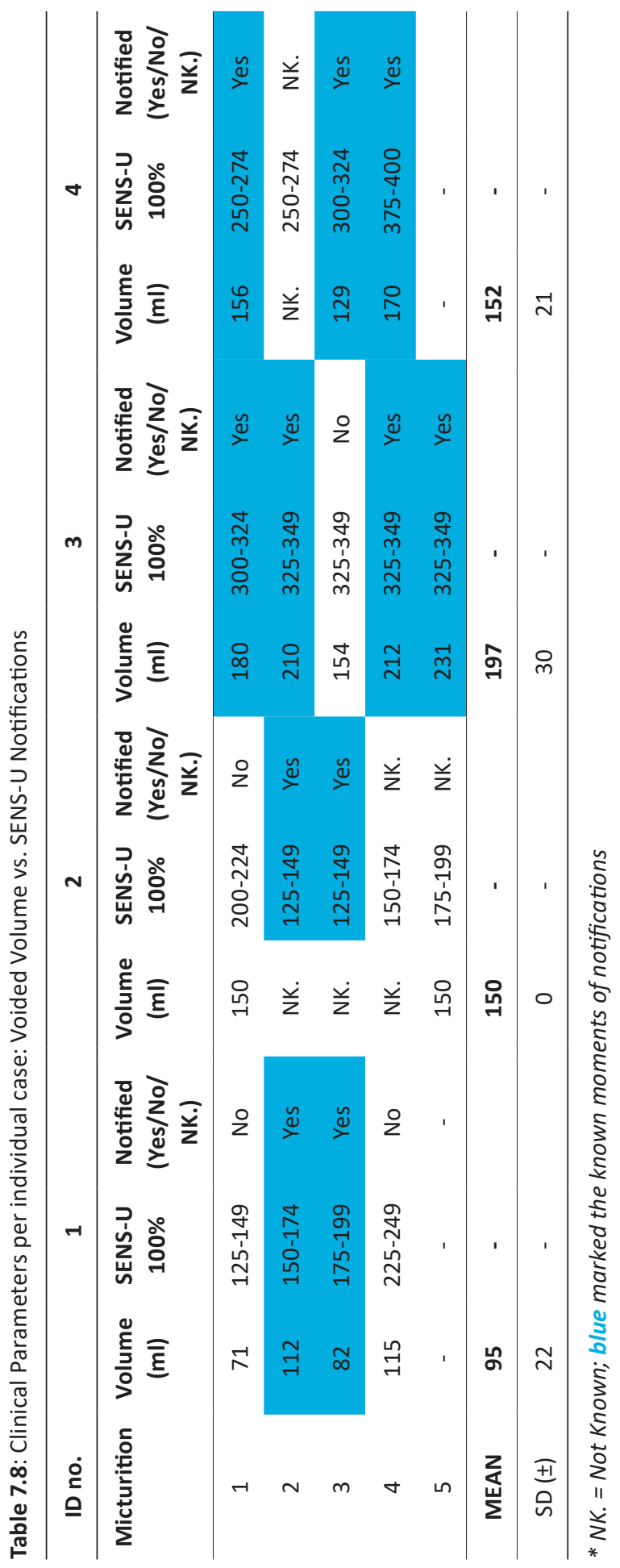


Next, two children stated that the device was too big on their belly, and felt uncomfortable underneath their cloths. Finally, the urotherapist(s) observed that for these patients, the voided volume did not correspond to the pre-set notification threshold; as result of an overestimation by the SENS-U, the urotherapist(s) also increased the threshold over time to ensure a proper voided volume. This observation is visualized in Table 7.8, showing for several patients adjustments in the notification threshold during the day.

\section{Conclusions}

The Wilhelmina Children's Hospital UMC Utrecht evaluated the SENS-U Bladder Sensor with a first group of children to assess if this new tool could potentially be used to teach children central inhibition of their bladder in order to suppress bladder overactivity. Based on this initial evaluation, we assume that the SENS-U might be suitable to support children in reaching (slightly) higher volumes when the threshold value is increased, possible suggesting suppression of bladder overactivity. A reason for this uncertainty is that that the SENS-U overestimated the actual bladder volume present which might be related to several factors, e.g. sensor positioning and bladder shape.

Regarding bladder shape: the SENS-U measures the bladder in the sagittal plan with four transducers in a field of view of $30^{\circ}$. When the bladder is detected in a higher number of transducers (higher filling status), it results in a higher estimated bladder filling status. However, the bladder shape can be affected by surrounding organs, influencing the SENS-U'S accuracy. For example, in patient no. 1, a transverse rectal diameter of $43 \mathrm{~mm}$ was observed, which is a clear sign of constipation [7]. An enlarged rectum might influence the bladder shape, causing the bladder to expand more into the cranial-caudal dimension ( = sagittal plan) compared to the anterior-posterior dimension.

Furthermore, it was observed that several children thought the SENS-U was too big, and that the corresponding double-sided adhesive was uncomfortable, both influencing their overall level of comfort. Therefore, it is advised to continue optimizing the SENS-U's measurement accuracy, and to improve the child's user experience considering both the shape of the sensor and the related double-side adhesive, to increase the level of compliance.

\section{OVERALL DISCUSSION}

This is the first clinical user evaluation illustrating the first steps towards a broader clinical implementation and valorization of the SENS-U. This evaluation indicated that the SENS-U is currently used by (pediatric) urologists, pediatricians and nurses for multiple pediatric applications e.g. treatment of (refractory) urinary incontinence (day/night), supporting children with a neurogenic bladder to perform intermittent (self) 
catheterization, and teaching children central inhibition of their bladder in order to suppress bladder overactivity.

In general, the children in the treatment group, who used to SENS-U for longer period, were (very) positive about this new adjunct treatment tool. For example, children suffering from urinary incontinence become more aware of their sense of urgency (biofeedback), thereby reducing the level of urinary incontinence. Especially the three autistic boys regained complete bladder control, even after previous treatment options had no (or limited) effect until now. However, additional clinical research is required to determine the appropriate duration, design and the level of (intensive) supervision for an effective treatment, thereby reducing the risk of relapse on the long-term and minimizing the risk of becoming dependent of the device. Therefore, (intensive) guidance of a urotherapist will remain crucial, especially to ensure that the SENS-U is used by the child as intended (i.e. correct position and notification threshold). Then, the child can be taught to respond to the actual urge of a full bladder through associative conditioning with the provided full-bladder notification. In time, the child could reduce the usage of the SENS-U, eventually relying on his/hers own (true) sense of urgency.

Considering the children who perform intermittent (self) catheterization with the support of SENS-U were also very positive. They were able to stay dry (often for the first time) in-between catheterization attempts, due to a more appropriate, volumebased catheterization schedule. This schedule potentially prevents urinary retention, high bladder pressures, unnecessary bladder catheterizations (i.e. too small bladder volume) and protects the upper urinary tract. This is also confirmed by the experiences of the research group.

However, it also became clear that if a child returns to his/her original time-based schedule, the number of wetting accidents increases again. For these children, the SENS-U would be more suitable to be used on a long-term basis (compared to children who use the SENS-U for (cognitive) bladder training). Also, the SENS-U is most beneficial for children who conduct intermittent catheterization independently, because they can act on the notifications themselves, instead of the caregiver(s) who might not be present at that exact moment in time. However, it was also indicated by several physician(s) that the SENS-U would not be suitable for children with a neurogenic bladder and a ventriculoperitoneal shunt, due to the presence of additional (cerebrospinal) fluid in the peritoneal cavity, which might result in measurement artefacts.

Next, it was originally hypothesized that the SENS-U would be beneficial for children with e.g. voiding postponement, by preventing the bladder from becoming too full and reducing the risk of urinary leakage. In the evaluation group, the objective was to evaluated the feasibility of using the SENS-U for teaching children central inhibition to suppress bladder overactivity. Instead of acting on a full-bladder notification by going to the bathroom before it is too late, this group aimed at postponing micturition by 
suppressing their falls sense of urgency and wait for the direct (bio)feedback of the SENS-U. As a result, these children should reach a higher voided volume (inline with their expected bladder capacity) and reduce their micturition frequency, thereby increasing their proper sense of urgency.

Based on the first (1 day) evaluation, it appears that SENS-U might be suitable for this purpose. However, there was uncertainty, because the SENS-U overestimated the actual bladder volume during this evaluation. Therefore, additional research has to be conducted to determine the factors of influence on the SENS-U's measurement accuracy. Next, a systematic clinical investigation has to be setup to compare the SENS-U to current, available treatment options for this patient population.

Finally, several technological opportunities were identified to further optimize the SENS-U and increase the level of accuracy, increase the treatment effectiveness, and to improve the child's user experience. First of all, it is advised to further reduce the size of the device. Several children (and caregiver(s)) reported that the rigid, rectangular shape was uncomfortable, underneath the clothing, especially for younger children and children who are in a wheelchair.

Secondly, it was regularly reported that the double-sided adhesive to fixate the SENS-U to the lower abdomen was uncomfortable or resulted in skin irritation (minor redness), especially when removing the device at the end of the (training)day. Also, the device itself sometimes came loose from the adhesive. Due to these practical device limitations, the evaluation group often stated that they did not yet see a clear added value to their own treatment. Therefore, it is advised to further reduce the size and optimize the materials used in the adhesive, to increase the level of comfort and ensure a high(er) level of compliance. In addition, it was suggested to use the SENS-U for multiple days, thereby reducing the number of times the device needs to be applied or removed, ensure a higher level of skin integrity.

\section{CONCLUSION}

In summary, the first steps are taken towards a broader clinical implementation of the SENS-U, indicated potential clinical benefits such as an increase in the sense of urgency by direct biofeedback, reducing the number of wetting accidents and residual volume(s), increasing the appropriateness of catheterization attempts, potentially supporting central inhibition, and becoming more independent. However, several technological opportunities were identified which have to be addressed to increase the SENS-U's clinical implementation and its valorization. 


\section{ACKNOWLEDGMENTS}

The author(s) would like to thank all the (pediatric) urologist, pediatrics and nurses from the contributing (inter)national medical institutions. For the provided cases by University Hospital Antwerp (Antwerp, Belgium), the author(s) would like to thank: G. De Win, T. Jacobs, S. Eerens, and K. De Baets. Next, for the Maastricht University Medical Center (Maastricht, the Netherlands) cases, the author(s) would like to thank P.R.H. Callewaert.

For the Jeroen Bosch Hospital ('s-Hertogenbosch, the Netherlands) cases, the author(s) would like to thank M. van Duren - van lersel. Then, for the clinical case provided by Wilhelmina Children's Hospital UMC Utrecht (Utrecht, the Netherlands), the author(s) would like to thank E. De Bruijn-Kempe.

Finally, for user evaluations conducted by (1) Erasmus MC Sophia Children's Hospital (Rotterdam, the Netherlands) and the (2) Wilhelmina Children's Hospital UMC Utrecht (Utrecht, the Netherlands), the author(s) would like to thank R. van Zon (1) and A.J. Nieuwhof-Leppink (2). 


\section{REFERENCES}

1. P. G. Van Leuteren and G. De Win, "VOLUME-DEPENDENT CATHETERIZATION WITH A WEARABLE ULTRASONIC BLADDER SENSOR IN A TEENAGE BOY: A CASE REPORT," in ICCS Meeting, Rome, Italy, 2018.

2. G. De Win, T. Jacobs, S. Eerens, K. De Baets, and P. G. Van Leuteren, "VOLUME-DEPENDENT CATHETERIZATION WITH A WEARABLE ULTRASONIC BLADDER SENSOR - A FEASIBILITY STUDY -," in 30th Congress ESPU(Nurses), Lyon, France, 2019.

3. P. G. Van Leuteren, P. R. H. Callewaert, and P. Dik, "THREE CASES OF AUTISTIC BOYS WITH REFRACTORY URINARY INCONTINENCE BUT RESPONDING WELL TO A BLADDER SENSOR DEVICE," in 5th Joint Meeting ESPU-SPU, Lisbon, Portugal, 2021.

4. Novioscan, "https://novioscan.com/," 2020. [Online]. Available: https://novioscan.com/. [Accessed: 19-Jun-2020].

5. A. J. Nieuwhof-Leppink, R. P. J. Schroeder, E. M. van de Putte, T. P. V. M. de Jong, and R. Schappin, "Daytime urinary incontinence in children and adolescents," Lancet Child Adolesc. Heal., vol. 3, no. 7, pp. 492-501, 2019. https://doi.org/10.1016/S2352-4642(19)30113-0

6. P. F. Austin et al., "The standardization of terminology of lower urinary tract function in children and adolescents: Update report from the standardization committee of the International Children's Continence Society," Neurourol. Urodyn., vol. 35, no. 4, pp. 471481, Apr. 2016. https://doi.org/10.1002/nau.22751

7. A. J. Klijn, M. Asselman, M. A. W. Vijverberg, P. Dik, and T. P. V. M. de Jong, "The Diameter of the Rectum on Ultrasonography As a Diagnostic Tool for Constipation in Children With Dysfunctional Voiding," J. Urol., vol. 172, no. 5, pp. 1986-1988, Nov. 2004. https://doi. org/10.1097/01.ju.0000142686.09532.46

8. T. A. Brouwer, C. van den Boogaard, E. N. van Roon, C. J. Kalkman, and N. Veeger, "Noninvasive bladder volume measurement for the prevention of postoperative urinary retention: validation of two ultrasound devices in a clinical setting," J. Clin. Monit. Comput., vol. 32, no. 6, pp. 1117-1126, 2018. https://doi.org/10.1007/s10877-018-0123-6 
SENS-U: a Series of Cases Reports 



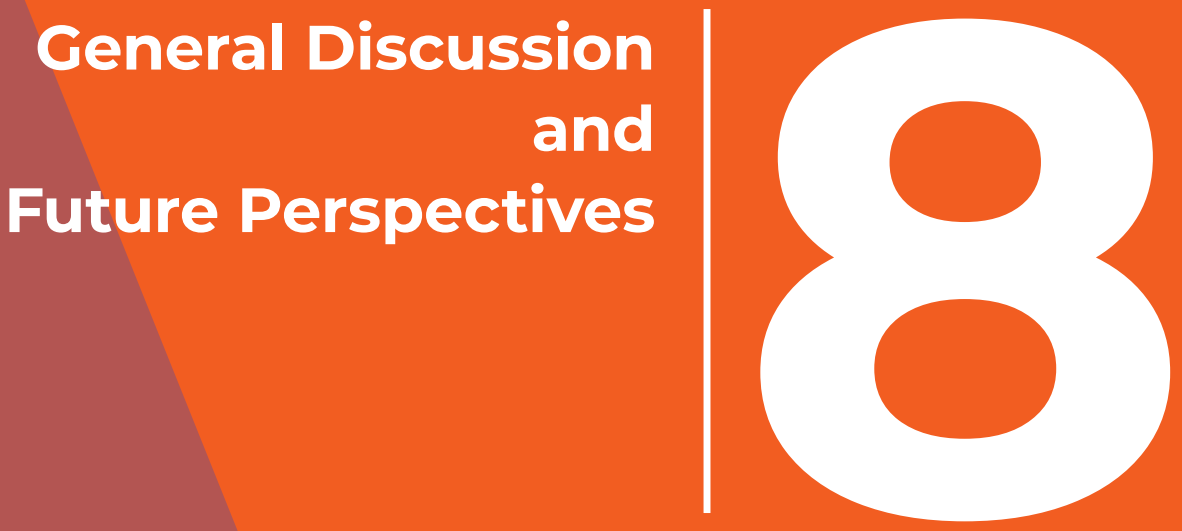




\section{GENERAL DISCUSSION}

This thesis presented the first results of the SENS-U in daily (clinical) life activities, which were recently described in Nature Reviews Urology as "a demonstration of the promise of wearable ultrasonography" [1]. The benefits of using continuous ultrasound for monitoring the nocturnal bladder function (e.g. urine loss, enuretic frequency) were also recently confirmed by the president of the ICCS, Mr. Tryggve Nevéus [2].

In addition, in a recent correspondence article by Monaghan et al. (2020) to the Journal of Pediatric Urology, they also confirmed that "the SENS-U confers several advantages over traditional alarm therapy, and joins other recent notable technological advancements which may expand the clinician's toolkit in the management of nocturnal enuresis" [3]. The authors also suggested that "that the SENS-U may also be useful in facilitating a more patient-centered treatment algorithm for nocturnal polyuria in tandem with other emerging technologies", especially when it is entirely based on homebased sensor technology [3].

In this section, the primary findings during the development and clinical evaluation of the UBM and its successor, the SENS-U, will be discussed. Next, the remaining opportunities to face in the future will be presented.

\section{Primary Findings}

During the technical - and clinical evaluation of the UBM (Chapter 2-3), it became clear that the performance of this first clinical prototype was influenced by 1 ) the belt-based design and 2) the detection range. First, while the child moved around, the elastic belt (including the ultrasound transducer) could move in an upwards direction, underestimating the bladder dimension, by only detecting the superior dome of the bladder. Second, when the child went to the toilet, the UBM and the child's pants could potentially be pulled down together, consequently repositioning of the device completely. Also, intermittent movement of the device could introduce the acoustic interference with air, resulting in a zero-dimension value. These observations showed the importance of increasing sensor's stability, to ensure adequate (future) clinical performance while using the device as intended.

Regarding the UBM's detection range, it was noted that for children with a smaller than age-expected bladder capacity and for older children (>10 years), the full bladder could not be detected accurately. For both cases, a single-element transducer (at a $0^{\circ}$ angle, perpendicular to the skin) could potentially measure above the bladder. Therefore, a redesign of the ultrasound transducer was required in order to increase the sensor's detection area, enabling the detection of a larger detectable bladder volume range.

Lastly, regarding the UBM, there were several (practical) limitations regarding the conducted pre-clinical safety evaluation. Due to the in-house available resources, 
the acoustic output power and the thermal index for the UBM transducer could only be estimated based on a worst-case scenario (assuming maximum transducer efficiency). To increase the level of certainty, especially to demonstrate future compliance to the European Medical Device Directive (MDD 93/42/EEC), it was advised to measure these acoustic parameters in accordance to the regulatory guidelines (IEC 60601-2-37) (conducted for the SENS-U, as referred to in the previous summary section).

During the development and clinical evaluation of the SENS-U, additional challenges presented themselves. First, in Chapter 4 and Chapter 5, it was observed that the full bladder could not always be detected accurately for children with an (relatively) obese abdomen, both while sitting and during activities of daily living.

Due to the curvature of the lower abdomen, the transducer orientation shifted, redirecting the field of view (FOV) away from the bladder region. In addition, the intensity of the acoustic transmission and reflection of the bladder wall decreases (higher absorption due to a thickened abdominal wall), reducing the detectability (and the notification-rate) of the SENS-U. Therefore, it is advised to be aware of this factor of influence when using this device for children with urinary incontinence.

Another challenge while using the SENS-U in daily clinical practice, is the initial sensor positioning. In Chapter 4, for one patient, the device was not accurately positioned at the start of the measurement. Based on the raw ultrasound data (lower part of the FOV) could be concluded that the SENS-U was positioned too high above the pubic bone. As a result, the acoustic reflections of the posterior bladder wall were too low to be detected by the SENS-U's algorithm. It is important to state that the device was positioned at the start of the cystometry procedure, when the bladder was empty. One of the SENS-U's functionalities is a position verification (activated by a smartphone application) which provides feedback to the user, to apply the device accurately. However, this functionality requires a minimal amount of urine to be detected. Still, even without position verification, the SENS-U was able to safely detect the bladder accurately in $90 \%$ of the children, demonstrating its clinical performance.

Nevertheless, initial sensor positioning remains an important potential factor of influence, and it is therefore advised to position the SENS-U some time after the last micturition (e.g. after 45-60 min, drinking two glasses of water) or before the early morning void (EMV) (after waking up), to ensure that a certain amount of urinary volume is present to be detected by the SENS-U's internal position verification algorithm.

Related to initial sensor positioning and its alignment with the bladder, are the following observations made during the first night-time, home-based evaluation of the SENS-U in children with enuresis. Data of the SENS-U showed clinically relevant fluctuations during the night, which could potentially be misinterpreted as a (partial) enuretic event. These fluctuations were mainly the result of the child's postural position during sleep. 
The SENS-U estimates the bladder fulling status in the sagittal plane, so when the child lies on its left or right side, the bladder shifts partially out of the FOV, potentially underestimating the actual volume.

In other words, there is a misalignment between the initial sensor positioning and the position of the bladder in the pelvic region, resulting In a decrease in the estimated bladder volume status, which could be stated as (partial) enuretic event. Therefore, it is advised to take the child's postural position into account while estimating the bladder volume status.

Lastly, the study-design could also have influenced the determined clinical performance of the SENS-U, i.e. the full-bladder detection rate and the notification-rate. First, in Chapter 5, the children were instructed to act on their own sense of urgency and follow their personal bladder training instructions. Therefore, some children proceeded to the toilet, before the bladder volume reached their personalized volume-based threshold (based on their maximum voided volume). For example, children with an overactive bladder, experiencing urinary urgency, or due to defecation. It was also observed that while monitoring two patients simultaneously during their bladder training, they responded to each other's full-bladder notifications. In other words, when one of them received a notification, the other child accompanied the other to the bathroom, without an own sense of urgency. Therefore, these patients did not experience a natural bladder filling pattern, for which the SENS-U is intended.

Second, in Chapter 6, during the night-time evaluation, it was stated that $57 \%$ of children experienced one or multiple enuretic events, without waking up. As a result, no data of these events could be collected in the (paper) voiding diary, and the SENS- $U$ data could not be verified, leading to un underestimating of the total measurable nocturnal bladder filling cycles. For future validation research, it is recommended to use an additional (digital) moisture-sensitive device, to ensure that each enuretic event is accurately recorded and can be verified with the SENS-U registrations.

\section{FUTURE PERSPECTIVES}

In this thesis, the first steps of the clinical implementation of the SENS-U were presented. Nevertheless, more research is still required to demonstrate the effectiveness of this new adjunct tool for both diagnostic - and treatment purposes for children with urinary incontinence, on a larger scale, during day and night. In addition, there still remain technological opportunities to further optimize the SENS-U in the near future, to positively increase the child's user experience. 


\section{Clinical Implementation}

In Chapter 7, the results of the first clinical user evaluation were presented, indicating that the SENS-U is currently used by medical professionals for multiple pediatric applications e.g. treatment of (refractory) urinary incontinence (day/night), supporting children with a neurogenic bladder to perform intermittent (self) catheterization, and teaching children central inhibition of their bladder in order to suppress bladder overactivity.

In general, children suffering from (refractory) urinary incontinence (day/night) were (very) positive about the SENS-U, supporting them in becoming more aware of their sense of urgency due to direct biofeedback, resulting in a reduced level of urinary incontinence. However, in order to prove that this new technology is beneficial in the treatment of children with urinary incontinence, it has to be compared to current, available treatment options. The first step towards this objective is already initiated by the department of Pediatric Urology of the Amalia's Children Hospital (Radboud UMC, Nijmegen, the Netherlands). In collaboration with the related departments of the Wilhelmina Children's Hospital UMC Utrecht (Utrecht, the Netherlands), Isala Hospitals (Zwolle, the Netherlands) and the clinic 'TOP voor kinderen' (Arnhem, the Netherlands), a multicenter project is defined for the Health Care Efficiency Research program (ZonMw, the Netherlands).

The aim of this randomized controlled trial (RCT) is to determine whether the SENS-U improves the (cost)effectiveness of standard urotherapy and specific urotherapy. The primary outcome measure is the level of daytime urinary incontinence after 3 months of urotherapy (with/without the SENS-U). If the project is approved, expected in December 2020 , the RCT is expected to start in spring 2021, including over more than 400 children in a timeframe of approximately 3 years.

Regarding nocturnal enuresis, the first steps towards clinical implementation of the SENS-U for both diagnostic - and treatment purposes has been made (Chapter 6). To further investigate the feasibility of this device, it is advised to increase the sample size and record data of several, consecutive nights, to allow multiple-case comparisons.

The next step would be to investigate the efficacy of the SENS-U as a new adjunct treatment tool, by notifying the child before the enuretic event, preventing wet sheets and potentially increasing the training effectiveness. It is hypothesized that the SENS-U may potentially be more effective compared to the standard, acoustic bedwetting alarm, due to its configuration and specific device features. First, as soon as a full bladder is detected by the SENS-U, a vibration notification is provided every 3 minutes with increased intensity, until the time of micturition. For children with enuresis and a decreased arousability from sleep, this feature could be beneficial, because they are unable to turn off the notification, and go back to sleep and still wet the bed. In addition, the SENS-U can also (additionally) notify the parents/caregivers through the Bluetooth ${ }^{\circledR}$ connectivity, allowing them to wake up their child before he or she wets the bed. 
Next, a new potential target population was identified: children who perform timedependent self-intermittent catheterization (TDIC) (without a ventriculoperitoneal shunt) in order to properly empty their bladder. These children were very positive about the SENS-U, enabling them to stay dry in-between catheterization attempts due to a more appropriate, volume-based catheterization schedule. Through this personalized approach, urinary retention, high bladder pressures, and unnecessary bladder catheterizations (i.e. too small bladder volume) can potentially be prevented.

However, there were also several practical limitations for this target population. First, it was observed that a smaller device size would be more comfortable and stable to wear, especially for children in a wheelchair (e.g. during transfers). Next, the used double-sided adhesive sometimes resulted in skin irritation (minor redness), which reduces the level of comfort while wearing it. Lastly, the initial observations suggested that VDIC would especially be beneficial for children who can independently perform VDIC. Otherwise, the parents should assist their child (similar as for TDIC), at the time of a full bladder, which might be unpractical in daily life (e.g. parents at work).

In Chapter $\mathbf{7}$ also the first observations were discussed regarding children who used the SENS-U to teach central inhibition in order to suppress their bladder overactivity. By providing direct biofeedback of the bladder filling status, children would be able to postpone micturition and improve their (true) sense of urgency. Based on the first evaluation, it appears that the SENS-U might be suitable for this purpose. However, additional research is required to prove the effectiveness of the new approach (i.e. with the previously mentioned multicenter RCT).

Finally, the SENS-U was initially intended to be used for children at school-age, suffering from urinary incontinence. However, there is also a major opportunity for adults, especially elderly, and amongst patients in nursing homes. The reported prevalence ranges from $5-70 \%$ and increases with age [4]. The manufacturer of the SENS-U is currently developing the next version of this device, intended for people of all ages dealing with urinary incontinence [5].

\section{Technological Opportunities}

In this thesis, several technological opportunities came to light for further SENS-U optimization, to increase both the level of accuracy and to improve the child's user experience.

\section{Sensor Positioning}

First, it was observed that the initial positioning of the device on the lower abdomen and intermittent movement of the user, partially influences the SENS-U'S accuracy. Suggestions were made to minimize the impact of these factors, e.g. through the implementation of a body position sensor inside the SENS-U, which could (digitally) compensate the fluctuations in the bladder filling estimation, in respect to body 
position. For example, during the night-time evaluation, left or right side lying of the child, resulted in a shift in the sensor's field of view, resulting in a temporary underestimation of the urinary volume present.

Next, the internal algorithm for the position verification (device functionality, "Position Check") has to be further optimized, to allow the positioning of the device, even at smaller volumes (i.e. shortly after micturition).

\section{Abdominal Curvature}

Second, it was concluded that the abdominal curvature is of influence on the SENS-U's transducer orientation, shifting the FOV upward (i.e. scanning above the bladder) or downwards (i.e. scanning towards to the pubic bone). This effect was specifically observed in children with overweight or childhood obesity (BMI index greater than the $85^{\text {th }}$ percentile). In addition, a thicker abdominal wall also results in a higher ultrasound absorption, decreasing the acoustic intensity at the depth of the bladder walls. Therefore, it is recommended to increase the FOV of the transducer (larger than $0-30^{\circ}$ ) for children with a high BMI-index, reducing the risk of misalignment between the sensor and the bladder, and reduce the current ultrasound frequency to increase the ultrasound intensity at the required measurement depth.

Nevertheless, when implementing the SENS-U in daily clinical practice, sensor positioning and childhood obesity still remain potential factors of influence which should be kept in mind.

\section{Device Size \& Adhesive}

The design and development of the SENS-U initially focused on developing a so-called minimum viable product (MVP); a first version of the medical device with the essential features to allow first users (i.e. children, parents, physician) to gain experience with the new device, to provide feedback and steer future device optimizations. Therefore, the size of the current SENS-U device $(95 \times 55 \times 16 \mathrm{~mm})$ was designed in such a way, allowing children to use it properly, and allowing qualified technicians to still make internal - and technical adjustments (if necessary).

Nevertheless, during the start of the implementation and valorization phase, several opportunities came to light (based on user feedback) regarding the user interface. Particularly, regarding the size of the device and the fixation method. First, especially for small and/or young children, the size of the device (incl. adhesive) was often reported as too big or bulky, potentially covering the entire lower abdominal surface area (Chapter 7). In addition, the rigid, rectangular shape was sometimes reported as uncomfortable, underneath the clothing (e.g. during transfers or switching body positions). This potentially influenced the device-adhesive interface (i.e. device peels off the patch), resulting in poor sensor-to-skin contact (Chapter 6), reducing the ultrasound transmission of the SENS-U. Secondly, skin irritation (minor redness or pressure points) was sometimes reported, particularly after removing the device e.g. before going to sleep or before taking a shower (device only splash proof). 
Therefore, it was recommended to further reduce the size of the SENS-U, by designing a more discrete, smaller, smoother, more organically shaped casing, in combination with more skin-friendly adhesive with a smaller footprint which can potentially be used for multiple days. Nevertheless, it will remain important to keep monitoring the possible side effects of the SENS-U during long-term use.

\section{Voiding Diary \& Uroflowmetry}

Lastly, in accordance to the ICCS guidelines, a voiding diary should be used for recording incontinence episodes either during day and/or night, depending on the type of urinary incontinence. In general, a paper-based voiding diary is used to document the voiding frequency and the corresponding urinary volumes. However, this method has limitations, because patient's often do not fill it in correctly or truthfully, and it is timeconsuming to interpret by the physicians or nurses during their consultations.

After the introduction of SENS-U, physicians indicated the diagnostic - and treatment potential of the SENS-U to automatically record a digital voiding diary. Especially for outpatient bladder training, when the physician provides the SENS-U to the child to be used at home, long-term data on voiding behavior can be recorded, which can be evaluated at the upcoming clinical appointment. The digital voiding diary can provided information on 1) the voiding frequency, 2) whether the child voided before or after the provided notification, 3) how long it took for the child to go to the bathroom and 4) indicate the filing status before micturition. A first example of a registration of consecutive natural filling cycles, including both the time of urination and notification, was already presented in Chapter 5. This figure illustrates the basis for a voiding diary.

In addition to the voiding diary provided by the SENS-U, it would also be of interest for the physician to know 1) how the child voided (e.g. tower-shaped, staccato, interrupted or plateau-shaped curve) and 2) if there was residual volume after voiding. To collect this information, the SENS-U could potentially be combined with home-based uroflowmetry. With this combination, the SENS-U could estimate the bladder filing status before micturition, and home-based uroflowmetry could determine the voided volume after micturition, instantly indicating the presence of an actual residual volume. Therefore, the combination of these technologies could potentially provide a complete overview of the child's voiding behavior, without (repeatedly) going to the clinic.

The next step would be to develop this additional software feature, including a user interface which is in line with the requirements for both the users (i.e. children and caregivers) and medical professionals.

\section{CONCLUSION}

In summary, this section discussed the primary findings observed during the technical - and clinical evaluation of both the UBM and the SENS-U. Also, several technological opportunities were identified to further optimize the SENS-U in the future, and potentially increase both the level of accuracy and improve the child's user experience. 


\section{REFERENCES}

1. B. Abelson, S. Majerus, D. Sun, B. C. Cill, E. Versi, and M. S. Damaser, "Ambulatory urodynamic monitoring: state of the art and future directions," Nat. Rev. Urol., vol. 16, no. 5, pp. 291-301, 2019. https://doi.org/10.1038/s41585-019-0175-5

2. T. Nevéus, "The amount of urine voided in bed by children with enuresis," J. Pediatr. Urol., vol. 15, no. 1, pp. 31.e1-31.e5, 2019. https://doi.org/10.1016/j.jpurol.2018.08.006

3. T. F. Monaghan et al., "Toward a Dry Tomorrow: Novel technologies in the treatment of nocturnal enuresis," J. Pediatr. Urol., 2020. https://doi.org/10.1016/j.jpurol.2020.06.034

4. I. Milsom and M. Gyhagen, "The prevalence of urinary incontinence," Climacteric, vol. 22, no. 3, pp. 217-222, 2019. https://doi.org/10.1080/13697137.2018.1543263

5. Novioscan, "https://novioscan.com/," 2020. [Online]. Available: https://novioscan.com/. [Accessed: 19-Jun-2020]. 

Summary

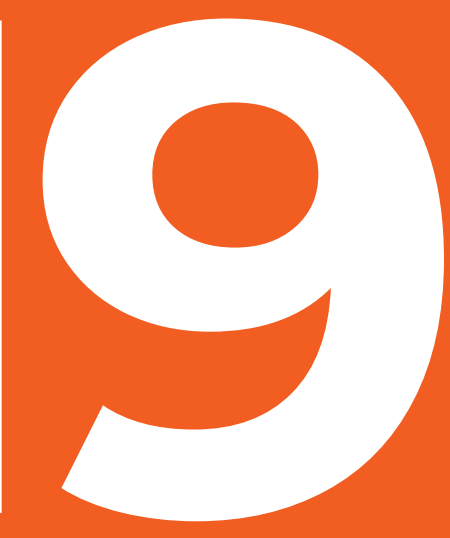




\section{SUMMARY}

This thesis focused on the development and validation of a new wearable ultrasonic bladder sensor for school-aged children suffering from urinary incontinence. In addition, the first steps towards the clinical implementation of this potentially, practice-changing device were explored. This section will summarize the general development roadmap of the SENS-U, and present the overall conclusions of the conducted clinical investigations.

\section{PART I: DEVELOPMENT \& CLINICAL VALIDATION PHASE}

In the first part of this thesis, the main objective was to determine the safety and performance of the first clinical prototype, the URIKA Bladder Monitor, and its re-designed successor, the SENS-U Bladder Sensor. Instead of developing a new ultrasonic device to estimate the actual bladder volume highly accurately, compared to e.g. available two-dimensional ultrasound scanners such as a BladderScan ${ }^{\circledR}$ or standard trans-abdominal ultrasound systems, the aim was to develop a small, discrete, wireless sensor which could be worn continuously during daily live activities and could provided an accurate, personalized, child-friendly notification before the bladder was full.

A device like this would allow physicians and nurses to prevent urinary incontinence, reduce the usage of incontinence products (i.e. diapers), potentially increase the current bladder training effectiveness (day and/or night), improve the child's (and its caregivers) quality of life and would provide new diagnostics insights into voiding behavior.

\section{Concept Development}

The development of a new, wearable ultrasonic bladder sensor was initiated late 2013, by the department of Pediatric Urology of the Wilhelmina Children's Hospital UMC Utrecht, together with the department of Medical Technology and Clinical Physics (ISO13485) of the University Medical Centre Utrecht (UMC Utrecht) (Utrecht, the Netherlands). The first lab-based, table-size prototype was based on detection principle of measuring the changes in the anterior - and posterior bladder dimension, which could serve as a potential indicator for the bladder filling status.

In vitro experiments on a self-constructed, tissue-mimicking bladder phantom (Bude et al. (1995)) and in vivo experiments on four healthy volunteers, demonstrated the previous stated detection principle. However, this first lab-based prototype was not suitable to be used for pediatric applications or in-house clinical investigations. First of all, the complete system needed to be miniaturized in such a way that it could be worn by a child. Secondly, the transducer itself needed to be stabilized, in order to measure continuously and autonomously at the same abdominal position, without the (hand-held) assistance of a medical professional. 
Following this first feasibility experiment, the department of Pediatric Urology started an internal innovation project, referred to as a Pontes Medical Project (Utrecht, the Netherlands). In this project, technical, clinical and business competences were brought together, with the objective to design and develop a first clinical prototype for in-house clinical investigations. For the technical and business expertise, the department of Pediatric Urology initiated a collaboration with the company Novioscan (Nijmegen, the Netherlands).

In Chapter 2, after almost one year of development, the design of a first, wearable clinical prototype, the URIKA Bladder Monitor (UBM), was presented. The UBM was a custom-made, wearable, A-mode based ultrasound device consisting of an electronic body pack and an ultrasound transducer assembly, worn around the waist with an elastic belt. The transducer assembly contained a single-element $3.81 \mathrm{MHz}$ transducer (at a $0^{\circ}$ angle), positioned perpendicular to the skin. Observational measurement data could be collected on an internal micro-SD card. To comply with the regulatory guidelines for medical devices, a technical file (or investigational medical device dossier [IMDD]) was compiled including i.e. the device requirements, (technical) design, a risk analysis and a description of the manufacturing processes.

In addition, in order to conduct in-house clinical investigations, a pre-clinical safety evaluation (in line with IEC 60601-2-37 regulatory requirements) was required as part of the preparation for ethics approval (Chapter 2). Therefore, the thermal (TIS) - and mechanical (MI) safety indices were determined, indicating whether the UBM was capable of introducing a rise in tissue temperature $\left(\right.$ TIS $_{\max }=1.0$ ) or generate non-thermal (cavitation) bioeffects $\left(\mathrm{MI}_{\max }=1.0\right)$. The pre-clinical safety evaluation stated that the UBM was not expected to exceed the thermal index and was not capable of exceeding the mechanical index.

Furthermore, the recommended limits for the acoustic exposure levels were not exceeded. It was concluded that the potential risk of any biological effects was very low and that the UBM was safe to be used (exclusively) for in-house clinical investigations.

From April 2015 until September 2015, after receiving ethics approval, the first clinical, observational feasibility study was conducted with the UBM in a group of 14 school-age children with dysfunctional voiding (Chapter 3).

The aim of the feasibility study was to determine the performance of the first clinical prototype. During an UBM monitoring session of 1.5-2 hours, the child wore the device and the anterior-posterior bladder dimension was determined. It was concluded that the UBM had a proper sensitivity (78.3\%), specificity (100\%) and detection rate (71\%), for a bladder dimension threshold of $5.03 \mathrm{~cm}$. Especially in younger children ( $<10$ years), the full bladder could be detected in all patients $(100 \%)$. By the end of 2015 , this first feasibility study demonstrated proof-of-concept and initiated a major, 
complete redesign of the UBM model focusing on miniaturization and improving the sensor's stability and increasing the detection range.

\section{Design \& Verification}

From March 2016 until October 2016, a specialized development team within Novioscan, focused on the redesign of the next wearable ultrasonic bladder sensor. This team consisted of a project \& quality manager, a hardware \& software engineer, a technical physician, an industrial designer and a marketing \& sales manager. This team used a development method in accordance to the $\mathrm{V}$-model. This method describes how each individual device requirement should be related to a specific acceptance test, ensuring every device requirement will be met when the product becomes available for clinical use.

Based on the results of the first clinical feasibility study, the user- and functional requirements of the device were defined, followed by the product architecture (i.e. block diagram presenting the product). This information became the backbone of the product to be. Next, a hardware, software and exterior product-design were defined based on the initial product architecture. Every design output was then verified against the initial requirement specification, to ensure that each individual requirement was covered.

Compared to the UBM, the redesigned product architecture was based on the integration of the electronic body pack $(165 \times 80 \times 28 \mathrm{~mm})$ and the ultrasound transducer assembly $(90 \times 72 \times 21 \mathrm{~mm})$. To increase the device's detection range, the field of view (FOV) was enhanced to $30^{\circ}$ (sagittal plane) through the combination of four individual ultrasound transducers, allowing bladder detection downwards into the pelvic region. Also, to prevent movement of the device while wearing it, the device was combined with a double-sided adhesive, to fixate it properly to the lower abdomen. Next, the micro-SD card for data collection was replaced by an internal memory chip, communicating with Bluetooth ${ }^{\circledR}$ Low Energy. Also, a vibration actuator was implemented, to provide an internal vibration notification, when the bladder is almost ( 80\%) full. This resulted in the miniaturized wireless, battery-operated ultrasound device, the SENS-U Bladder Sensor (SENS-U), combined with a personal smartphone application (size: 95×55×16 mm, $\sim 40 \%$ reduction in volume compared to the UBM's transducer assembly, Chapter 4).

\section{Validation \& Certification}

In order to implement the SENS-U as a new adjunct diagnostic or treatment tool for children with urinary incontinence, it is required to obtain CE certification, by demonstrating compliance with the essential requirements in accordance to the European Medical Device Directive (MDD 93/42/EEC, a conformity assessment). When a medical device obtains a CE-marking, the manufacture is able to sell the device freely within the European Economic Area, which allows many physicians, and their patients, to get access to new medical technology. 
The conformity assessment procedure depends on the class of the device. For the SENS-U, it was stated as a class lla medical device, because it is an active (electrical) medical device (for diagnosis) intended to supply (ultrasound) energy which will be absorbed by the human body. Therefore, it requires the involvement of a certified notified body. Next, the conformity assessment requires support of sufficient clinical evidence (a clinical evaluation), in order to demonstrate that the device is safe, performs as is intended, and that any undesirable side-effects are minimized and acceptable when weighed against the benefits for the patients. Therefore, a second clinical, observational study was conducted at the department of Pediatric Urology of the Wilhelmina Children's Hospital UMC Utrecht (Utrecht, the Netherlands) (Chapter 4).

From March 2017 until September 2017, this clinical investigation included 30 children (6-12 years) who were scheduled for a standard, clinical (video) urodynamic evaluation (Chapter 4).

Before the procedure, the SENS-U was positioned with a double-sided adhesive on the lower abdomen (combined with standard ultrasound gel), just above $(1 \mathrm{~cm})$ the pubic bone. Parallel to the standard (video) urodynamic evaluation, the SENS-U continuously (every $30 \mathrm{~s}$ ) estimated the bladder filling status over a broad range of infused bladder volumes. The results indicated that the SENS-U was able to detect a full bladder with a success rate of $90 \%$ and that there was a strong, positive correlation $\left(r_{s}=0.94\right)$ between the measured bladder dimensions by the SENS-U and the infused volume. Also, although the notification function was not turned on, the SENS-U could (theoretically) notify the child in almost $90 \%$ of the cases, based on a personalized, volume-based notification threshold.

Parallel to the clinical evaluation process, the SENS-U was also technically evaluated in accordance to international basic safety and essential performance standards for medical devices, for both the professional - and home healthcare environment, by DEKRA Certification B.V. (Arnhem, the Netherlands). During this process, the product's technical file (e.g. design files, risk analysis and user manual) was reviewed for compliance with the relevant safety standards. Next, the device itself was subjected to multiple (potentially destructive) tests regarding i.e. electrical safety, environmental impact, acoustic safety, temperature, biocompatibility, mechanical strength (i.e. impact/ drop tests, vibration/shock tests) and electromagnetic compatibility (EMC).

In September 2017, the compliance procedure was completed and the SENS-U became certified in accordance to the applicable international standards for both the professional - and home healthcare environment.

In order to obtain a CE-marking for the SENS-U, the device was subjected to a conformity assessment by the notified body, SGS Belgium NV (Antwerp, Belgium, NoBo-1639), mid Augustus 2017. During this process, the manufacturer of the SENS-U, Novioscan, was audited to confirm that the technical documentation of both the SENS-U 
(MDD 93/42/EEC) and their quality management system (ISO13485:2016) complied with the applicable regulatory requirements.

On March 20, 2018, Novioscan obtained both the CE-marking for the SENS-U and the certification for their quality management system for the design, development, manufacturing and distribution of these particular medical devices. From this moment, the SENS-U became available for the European medical device market, enabling physicians on a broader scale to implement this new tool to monitor the bladder content of children with urinary incontinence problems.

\section{PART II: CLINICAL IMPLEMENTATION \& VALORIZATION PHASE}

The second part of this thesis focused on the clinical implementation and valorization of the SENS-U for children with urinary incontinence during daily life activities. The main objectives were to:

1. Evaluate the SENS-U's performance during daily life activities.

2. Verify the accuracy for nighttime registration of the bladder filling.

3. Establish and verify the clinical benefits of the device.

Therefore, a new clinical pilot study was initiated to assess the performance of the SENS-U for monitoring natural bladder filling in children during activities of daily living (in the professional healthcare environment). Also, the level of response to the provided full-bladder notification was evaluated (Chapter 5). In this study, 15 children (6-16 years) were included who were admitted for their inpatient bladder training at the Wilhelmina Children's Hospital UMC Utrecht (Utrecht, the Netherlands). Parallel to one training day, the child wore the SENS-U which determined the bladder filling status and provided a (vibration) notification when the bladder was almost full ( $80 \%)$. This investigation showed that the SENS-U was an accurate, easy to use, patient-friendly device with a similar precision compared to the previous conducted static, (video)urodynamic assessment.

Chapter $\mathbf{5}$ also indicated that almost all children responded positively to provided full-bladder notifications (median level of response of 100\%) and that they preferred the vibration notification on the device itself, compared to a smartphone and/or acoustic notification.

The evaluation of the daytime, clinical implementation of the SENS-U in the professional healthcare environment, triggered the next implementation step: children with enuresis in their home healthcare environment (Chapter 6). For this population, the SENS-U can potentially prevent the enuretic event, ensure dry bedsheets and increase the treatment effectiveness, through associative conditioning between the notification and the actual urge of a full bladder. Also, the SENS-U can be applied for diagnostic purposes, by monitoring the nocturnal bladder function, without disturbance of the 
child's sleep time. This remains very difficult with currently, available resources, such as a standard, acoustic bedwetting alarm.

In Chapter 6, the first observational, home-based feasibility study was conducted to assess the performance of the SENS-U for monitoring the natural nocturnal bladder filling in children with enuresis. To minimize the impact on their current treatment, the SENS-U's full-bladder notifications were deactivated. The results demonstrated that the SENS-U was able to monitor the nocturnal bladder filling successfully, within its detection range (>83\%). Secondly, the device did not significantly influence the children's sleeping behavior.

Finally, Chapter $\mathbf{7}$ describes a first series of (inter)national, clinical cases reports collected to illustrate the clinical implementation and gain insight into the clinical benefits of the SENS-U. A collection of 21 cases from five (inter)national medical institutions in the Netherlands and Belgium indicated that the SENS-U supports children by 1) increasing the sense of urgency by direct biofeedback, 2) reducing the level of urinary incontinence, 3) decreasing residual volume(s), 4) increasing the appropriateness of catheterization attempts, 5) becoming more independent, and 6) potentially supporting central inhibition to suppress bladder overactivity.

However, it also became clear that additional clinical research is required to determine the appropriate duration, design and level of (intensive) supervision for an effective treatment, thereby minimizing the risk of relapse and reducing the risk of becoming dependent of the device. Finally, several technological opportunities were identified which could be beneficial for a broader clinical implementation and valorization. Particularly the user interface (device size (too big) and fixation method (skin irritation)) can be further optimized, in order to increase the level of comfort during use and thereby ensuring a high(er) level of compliance.

\section{CONCLUSION}

In summary, this thesis presented the design and development of a new, wearable ultrasonic bladder sensor for children suffering from urinary incontinence, the SENS-U, and confirmed its clinical safety and performance through (safety) verification and the clinical validation.

In addition, the first steps towards a broader clinical implementation were discussed, presenting the first potential clinical benefits of SENS-U: increasing the awareness of a full bladder through direct biofeedback, being able to become and stay dry, providing insight regarding possible residual volume, producing better voided or catheterized volumes, increasing the quality of life, supporting central inhibition and becoming more independent. However, there was several technological opportunities were identified which could be beneficial for a broader clinical implementation and valorization of the SENS-U. 


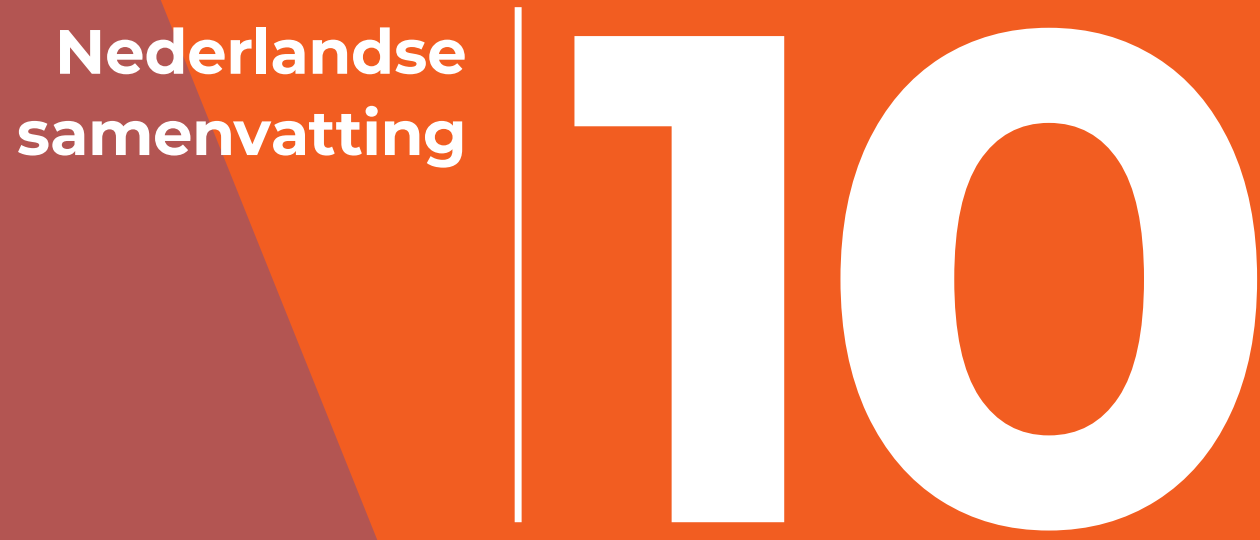


\section{SAMENVATTING}

Dit proefschrift richtte zich op de ontwikkeling en validatie van een nieuwe draagbare ultrasound blaassensor voor schoolgaande kinderen met urine-incontinentie. Tevens werden de eerste stappen verkend, richting de klinische implementatie van dit potentieel, praktijk-veranderde hulpmiddel. Dit hoofdstuk beschrijft het ontwikkelproces van de SENS-U en presenteert de conclusies van de uitgevoerde klinische onderzoeken.

\section{DEEL I: ONTWIKKELING \& KLINISCHE VALIDATIEFASE}

In het eerste deel van dit proefschrift was het primaire doel om de veiligheid en prestatie van het eerste klinische prototype, de URIKA Blaasmonitor, en haar door doorontwikkelde opvolger, de SENS-U Blaassensor, te bepalen. In plaats van een nieuw ultrasound apparaat te ontwikkelen om zeer nauwkeurig het werkelijke blaasvolume te meten (zoals bijv. met tweedimensionale ultrasound scanners zoals een BladderScan ${ }^{\circledR}$ of standaard transabdominale echografie), was het doel om een kleine, discrete, draadloze sensor te ontwikkelen, die continu gedragen kon worden tijdens dagelijkse activiteiten en die nauwkeurig een persoonlijke, kindvriendelijke melding geeft voordat de blaas vol is.

Een hulpmiddel als dit biedt artsen en verpleegkundigen de mogelijkheid om urineincontinentie te voorkomen, het gebruik van incontinentieproducten (bijv. luiers) te verminderen, de huidige effectiviteit van de blaastraining (dag en / of nacht) mogelijk te verhogen, de kwaliteit van leven van het kind (en zijn verzorgers) te verbeteren en het zou tot nieuwe diagnostische inzichten kunnen leiden omtrent het plasgedrag.

\section{Concept Ontwikkeling}

De ontwikkeling van een nieuwe, draagbare ultrasound blaassensor is eind 2013 gestart door de afdeling Kinderurologie van het Wilhelmina Kinderziekenhuis UMC Utrecht, samen met de afdeling Medische Technologie en Klinische Fysica (ISO13485) van het Universitair Medisch Centrum Utrecht (UMC) Utrecht (Utrecht, Nederland). Het eerste lab-model prototype (tafelformaat) was gebaseerd op het detectieprincipe van het meten van de veranderingen in de voor - achterwaartse blaasdimensie, wat zou kunnen dienen als een potentiële indicator voor de vullingsstatus van de blaas.

In vitro experimenten met een zelfgebouwd, weefsel-nabootsend blaasfantoom (Bude et al. (1995)) en in vivo experimenten met vier gezonde vrijwilligers, demonstreerde het eerder genoemde detectieprincipe. Dit eerste lab-model prototype was echter niet geschikt om te worden gebruikt bij kinderen of voor intern klinisch onderzoek. Allereerst moest het complete systeem zo verkleind worden, dat het door een kind gedragen kon worden. Ten tweede moest de transducer zelf worden gestabiliseerd op dezelfde buikpositie om continu en autonoom de blaasvulling te kunnen meten, zonder (manuele) assistentie van een medische professional. 
$\mathrm{Na}$ dit eerste haalbaarheidsexperiment is de afdeling Kinderurologie gestart met een intern innovatieproject, een Pontes Medical Project (Utrecht, Nederland). In dit project werden technische, klinische en zakelijke competenties samengebracht, met als doel om een eerste klinisch prototype te ontwerpen en te ontwikkelen voor interne klinische onderzoeken. Voor de technische en zakelijke expertise is de afdeling Kinderurologie een samenwerking aangegaan met het bedrijf Novioscan (Nijmegen, Nederland).

In Hoofdstuk 2, na bijna een jaar van ontwikkeling, werd het ontwerp van een eerste, draagbaar klinisch prototype, de URIKA Blaasmonitor (UBM), gepresenteerd. De UBM was een op maat gemaakte, draagbare, op A-modus gebaseerd ultrasound apparaat, bestaande uit een houder voor de elektronica en een behuizing voor de ultrasound transducer, die rondom de taille werd gedragen met een elastische riem. De transducerbehuizing bevatte een 3.81 MHz transducer met één element (onder een hoek van $0^{\circ}$ ), gepositioneerd loodrecht op de huid. Observationele meetgegevens konden worden verzameld op een interne micro-SD-kaart. Om te voldoen aan de wettelijke richtlijnen voor medische hulpmiddelen, is een technisch dossier ("Investigational medical device dossier" [IMDD]) opgesteld, bestaande uit o.a. de eisen voor het hulpmiddel, het (technisch) ontwerp, een risicoanalyse en een beschrijving van de fabricageprocessen.

Tevens was als onderdeel voor ethische goedkeuring voor toekomstig intern klinisch onderzoek, een preklinische veiligheidsevaluatie (gebaseerd op de wettelijke vereisten van IEC 60601-2-37 richtlijn) vereist (Hoofdstuk 2). Hiervoor werden de thermische (TIS) - en mechanische (MI) veiligheidsindices bepaald, die aangeven of de UBM in staat was een verhoging van de weefseltemperatuur $\left(\right.$ TIS $\left._{\max }=1.0\right)$ te introduceren of niet-thermische (cavitatie) bio-effecten te genereren $\left(\mathrm{MI}_{\max }=1.0\right)$. Uit de preklinische veiligheidsevaluatie bleek, dat de UBM naar verwachting de thermische index en de mechanische index niet kon overschrijden. Tevens werden de aanbevolen limieten voor de akoestische intensiteit niet overschreden. Er werd geconcludeerd. dat het potentiële risico van biologische effecten zeer laag was en dat de UBM veilig kon worden gebruikt voor (uitsluitend) intern klinisch onderzoek.

Van april 2015 tot september 2015 werd, na goedkeuring van het ethisch comité, het eerste klinische, observationele haalbaarheidsonderzoek uitgevoerd met de UBM in een groep van 14 schoolgaande kinderen met disfunctioneel plassen (Hoofdstuk 3).

Het doel van deze haalbaarheidsstudie was om de prestaties van het eerste klinische prototype te bepalen. Tijdens een UBM-meetsessie van 1.5-2 uur droeg het kind het hulpmiddel en werd de voor-achterwaartse blaasdimensie bepaald. Er werd geconcludeerd, dat de UBM een redelijke gevoeligheid (78.3\%), specificiteit $(100 \%)$ en detectiepercentage $(71 \%)$ had voor een blaasdimensie-drempel van $5.03 \mathrm{~cm}$. Vooral bij jongere kinderen ( $<10$ jaar) kon de volle blaas bij alle patiënten worden gedetecteerd (100\%). Eind 2015 demonstreerde deze eerste haalbaarheidsstudie het 'proof-of-concept' en initieerde een grote doorontwikkeling van het UBM-model, 
gericht op miniaturisatie en verbetering van de stabiliteit van de sensor en vergroting van het detectiebereik.

\section{Ontwerpen \& Verifiëren}

Van maart 2016 tot oktober 2016 richtte een gespecialiseerd ontwikkelteam binnen Novioscan zich op de doorontwikkeling van de draagbare ultrasound blaassensor. Dit team bestond uit een project \& kwaliteitsmanager, een hardware \& software ontwikkelaar, een klinisch technoloog, een industrieel ontwerper en een marketing \& sales manager. Dit team gebruikte een ontwikkelmethode volgens het V-model. Deze methode beschrijft, hoe elke individuele producteis moet worden gerelateerd aan een specifieke acceptatietest, zodat aan elke producteis wordt voldaan, wanneer het product beschikbaar komt voor klinisch gebruik.

Op basis van de resultaten van de eerste klinische haalbaarheidsstudie werden de gebruikers- en functionele eisen van het hulpmiddel gedefinieerd, gevolgd door de productarchitectuur (een blokschema dat het product voorstelt). Deze informatie werd de basis voor het toekomstige product. Vervolgens werd een ontwerp voor de hardware-, software- en het uiterlijk van het product gedefinieerd op basis van de oorspronkelijke productarchitectuur. Elk ontwerp-resultaat werd vervolgens geverifieerd aan de hand van de oorspronkelijke producteisen, om ervoor te zorgen dat aan elke individuele eis werd voldaan.

Vergeleken met de UBM, is de nieuwe productarchitectuur gebaseerd op de integratie

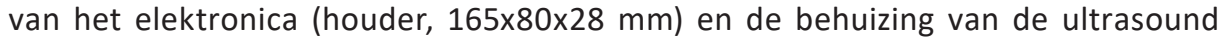
transducer $(90 \times 72 \times 21 \mathrm{~mm})$. Om het detectiebereik van het apparaat te vergroten, werd de kijkhoek vergroot tot $30^{\circ}$ (sagittale vlak) door de combinatie van vier individuele ultrasound transducers, waardoor het mogelijk werd, om de blaas te detecteren dieper in het bekken. Om zowel de beweging van het apparaat tijdens het dragen te voorkomen en het goed op de onderbuik te kunnen positioneren, werd de behuizing gecombineerd met een dubbelzijdige pleister. Tevens werd de micro-SD-kaart voor dataopslag vervangen door een interne geheugenchip, die communiceert met Bluetooth ${ }^{\circledR}$ Low Energy. Er werd ook een trilmotor geïmplementeerd, om een interne trilmelding te geven wanneer de blaas bijna ( $80 \%)$ vol is. Dit resulteerde in een geminiaturiseerd, draadloos, batterij-gedreven ultrasound apparaat, de SENS-U Blaassensor (SENS-U), gecombineerd met een persoonlijke smartphone-applicatie (afmeting: 95×55×16 mm, $\sim 40 \%$ kleiner in volume vergeleken met de UBM ultrasound transducer behuizing, Hoofdstuk 4).

\section{Validatie \& Certificering}

Om de SENS-U te implementeren als een nieuw hulpmiddel voor diagnose of behandeling van kinderen met urine-incontinentie, moet CE-certificering worden verkregen, door aan te tonen dat wordt voldaan aan de essentiële eisen in overeenstemming met de Europese richtlijn voor medische hulpmiddelen (MDD 93/42/EEG, een 
conformiteitsbeoordeling). Wanneer een medisch hulpmiddel een CE-markering krijgt, kan de fabrikant het hulpmiddel vrij verkopen binnen de Europese Economische Ruimte, waardoor vele artsen en hun patiënten toegang krijgen tot nieuwe medische technologie.

De conformiteitsbeoordelingsprocedure is afhankelijk van de (risico) klasse van het apparaat. De SENS-U werd definieert als een klasse Ila medisch hulpmiddel, omdat het een actief (elektrisch) medisch hulpmiddel is (voor diagnose), dat bestemd is om (ultrasound) energie te leveren, die door het menselijk lichaam wordt geabsorbeerd. De betrokkenheid van een gecertificeerde aangemelde instantie is voor deze klasse vereist. Vervolgens vereist de conformiteitsbeoordeling ondersteuning van voldoende klinisch bewijs (een klinische evaluatie) om aan te tonen, dat het hulpmiddel veilig is, werkt zoals het bedoeld is en dat alle ongewenste bijwerkingen geminimaliseerd en aanvaardbaar zijn, wanneer ze worden afgewogen tegen de voordelen voor de patiënten. Hieruit volgend is een tweede klinische observationele studie uitgevoerd bij de afdeling Kinderurologie van het Wilhelmina Kinderziekenhuis UMC Utrecht (Utrecht, Nederland) (Hoofdstuk 4).

Van maart 2017 tot september 2017 werden in dit klinisch onderzoek 30 kinderen (6-12 jaar) geïncludeerd, die gepland waren voor een standaard klinische (video) urodynamisch onderzoek (Hoofdstuk 4).

Voorafgaand aan het (video) urodynamisch onderzoek werd de SENS-U met een dubbelzijdige pleister op de onderbuik (gecombineerd met standaard echo-gel) geplaatst, net boven $(1 \mathrm{~cm})$ het schaambeen. Parallel aan het (video) urodynamisch onderzoek, schatte de SENS-U continu (elke $30 \mathrm{sec}$ ) de vullingsstatus van de blaas over een breed bereik qua gevuld blaasvolume. De resultaten gaven aan, dat de SENS-U een volle blaas kon detecteren met een succespercentage van $90 \%$ en dat er een sterke, positieve correlatie $\left(r_{s}=0.94\right)$ was, tussen de gemeten blaasdimensies door de SENS-U en het gevulde blaasvolume. Hoewel de notificatie functionaliteit was uitgeschakeld, kon de SENS-U het kind (theoretisch) in bijna 90\% van de gevallen informeren, op basis van een gepersonaliseerde, volume gebaseerde notificatiedrempel.

Parallel aan het klinisch evaluatieproces werd de SENS-U ook technisch geëvalueerd door DEKRA Certificering B.V. (Arnhem, Nederland), conform internationale normen voor basisveiligheid en essentiële prestaties voor medische hulpmiddelen, voor zowel de professionele- als de thuisomgeving. Tijdens dit proces werd het technisch dossier van het product (o.a. ontwerp, risicoanalyse en gebruikershandleiding) beoordeeld op naleving van de relevante veiligheidsnormen. Vervolgens werd het hulpmiddel zelf onderworpen aan meerdere (potentieel destructieve) testen met betrekking tot elektrische veiligheid, milieu-impact, akoestische veiligheid, temperatuur, biocompatibiliteit, mechanische sterkte (o.a. impact- / valtesten, trillings- / schroktesten) en elektromagnetische compatibiliteit (EMC). 
In september 2017 is de technische evaluatie afgerond en is de SENS-U gecertificeerd volgens de geldende internationale normen voor zowel de professionele - als de thuisomgeving.

Om een CE-markering voor de SENS-U te verkrijgen, werd het medisch hulpmiddel medio augustus 2017 onderworpen aan een conformiteitsbeoordeling door de aangemelde instantie, SGS Belgium NV (Antwerpen, België, NoBo-1639). Tijdens dit proces werd de fabrikant van de SENS-U, Novioscan, geauditeerd om vast te stellen, dat de technische documentatie van zowel de SENS-U (MDD 93/42/EEG) als het kwaliteitsmanagementsysteem (ISO13485:2016) voldeden aan de van toepassing zijnde wet- en regelgeving.

Op 20 maart 2018 behaalde Novioscan zowel de CE-markering voor de SENS-U als de certificering voor hun kwaliteitsmanagementsysteem voor het ontwerpen, het ontwikkelen, het produceren en het distribueren van dit type medische hulpmiddelen. Vanaf dit moment werd de SENS-U beschikbaar voor de Europese markt voor medische hulpmiddelen, waardoor artsen op brede schaal dit nieuwe hulpmiddel konden implementeren, om de vullingsstatus van de blaas te monitoren bij kinderen met incontinentieproblemen.

\section{DEEL II: KLINISCHE IMPLEMENTATIE \& VALORIZATIEFASE}

Het tweede deel van dit proefschrift richtte zich op de klinische implementatie en valorisatie van de SENS-U voor kinderen met urine-incontinentie, tijdens het dagelijks leven. De belangrijkste doelstellingen waren:

1. Evalueer de prestaties van de SENS-U tijdens dagelijkse activiteiten.

2. Verifieer de nauwkeurigheid voor nachtelijke registratie van de blaasvulling.

3. Bepaal en verifieer de klinische voordelen van het hulpmiddel.

Hiervoor werd een nieuwe klinische pilotstudie gestart om de prestaties van de SENS-U te beoordelen voor het monitoren van blaasvulling bij kinderen tijdens dagelijkse activiteiten (in de professionele gezondheidszorg). Ook werd de reactie op de gegeven volle blaas - notificaties geëvalueerd (Hoofdstuk 5). In deze studie werden 15 kinderen (6-16 jaar) geïncludeerd, die werden opgenomen voor hun klinische blaastraining in het Wilhelmina Kinderziekenhuis UMC Utrecht (Utrecht, Nederland). Parallel aan één trainingsdag droeg het kind de SENS-U, die de vullingsstatus van de blaas bepaalde en een (tril) notificatie gaf, wanneer de blaas bijna vol was ( 80\%). Uit dit onderzoek bleek dat de SENS-U een nauwkeurig, gebruiksvriendelijk, patiëntvriendelijk hulpmiddel was met een vergelijkbare precisie ten opzicht van de eerder uitgevoerde statische, (video) urodynamische evaluatie.

Hoofdstuk 5 gaf ook aan, dat bijna alle kinderen positief reageerden op volle blaasnotificaties (100\% [mediaan] responsie) en dat ze de voorkeur gaven aan de tril- 
notificatie op het apparaat zelf, vergeleken met een smartphone en / of akoestische melding.

De evaluatie van de klinische implementatie van de SENS-U overdag in de professionele gezondheidszorg initieerde de volgende implementatiestap: kinderen met enuresis in hun thuisomgeving (Hoofdstuk 6). Voor deze populatie kan de SENS-U mogelijk de enuretische episode voorkomen, zorgen voor droge lakens en de effectiviteit van de behandeling verhogen, door associatieve conditionering tussen de notificatie en de daadwerkelijke aandrang van een volle blaas. Tevens kan de SENS-U worden gebruikt voor diagnostische doeleinden, door de nachtelijke blaasfunctie te monitoren, zonder de slaap van het kind te verstoren. Dit blijft namelijk erg moeilijk met de momenteel beschikbare middelen, zoals een standaard, akoestische plaswekker.

In Hoofdstuk 6 werd de eerste observationele haalbaarheidsstudie thuis uitgevoerd, om de prestaties van de SENS-U te beoordelen voor het monitoren van de nachtelijke blaasvulling bij kinderen met enuresis. Om de impact op hun huidige behandeling te minimaliseren, werden de volle blaas - notificaties van de SENS-U gedeactiveerd. De resultaten toonden aan, dat de SENS-U de nachtelijke vulling van de blaas, binnen het detectiebereik, met succes kon volgen (>83\%). Ten tweede had het apparaat geen significante invloed op het slaapgedrag van de kinderen.

Ten slotte beschrijft Hoofdstuk 7 een eerste serie (inter)nationale, klinische casussen verzameld om de klinische implementatie te illustreren en om inzicht te krijgen in de klinische voordelen van de SENS-U. De verzameling van 21 casussen van vijf (inter) nationale medische instellingen in Nederland en België liet zien dat de SENS-U kinderen ondersteunt door: 1) het blaasgevoel te verbeteren via directe biofeedback, 2) het verminderen van urine-incontinentie, 3) het verminderen van residu naar mictie, 4) het bijdragen aan efficiënt katheteriseren, 5) toename in onafhankelijkheid, en 6) de mogelijke bijdrage bij centrale inhibitie ter onderdrukking van blaasoveractiviteit.

Het werd echter ook duidelijk dat aanvullend klinisch onderzoek nodig is om de juiste duur, opzet en niveau van (intensief) begeleiding te bepalen voor een effectieve behandeling, waardoor het risico op terugval wordt geminimaliseerd en het risico op afhankelijkheid van het hulpmiddel wordt verkleind. Tot slot werden verschillende technologische mogelijkheden geïdentificeerd die gunstig zouden kunnen zijn voor een bredere klinische implementatie en valorisatie. Met name de gebruikersinterface (apparaat grootte (te groot) en fixatiemethode (huidirritatie)) kan verder worden geoptimaliseerd om het gebruikscomfort te verhogen en daarmee duurzaam gebruik te garanderen. 


\section{CONCLUSIE}

Dit proefschrift beschreef het ontwerp en de ontwikkeling van een nieuwe, draagbare ultrasound blaassensor voor kinderen met urine-incontinentie, de SENS-U, en bevestigde de klinische veiligheid en prestaties door (veiligheid) verificatie en de klinische validatie.

Daarnaast werden de eerste stappen naar een bredere implementatie besproken, waarbij de eerste potentiële klinische voordelen van SENS-U werden beschreven: het bewustzijn van een volle blaas vergroten door directe biofeedback, droog worden en blijven, inzicht geven over een mogelijk residu na mictie, bijdragen aan betere mictie - of gekatheteriseerde volumes, verbeteren van de kwaliteit van leven, ondersteuning bij centrale inhibitie, en een toename in onafhankelijkheid. Er werden echter ook verschillende technologische mogelijkheden geïdentificeerd die een bijdrage kunnen leveren aan een bredere klinische implementatie en valorisatie van de SENS-U. 
Nederlandse samenvatting 

List of abbreviations Co-authors and affiliations Dankwoord Curriculum Vitae List of publications Patent

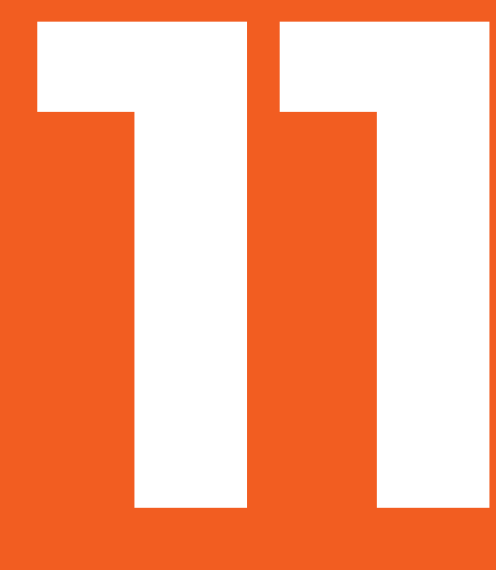




\section{LIST OF ABBREVIATIONS}

\begin{tabular}{|c|c|}
\hline$A_{\text {aprt }}$ & $-12 \mathrm{~dB}$ output beam area \\
\hline$A B S$ & Acrylonitrile Butadiene Styrene \\
\hline AG & Abdominal Girth \\
\hline ALARA & As Low As Reasonably Achievable \\
\hline$A-P$ & Anterior-Posterior \\
\hline AUC & Area Under the Curve \\
\hline AW & Anterior Wall \\
\hline $\mathrm{BIA}$ & Bioelectrical Impedance Analysis \\
\hline BLE & Bluetooth ${ }^{\circledR}$ Low Energy \\
\hline BMI & Body Mass Index \\
\hline c & Speed of sound \\
\hline C & Capacitor \\
\hline CE & Conformité Européenne \\
\hline $\mathrm{CISC}$ & Clean Intermittent Self Catheterization \\
\hline CPLD & Complex Programmable Logic Device \\
\hline CSHQ & Children's Sleep Habit Questionnaire \\
\hline CV\&V & Vereniging van Nederlandse Incontinentie Verpleegkundigen \\
\hline d & Dimension \\
\hline$d B$ & Decibels \\
\hline$\Delta \mathrm{t}$ & Time delay \\
\hline DV & Dysfunctional Voiding \\
\hline EBC & Expected Bladder Capacity \\
\hline EBP & Electronic Body pack \\
\hline EMC & Electromagnetic compatibility \\
\hline EMCR & Erasmus MC Sophia Children's Hospital \\
\hline EMG & Electromyography \\
\hline EMV & Early Morning Volume \\
\hline ESPU & European Society of Pediatric Urology \\
\hline EVV & Enuretic Voided Volume \\
\hline$f_{\text {awf }}$ & Acoustic Working Frequency \\
\hline FOV & Field Of View \\
\hline HV & High Voltage \\
\hline ICCS & International Children's Continence Society \\
\hline IEC & International Electrotechnical Commission \\
\hline IMDD & Investigational Medical Device Dossier \\
\hline IQR & Interquartile Range \\
\hline $\mathrm{I}_{\text {SATA }}$ & Spatial-Average Temporal-Average Intensity \\
\hline ISO & Internationale Organisatie voor Standaardisatie \\
\hline $\mathrm{I}_{\text {SPTA.3 }}$ & Derated Spatial-Peak, Temporal-Average Intensity \\
\hline JBZ & Jeroen Bosch Hospital \\
\hline LUT & Lower Urinary Tract \\
\hline MBC & Maximum Bladder Capacity \\
\hline
\end{tabular}




\begin{tabular}{|c|c|}
\hline MDD & European Medical Device Directive 93/42/EEC \\
\hline MI & Mechanical Index \\
\hline MNE & Monosymptomatic Nocturnal Enuresis \\
\hline MUMC & Maastricht University Medical Center \\
\hline MVP & Minimum Viable Product \\
\hline MVV & Maximum Voided Volume \\
\hline NMNE & Non-Monosymptomatic Nocturnal Enuresis \\
\hline NNBF & Natural Nocturnal Bladder Filling \\
\hline NVK & Nederlandse Vereniging voor Kindergeneeskunde \\
\hline NVU & Nederlandse Vereniging voor Urologie \\
\hline OAB & Overactive Bladder \\
\hline PCB & Printed circuit board \\
\hline $\mathrm{PII}_{.3}$ & (derated) Pulse-Intensity Integral \\
\hline $\mathrm{P}_{+}$ & Peak Positive Pressure \\
\hline$P_{r .3}$ & (derated) Peak-Rarefactional acoustic pressure \\
\hline PRF & Pulse Repetition Frequency \\
\hline PRP & Pulse Repetition Period \\
\hline PW & Posterior Wall \\
\hline QoL & Quality of Life \\
\hline RCT & Randomized Controlled Trial \\
\hline RF & Radiofrequency \\
\hline RRI & Relative Reflected Intensity \\
\hline ROC & Receiver Operating Characteristics \\
\hline$r_{s}$ & Spearman's Rank Correlation \\
\hline$S$ & Pulse Forming Network \\
\hline SD & Standard Deviation \\
\hline SPSS & Statistical Package for the Social Sciences \\
\hline$T_{0}$ & Time of placement \\
\hline TDIC & Time-dependent intermittent self-catheterization \\
\hline TIS & Soft-Tissue Thermal Index \\
\hline TUS & Transabdominal Ultrasound \\
\hline $\mathrm{T}_{\text {void }}$ & Time of void \\
\hline UAB & Underactive bladder \\
\hline UBM & URIKA Bladder Monitor \\
\hline UI & Urinary Incontinence \\
\hline UMC & University Medical Centre \\
\hline USB & Universal Serial Bus \\
\hline UTI & Urinary tract infection \\
\hline UZA & University Hospital Antwerp \\
\hline VDIC & Volume-dependent intermittent self-catheterizatio \\
\hline $\mathrm{V}_{\text {INF }}[\mathrm{min}]$ & Minimal detectable volume \\
\hline VP & Voiding postponement \\
\hline $\mathrm{V}_{\text {void }}$ & Urinary volume voided \\
\hline $\mathrm{V}_{\text {TDIC }}$ & Time-dependent catheterized volume \\
\hline
\end{tabular}


PART II | Chapter 11

$V_{\text {vDIC }} \quad$ Volume-dependent catheterized volume

WKZ Wilhelmina Children's Hospital

$\mathrm{W}_{0} \quad$ Acoustic output power

$X \quad$ Ultrasound transducer

$\eta \quad$ Transducer efficiency 


\section{CO-AUTHORS AND AFFILIATIONS}

B.A. de Vries

G.C.J. de Joode-Smink

B. ten Haken

T.P.V.M. de Jong

P. Dik

A.J. Klijn

A.J. Nieuwhof-Leppink

W.M.J. Kwinten
Department of Pediatric Urology, Wilhelmina Children's Hospital UMC Utrecht, Utrecht, The Netherlands

Technical Medicine, University of Twente, Enschede, The Netherlands

Department of Pediatric Urology, Wilhelmina Children's Hospital UMC Utrecht, Utrecht, The Netherlands

MIRA Institute for Biomedical Technology and Technical Medicine, Enschede, The Netherlands

Department of Pediatric Urology, Wilhelmina Children's Hospital UMC Utrecht, Utrecht, The Netherlands

Department of Pediatric Urology, University Children's Hospital AMC, Amsterdam, The Netherlands

Department of Pediatric Urology, Wilhelmina Children's Hospital UMC Utrecht, Utrecht, The Netherlands

Department of Pediatric Urology and Andrology, Sechenov Moscow State Medical University, Moscow, Russia.

Department of Pediatric Urology, Wilhelmina Children's Hospital UMC Utrecht, Utrecht, The Netherlands

Department of Medical Psychology and Social Work, Urology, Wilhelmina Children's Hospital UMC Utrecht, Utrecht, the Netherlands

Department of Pediatric Urology, Wilhelmina Children's Hospital UMC Utrecht, Utrecht, The Netherlands

Faculty of Science and Technology, University of Twente, Enschede, the Netherlands.

M. van Duren - van lersel Department of Pediatrics, Jeroen Bosch Hospital, 's-Hertogenbosch, the Netherlands

P.E. Jira

Department of Pediatrics, Jeroen Bosch Hospital, 's-Hertogenbosch, the Netherlands

P.R.H. Callewaert

Department of Urology, Maastricht University Medical Center, Maastricht, the Netherlands

G. de Win

Faculty of Medicine and Health Sciences, University of Antwerp, Antwerp, Belgium

Department of Urology, Antwerp University Hospital, Edegem, Belgium

Department of Urology, Antwerp University Hospital, Edegem, Belgium 
S. Eerens Department of Pediatrics, Antwerp University Hospital, Edegem, Belgium

K. de Baets Department of Urology, Antwerp University Hospital, Edegem, Belgium

E. De Bruijn-Kempe

Department of Pediatric Urology, Wilhelmina Children's Hospital UMC Utrecht, Utrecht, The Netherlands

R. van Zon

Department of Pediatric Urology, Erasmus MC Sophia Children's Hospital, Rotterdam, the Netherlands 


\section{DANKWOORD}

Het is zover: Wat begon als een technologische vraagstelling uit de klinische praktijk, heeft geleid tot een nieuw medische hulpmiddel in de kinder-incontinentie zorg van vandaag én mijn proefschrift! Deze weg heb ik zeker niet alleen afgelegd en ik wil hen die mij hierbij geholpen hebben dan ook graag bedanken.

\section{(Co) promotoren:}

Mijn promotor, prof. dr. ir. B. ten Haken, beste Bennie: graag bedank ik jou voor de mogelijkheid die jij mij geboden hebt om dit promotieonderzoek als (contract) promovendus te kunnen uitvoeren binnen jouw vakgroep. Dankzij jouw ervaring met externe promovendi en jouw motiverende hulp en kritische input van de afgelopen jaren is dit promotieonderzoek naar een hoger niveau getild. Tevens wil ik je hartelijk danken voor alle ondersteuning bij de procedurele zaken rondom het promoveren aan de Universiteit Twente. Ik zie er naar uit om ook na dit promotieonderzoek te blijven samenwerken, en gezamenlijk nieuwe toepassingen van deze draagbare ultrasound techniek te verkennen.

Mijn copromotor, prof. dr. P. Dik, beste Pieter: het prille begin waar dit promotieonderzoek aan ten grondslag ligt, herinner ik me nog als de dag van gisteren. Dinsdag 3 september 2013, de start van mijn eerste 10 -weekse klinische stage bij de afdeling kinderurologie voor de master-opleiding 'Technical Medicine (TG)', waarbij ik mij zou richten op het 'Sympathicus bandje', een band die middels huidgeleiding een kind zou kunnen aangeven wanneer de blaas vol is.

Ik stapte op deze eerste dag jouw kantoor binnen, gemotiveerd en wat gespannen, en wat zei jij vervolgens toen ik vroeg naar de status van deze stage-opdracht? Paul, jouw (TG) voorgangers hebben nét laten zien dat dit armbandje niet gaat werken.... dus kun je iets nieuws gaan bedenken?! Of terwijl, een 'blanco' start! Na een goede kop koffie, een creatieve brainstorm en een duik in bestaande wetenschappelijke literatuur, werd de basis gelegd voor de draagbare ultrasound blaassensor, de SENS-U, én dit proefschrift als bijzonder eindproduct. Pieter, ik ben je zeer dankbaar voor al het enthousiasme, creativiteit, aanstekelijkheid en (klinische/onderzoeks) mogelijkheden die je mij geboden hebt gedurende deze onvergetelijke tijd! Ondanks de klinische zorg om jouw patiënten, maakte je altijd tijd voor vragen, het tekenen van een (weer het zoveelste) document voor ethische goedkeuring of een luisterend oor. Ik zie er naar uit om gezamenlijk de SENS-U verder te implementeren, te valideren en te optimaliseren, zodat kinderen met urine-incontinentie zo optimaal mogelijk behandelt kunnen worden.

\section{Promotiecommissie:}

De leden van de promotiecommissie, prof. dr. ir. C.L. de Korte, prof. dr. ir. R.M. Verdaasdonk, prof. dr. W.F.J. Feitz, prof. dr. G. de Win en dr. J.G.L Cobussen-Boekhorst, 
graag wil ik jullie bedanken voor de tijd die jullie genomen hebben om dit proefschrift door te lezen, te beoordelen en deel te nemen in de promotiecommissie.

\section{Paranimfen:}

Heel veel dank aan mijn paranimfen, mijn broer Ruud van Leuteren en mijn vriendin, Hannah van Scheepen. Beide Klinisch Technologen in hart en nieren, en mijn klankbord gedurende dit gehele promotieonderzoek! Bij jullie kan ik altijd terecht voor feedback, advies en een goed gesprek en ik zie er naar uit jullie beide aan mijn zijde te hebben tijdens de verdediging van mijn proefschrift.

\section{Coauteurs:}

Graag bedank ik alle coauteurs van de artikelen in dit proefschrift voor alle tijd die ze hebben genomen voor het reviewen en reviseren van de manuscripten. Uw waardevolle feedback heeft bijgedragen aan een hoger niveau, snelle acceptatie in hoogstaande wetenschappelijk vakliteratuur en vele presentaties op (inter)nationale congressen op het gebied van kinderurologie.

\section{Novioscan:}

Mijn promotieonderzoek zou onmogelijk geweest zijn zonder de hulp en steun van Novioscan (Nijmegen, Nederland). Na mijn afstuderen heb ik als afgestudeerd Klinisch Technoloog mijn afstudeeronderzoek binnen dit jonge bedrijf kunnen voortzetten, in nauwe samenwerking met het Wilhelmina Kinderziekenhuis te Utrecht.

Zonder Novioscan zou de SENS-U Blaassensor niet binnen het termijn van mijn promotieonderzoek zowel ontwikkeld, gevalideerd, CE-gemarkeerd én geïmplementeerd kunnen zijn voor de zorg voor kinderen met urine-incontinentie. In het bijzonder, Reinout Woltjer, bedankt voor het kritische reviewen van mijn artikelen voorafgaand aan publicatie, en Jorien de Jonge, bedankt voor alle mooie momenten als deel van 'team Utrecht'. De rest van het Novioscan team: bedankt voor de prettige samenwerking gedurende de afgelopen, soms turbulente, jaren! Ik wil Novioscan bedanken voor de kansen die het mij gegeven heeft om ook (inter)nationaal mijn onderzoek onder de aandacht te kunnen brengen met een bijzonder, waardevol klinisch netwerk als resultaat. Tevens wil ik graag 'Essity Hygiene and Health AB (Gotenburg, Zweden)' bedanken voor haar vertrouwen én positieve impuls in Novioscan. Ik vind het een eer om gezamenlijk nieuwe technische innovaties te ontwikkelen op het gebied van continentiezorg.

\section{Patiënten:}

Graag bedank ik ook alle kinderen (en hun ouders/verzorgers) die vrijwillig deelgenomen hebben aan de klinische studies die beschreven zijn in dit proefschrift. Zonder jullie hulp hadden we nooit geweten of ons idee zou gaan werken! Dankzij jullie bijdrage, kunnen we nu heel veel kinderen helpen bij hun continentie-training. 


\section{Collega's afdeling kinderurologie:}

Dit promotieonderzoek had tevens zeker niet zo goed uitgevoerd kunnen worden zonder alle hulp van (oud)collega's uit het Wilhelmina Kinderziekenhuis te Utrecht. Graag bedank ik alle (kinder)urologen (Prof. dr. Tom de Jong, Dr. Aart Klijn, Drs. Keetje de Mooij, Dr. Panagiotis Mitsos, Dr. George Tsachouridis, Dr. Rogier Schroeder, Dr. Alexander Stillebroer, prof. dr. Laetitia de Kort), urotherapeuten (Anka, Gerrie, Annemiek, Lottie, Edith, Martine), verpleegkundig specialisten (Ellen, Laurence), secretaresses (Marjan, Margo) en alle studenten 'Technical Medicine' voor hun ondersteuning bij de opzet, de selectie, de inclusie en de uitvoering van de klinische studies met de blaassensor.

Daarnaast wil ik in het bijzonder afstudeerstudenten (TG-M3) Bas de Vries, Wenche Kwinten en Nynke Wijbenga bedanken, waarmee ik altijd kon sparren over onderzoekszaken, maar ook mijn problemen of frustraties kon bespreken, onder het genot van een goede cappuccino in het (te kleine) kantoor van Pieter.

\section{Familie en vrienden:}

Graag wil ik al mijn (studie)vrienden bedanken voor hun interesse en steun én voor de mooie momenten om de gedachten rondom het promotieonderzoek even te kunnen verzetten. In het bijzonder Seline: om aan te haken op het dankwoord uit jouw proefschrift: Ik vind het ook altijd erg gezellig om met ons kleine fietsclubje (Seline, Hannah, en mijzelf) op pad te gaan en Nederland te verkennen op onze wielrenfietsen! Dé manier om er even helemaal uit te zijn en gezellig bij te kletsen over van alles! 'Kop over Kop' \& 'Erop en Erover'!

Fieke, Nicole, wat is het toch altijd gezellig als ik jullie weer spreek! Genieten van een dinertje, digitale escape-rooms en lekker bijkletsen. Ook wil ik mijn studievriendengroep "Awesome Enschede" bedanken voor alle gezellige momenten tijdens de studie en daarna! Samen onze positie verwerven als nieuwe beroepsgroep in de snel veranderende gezondheidzorg. Geweldig!

En dan de festivalgroep: al jaren langs genieten we met $z$ 'n allen van prachtige festivals zoals PinkPop, Lowlands en Down The Rabbit Hole! Heerlijk een lang weekend er tussenuit, genieten van goede muziek, een koud drankje én goede gesprekken onder de partytent. De perfecte manier om het hoofd helemaal leeg te maken en er even helemaal uit te zijn! Bedankt allemaal én op naar het volgende (zelfgeorganiseerde) festival!

En de buurtjes, Manon, Wim en Lauren: dank voor alle gezelligheid de afgelopen jaren! Erg fijn dat we altijd bij elkaar kunnen aankloppen voor een kop koffie of een goed gesprek, en als er iets is, we elkaar altijd kunnen helpen waar nodig. Manon, ik wens jou ook veel succes met de afronding van jouw promotieonderzoek! 
Renze en Jay, ik wil jullie beide hartelijk dank voor jullie motiverende begeleiding gedurende het laatste jaar van mijn promotieonderzoek. Zonder jullie positieve en sportieve aanpak, had ik hier zeker niet zo gestaan!

Graag wil ik mijn schoonfamilie bedanken, waarbij ik mij altijd welkom voel én kan genieten van heerlijk dineren en een goed glas wijn. En vanzelfsprekend mijn eigen familie, mijn broers en (schoon)zussen en in het bijzonder mijn ouders: bedankt voor jullie onvoorwaardelijk steun tijdens deze bijzondere jaren. Jullie zijn er altijd voor mij tijdens de pieken en dalen, én halen het beste in mij naar boven!

Tot slot, lieve Hannah, ik ben jou erg dankbaar voor al jouw hulp, steun, rust en liefde tijdens deze (soms turbulente) jaren. Jij staat altijd voor mij klaar als mijn luisterend oor én ik ben altijd echt op mijn plek. Ik ben erg benieuwd naar alle mooie momenten die we samen nog mogen meemaken! 


\section{CURRICULUM VITAE}

Paulus Gerardus van Leuteren (Paul) was born on June 6th, 1990 in Hengelo (Overijssel, the Netherlands). After graduating at the 'Lyceum de Grundel' in Hengelo (VWO, pre-university education), he started the 3-year Technical Medicine Bachelor's program at the University of Twente (Enschede, the Netherlands) in September 2009. He completed his propaedeutic year 'with distinction' [cum laude] and finalized the overall Bachelor program within 3 years, after completing his multidisciplinary assignment under the supervision of (future co-promotor) prof. dr. P. Dik.

In 2012, he started the 3-year Technical Medicine Master's program, Medical Sensing \& Stimulation, which focusses on acquisition, processing and interpretation of medical signals for both diagnostic - and therapeutic purposes. After the first year of technological deepening in a clinical context, he started his four consecutive 10-week internships in several (university) medical institutions. At the department of Pediatric Urology (Wilhelmina Children's Hospital UMC Utrecht, Utrecht, the Netherlands), he first developed and evaluated the feasibility of a new ultrasonic, lab-based prototype for monitoring the urinary bladder filling in children with urinary incontinence (see INTRODUCTION of this thesis). He did his second internship at the department of Orthopedics \& Trauma Surgery (Isala, Zwolle, the Netherlands), were he researched the correlation between accelerometric measurements of gait, and recovery after a fracture of the lower extremity. The following two internships were under supervision of the department of Internal Medicine (Rijnstate, Arnhem, the Netherlands). First, he contributed to the development of an automatic detection algorithm of a glucose sensor, in close collaboration with the company Inreda Diabetic BV. (Goor, the Netherlands). Next, he investigated the feasibility of resistance-based bio-impedance analysis for volume assessment in dialysis patients.

In September 2014, he started his graduation internship at the department of Pediatric Urology (Wilhelmina Children's Hospital UMC Utrecht, Utrecht, the Netherlands), were he built on the research he started during his first 10-week internship, focusing on the design, development and the clinical evaluation of first clinical, wearable prototype: the URIKA Bladder Monitor (see: PATENT).

After a successful graduation 'with distinction' [cum laude], he started working as a Technical Physician at Novioscan BV. (Nijmegen, the Netherlands), and continued his clinical research as a guest researcher at the department of Pediatric Urology in Utrecht, under the supervision of prof. dr. P. Dik. From January 2019, Paul registered as an external PhD candidate at the University of Twente, under the supervision of promotor, prof. dr. ir. B. ten Haken, and co-promotor prof. dr. P. Dik. His PhD program resulted in multiple presentations at national - and international congresses in the field of Pediatric 
Urology, of which several presentations were on the shortlist for a prize (see: LIST OF PUBLICATIONS).

As of mid 2019, Paul became 'Chief Medical Officer' at Novioscan, where he is the primary expert on medical affairs, and supports the (development) team with respect to clinical investigation(s) and validation of wearable ultrasound applications. On April $1^{\text {st }}, 2020$, Novioscan BV. was acquired by Essity Hygiene and Health AB (Gothenburg, Sweden). Paul continues his work on the development and clinical evaluation of a new ultrasound device, intended for people of all ages dealing with urinary incontinence.

Since July $1^{\text {st }}, 2020$, Paul is officially registered as a Clinical Technologist (protected title) under the Individual Healthcare Professions Act (BIG act, nr: 19927378282).

With the thesis that lies before you, he completed his PhD-program entitled "DEVELOPMENT, VALIDATION AND IMPLEMENTATION OF A WEARABLE ULTRASONIC BLADDER SENSOR FOR PEDIATRIC APPLICATIONS" which he defended on December $10^{\text {th }}$, 2020 (at 12:45) at the University of Twente (Enschede, the Netherlands). 


\section{LIST OF PUBLICATIONS}

van Leuteren PG, de Vries BA, de Joode-Smink GCJ, ten Haken B, de Jong TPVM, Dik P. URIKA, continuous ultrasound monitoring for the detection of a full bladder in children with dysfunctional voiding: a feasibility study. Biomed Phys Eng Express. 2017;3(1):1-7. doi: 10.1088/2057-1976/aa589f

van Leuteren PG, Klijn AJ, De Jong TPVM, Dik P. SENS-U: Validation of a wearable ultrasonic bladder monitor in children during urodynamic studies. J Pediatr Urol. 2018;14(6):569.e1-569.e6. doi:10.1016/j.jpurol. 2018.07.018

van Leuteren PG, Nieuwhof-Leppink AJ, Dik P. SENS-U: Clinical evaluation of a fullbladder notification - a pilot study. J Pediatr Urol. 2019; 15(4): 381.e1-381.e5. doi:10.1016/j.jpurol.2019.04.006

Kwinten WMJ, van Leuteren PG, van Duren - van lersel M, Dik P, Jira PE. SENS-U: Continuous home monitoring of natural nocturnal bladder filling in children with nocturnal enuresis: an observational study. J Pediatr Urol. 2020;16(2): 196.e1-196. doi: 10.1016/j.jpurol.2020.01.012.

PRESENTATIONS « The abstract was on the shortlist for a prize

van Leuteren PG, de Bruijn-Kempe E, Hermsen-Heilema L, ten Haken B, Dik P. URIKA, CONTINUOUS ULTRASOUND MONITORING OF URINARY BLADDER FILLING IN CHILDREN WITH DYSFYNCTIONAL VOIDING: A PILOT STUDY, 26 $6^{\text {th }}$ Congress ESPU-Nurses, Prague, Czech Republic, October 2015

$\star$ van Leuteren PG, de Vries BA, de Joode-Smink GCJ, ten Haken B, de Jong TPVM, Dik P. URIKA: WEARABLE ULTRASOUND MONITORING FOR THE DETECTION OF A FULL BLADDER IN CHILDREN WITH DYSFUNCTIONAL VOIDING: A PILOT STUDY, $27^{\text {th }}$ Congress ESPU(Nurses), Harrogate, United Kingdom, June 2016

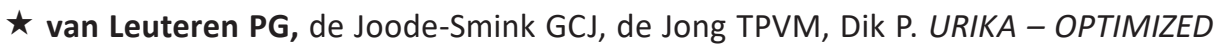
BLADDER MONITOR FOR THE DETECTION OF A FULL BLADDER IN CHILDREN WITH DAYTIME INCONTINENCE: A FEASIBILITY STUDY, $28^{\text {th }}$ Congress ESPU-Nurses, Barcelona, Spain, April 2017

van Leuteren PG, de Bruijn-Kempe E, Hermsen-Heilema L, de Jong TPVM, Dik P. NOVIOMINI - CONTINUOUS ULTRASOUND MONITORING FOR URINARY BLADDER IN CHILDREN DURING (VIDEO) URODYNAMICS: A PILOT STUDY, $28^{\text {th }}$ Congress ESPU-Nurses, Barcelona, Spain, April 2017 
van Leuteren PG, Woltjer R, de Jong TPVM, Dik P. SENS-U: VALIDATION OF A WEARABLE ULTRASONIC BLADDER MONITOR IN CHILDREN DURING URODYNAMIC STUDIES, 29 ${ }^{\text {th }}$ Congress ESPU(Nurses), Helsinki, Finland April 2018

van Leuteren PG, Nieuwhof-Leppink AJ, de Jong TPVM, Dik P. SENS-U: CLINICAL EVALUATION OF A FULL BLADDER NOTIFICATION - A FEASIBILITY STUDY, ICCS Meeting, Rome, Italy, September 2018

van Leuteren PG, de Win G. VOLUME-DEPENDENT CATHETERIZATION WITH A WEARABLE ULTRASONIC BLADDER SENSOR IN A TEENAGE BOY: A CASE REPORT, ICCS Meeting, Rome, Italy, September 2018

van Leuteren PG. SENS-U: REGIE OVER EIGEN BLAAS, V\&VN CV\&V congres, Nijkerk, the Netherlands, April 2019

van Leuteren PG, Nieuwhof-Leppink AJ, de Jong TPVM, Dik P. SENS-U: CLINICAL EVALUATION OF A FULL BLADDER NOTIFICATION - A FEASIBILITY STUDY, $30^{\text {th }}$ Congress ESPU-Nurses, Lyon, France, April 2019

Kwinten WMJ, van Leuteren PG, van Duren - van lersel M, Dik P, Jira PE. SENS-U: CONTINUOUS HOME MONITORING OF NOCTURAL BLADDER FILLING IN CHILDREN WITH ENURESIS - A FEASIBILITY STUDY, 30 ${ }^{\text {th }}$ Congress ESPU(Nurses), Lyon, France, April 2019

de Win G, Eerens S, de Baets $\mathrm{K}$, van Leuteren PG, VOLUME-DEPENDENT CATHETERIZATION WITH A WEARABLE ULTRASONIC BLADDER SENSOR - A FEASIBILITY STUDY, 30 ${ }^{\text {th }}$ Congress ESPU(Nurses), Lyon, France, April 2019

van Leuteren PG, Kwinten WMJ, van Duren - van lersel M, Dik P, Jira PE. FEASIBILITY OF A WEARABLE ULTRASONIC BLADDER SENSOR FOR MONITORING OF NIGHT-TIME BLADDER FILLING AT HOME IN CHILDREN WITH ENURESIS, ICCS Meeting, Gdansk, Poland, September 2019

van Leuteren PG, Callewaert PRH, Dik P. THREE CASES OF AUTISTIC BOYS WITH REFRACTORY URINARY INCONTINENCE BUT RESPONDING WELL TO A BLADDER SENSOR $D E V I C E, 5^{\text {th }}$ Joint Meeting of ESPU-SPU, Lisbon, Portugal, April 2021. 
(19) United States

(12) Patent Application Publication (10) Pub. No.: US 2017/0258386 A1 Woltjer et al.

(43) Pub. Date:

Sep. 14, 2017

(54) WEARABLE ULTRASOUND DEVICE FOR SIGNALIING CHANGES IN A HUMAN OR ANIMAL BODY

(71) Applicant: UMC Utrecht Holding B.V, Utrecht (NL)

(72) lnventors: Reinout Woltjer, Utrecht (NL); Huibert Alexander Tjabbes, Utrech (NL), Renatus Eligius Van de Vosse, Utrecht (NL); Jan Jacob Koning. Utrocht (NL); Paulus Gerardus Van Leuteren, Amersfoort (NL); Pieter Dik, Zeist (NL); Albert Harald Westra, Utrecht (NL); Leonard Jan Van Schelven, Houten (NL)

(21) Appl. No.: 15/608,653

(22) Filed: May 30, 2017

\section{Related U.S. Application Data}

(63) Continuation of application No. PCT/NL2015/ 050828, filed on Now. 26, 2015.
(30)

$$
\text { Foreign Application Priority Data }
$$

Nov. 27. 2014 (NL) 2013884

Publication Classification

(5I) Int. C1.

$\begin{array}{ll}\text { A6IB 5/20 } & (2006.01) \\ \text { A6IN 5/06 } & (2006.01) \\ \text { GOSF 19/00 } & (2006.01) \\ \text { A6IB \&/00 } & (2006.01)\end{array}$

(52) U.S. Cl.

CPC

A6IB 5/20 (2013.01); A6IB $8 / 4472$ (2013.01); A6IN 5/0613 (2013.01); G06F I9/34I8 (2013.01); A6IB $\$ 00$ (2013.01); $A 6 I N 7 / 00(2013.01)$

\section{ABSTRACT}

A wearable ultrasound device for signalling changes in human or animal body, and use of such a wearable device for signalling over a prolonged period of time. In an example the changes occur in a bladder. Such is especially relevant for elderly penons, women after delivery of a baby, lesion patients, demented people, children, and others, have a difficulty to control functioning of the bladder, and to be at the toilet on time to urinate.

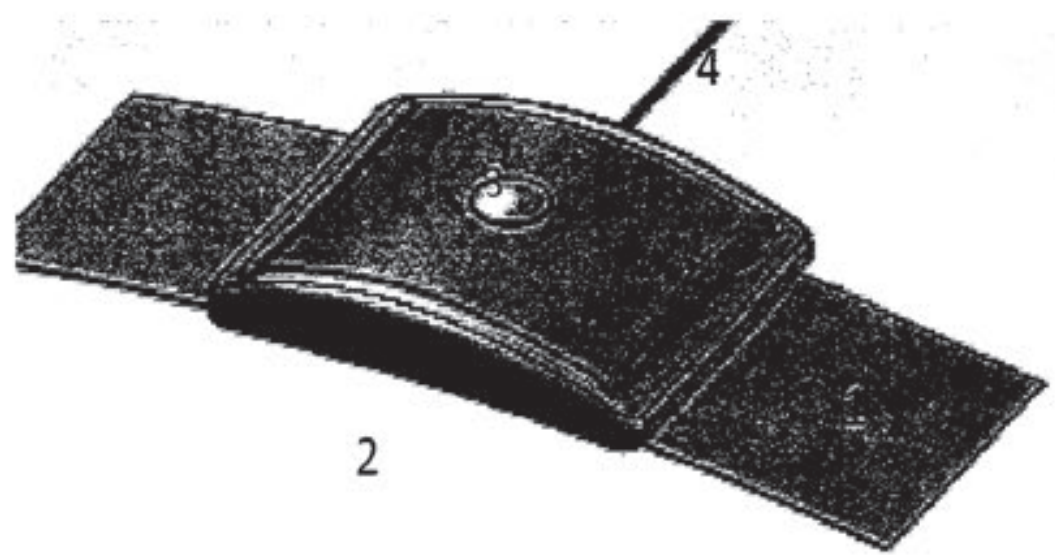





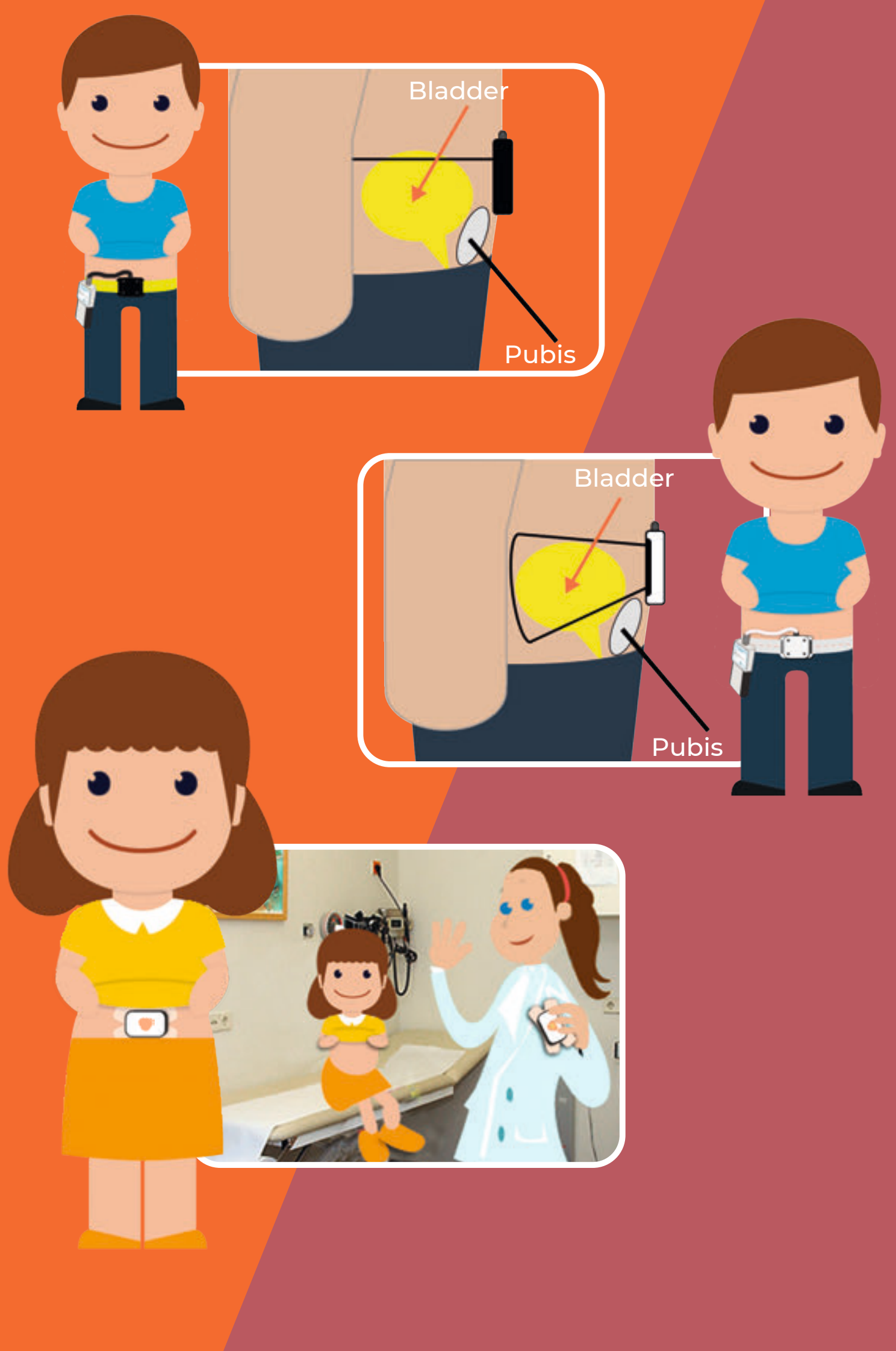

